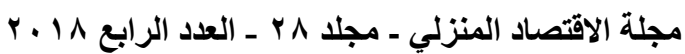

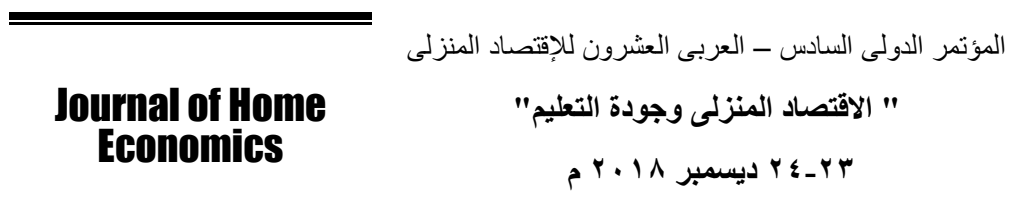

$\overline{\text { http://homeEcon.menofia.edu.eg }}$

ISSN 1110-2578

\title{
تحمل الزوج للمسئوليات الأسرية من وجة نظر الزوجة و علاقته بالضغوط

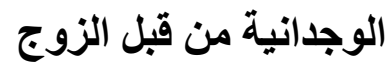

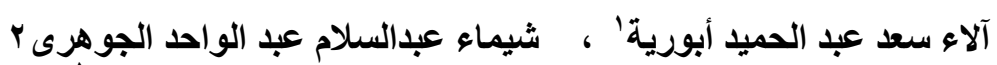

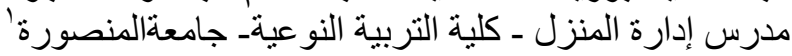

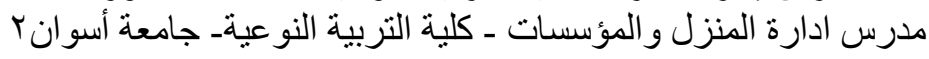

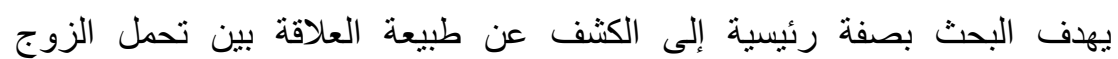

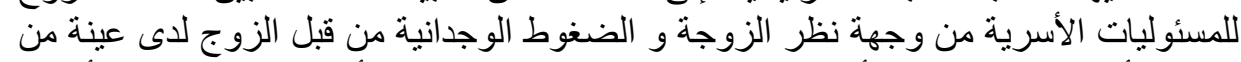

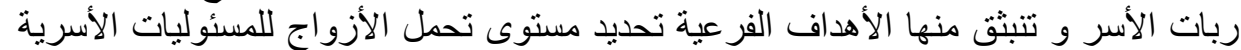

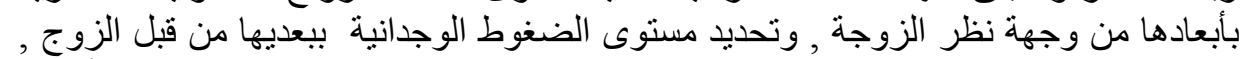

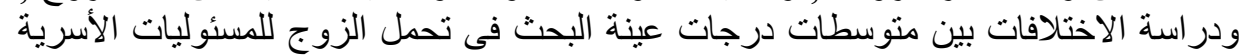

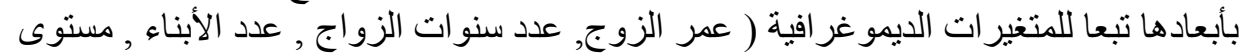

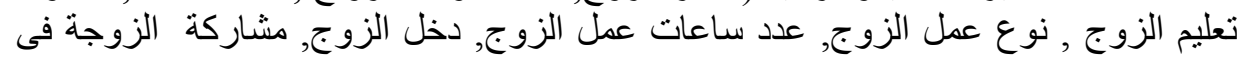

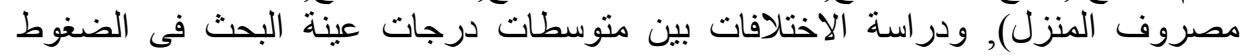

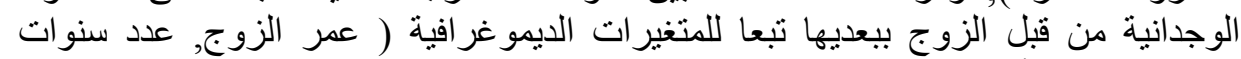

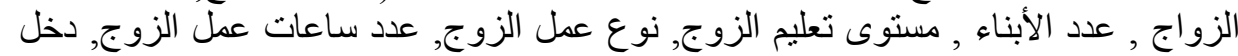

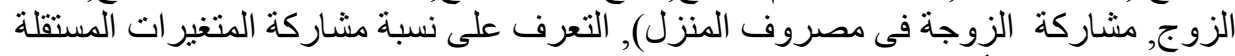

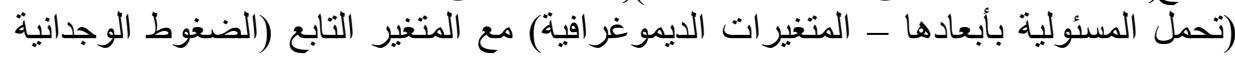

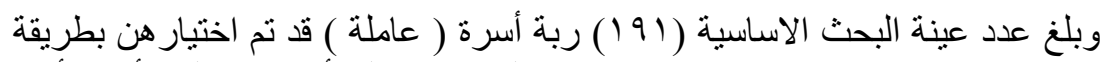

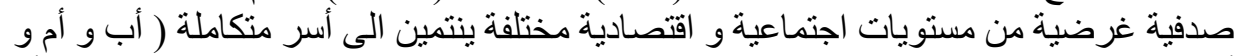

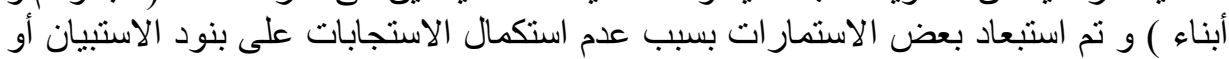

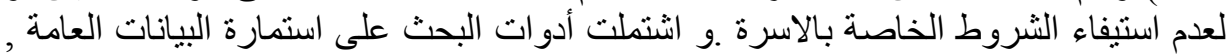

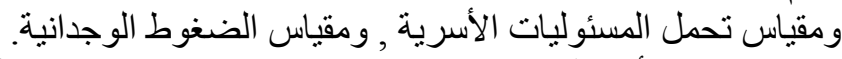

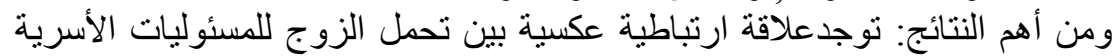

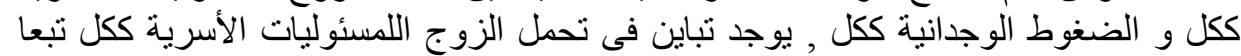

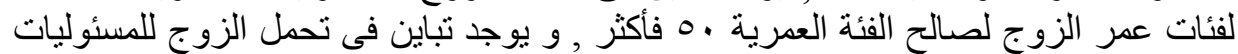

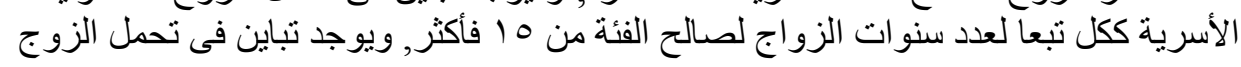




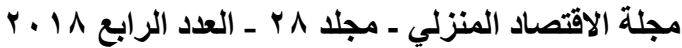

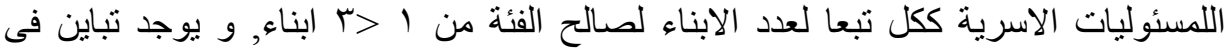

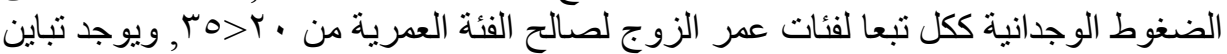

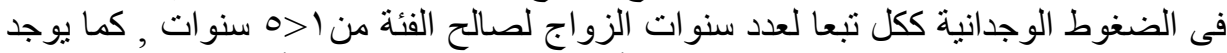

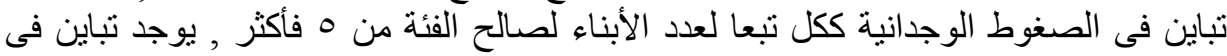

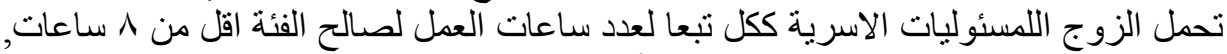

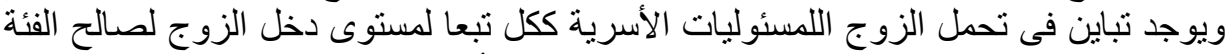

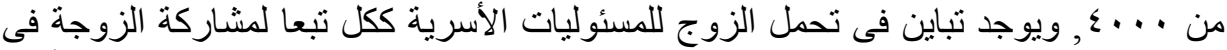

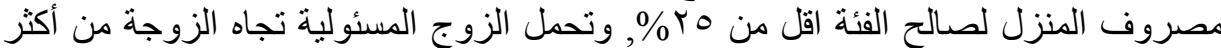

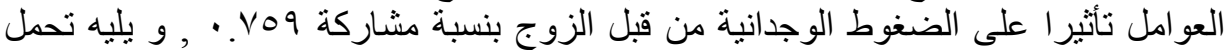

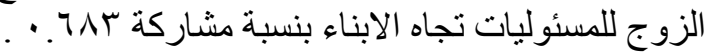

من السنن الإلهية في الأسر أنها أسست على قطبين تتكامل مسئولياتهما و وتتجانس

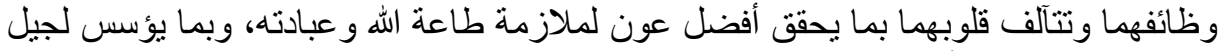

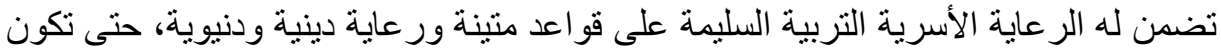

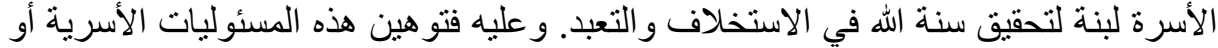

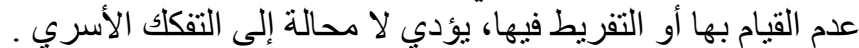

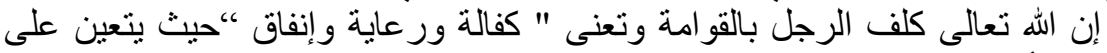

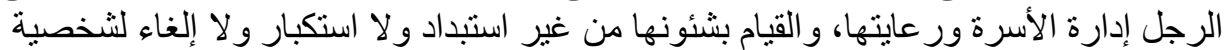

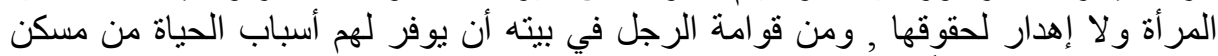

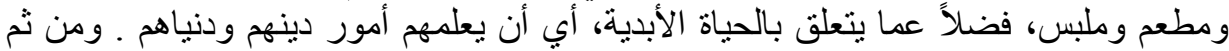

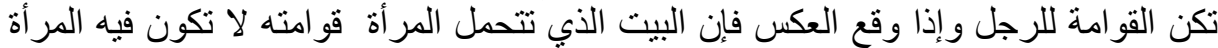

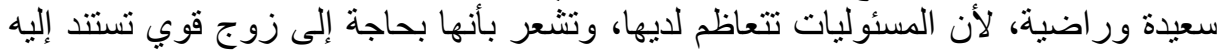

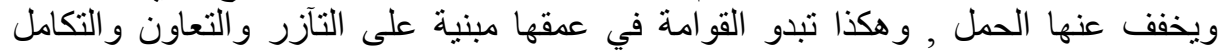

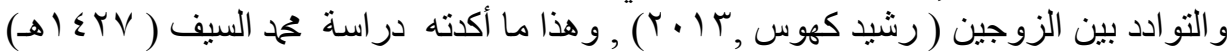

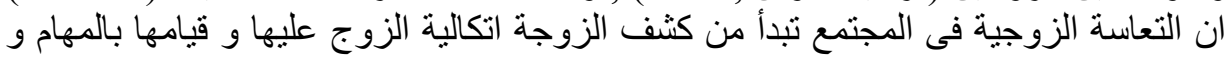

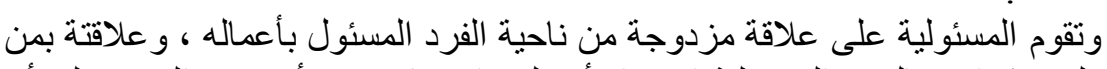

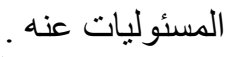

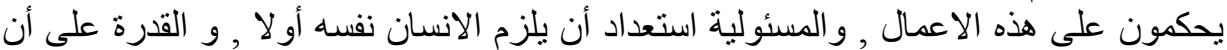

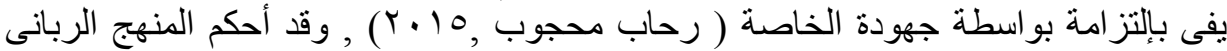

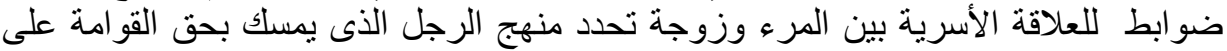

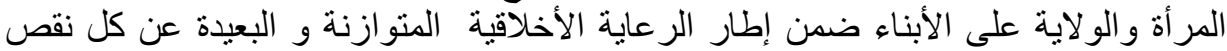

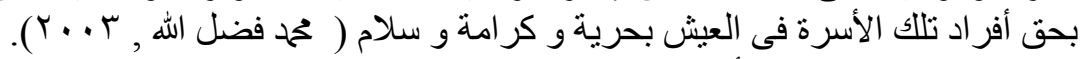

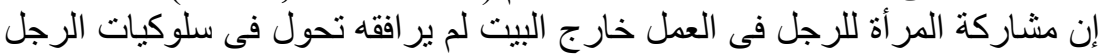

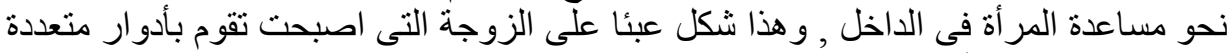

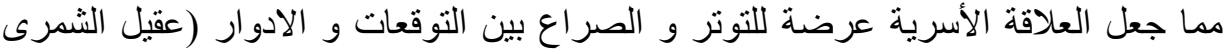




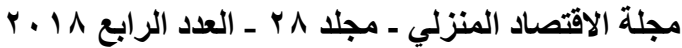

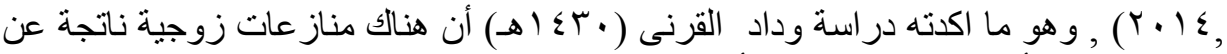

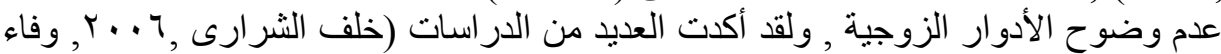

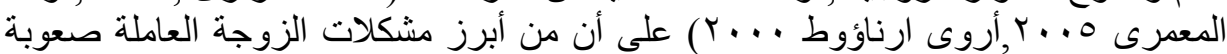

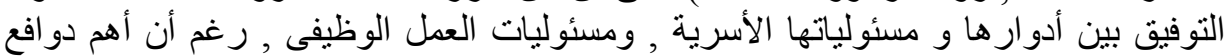

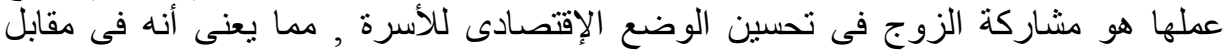

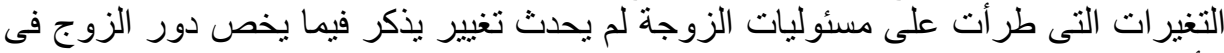

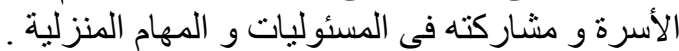

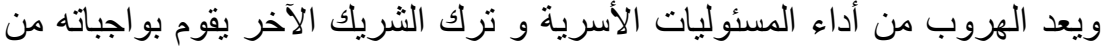

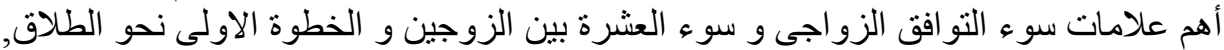

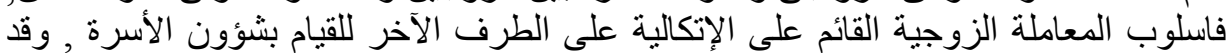

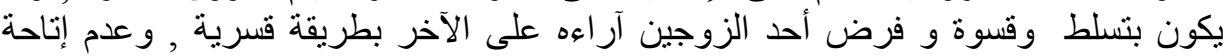

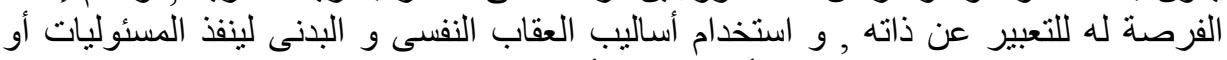

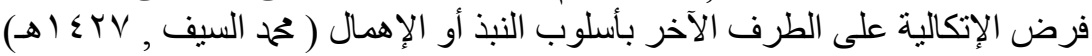

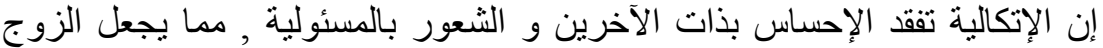

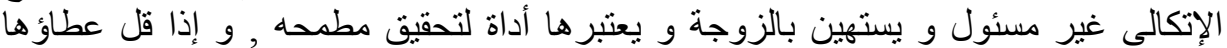

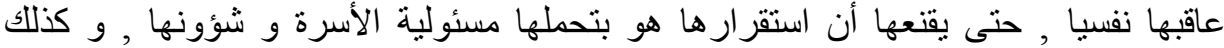

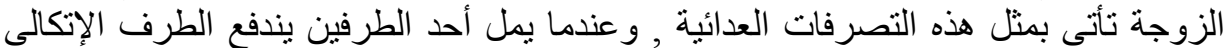

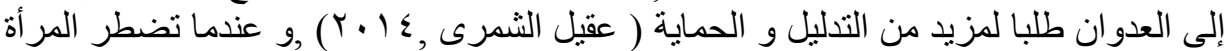

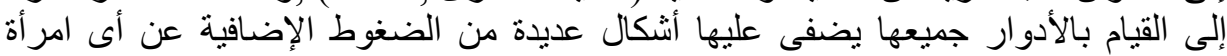

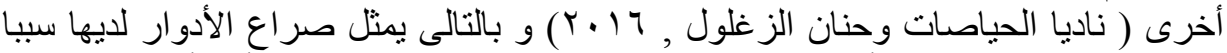

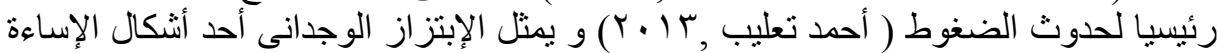

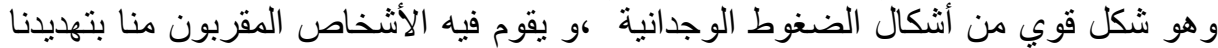

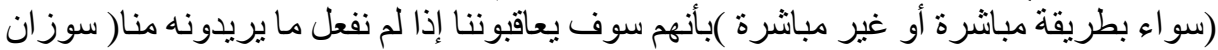

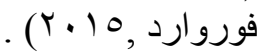

والابتز از الوجدانى هو نمط من التعامل السلبي يلجأ إليه الزوج/ الزوجة إلى استغلال

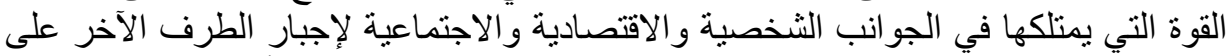

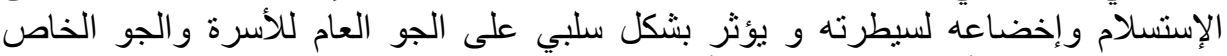

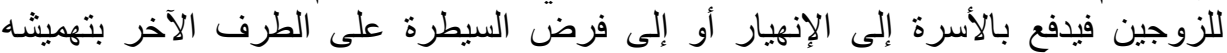

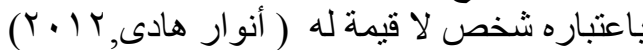

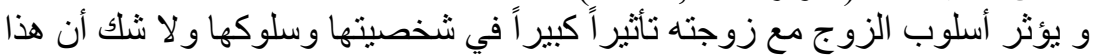

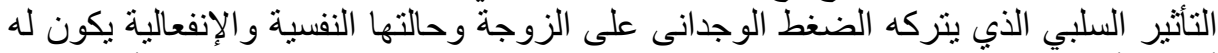

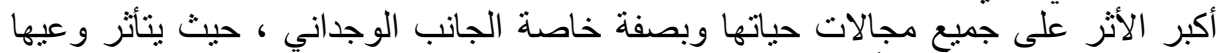

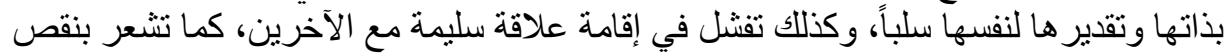

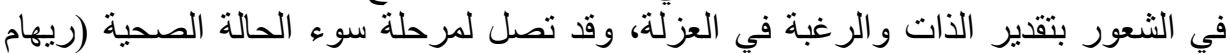

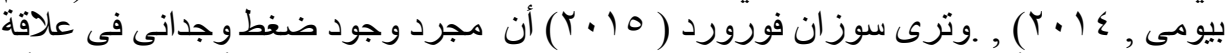

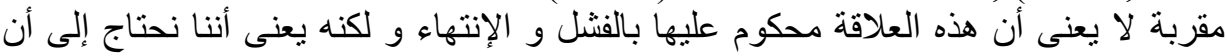




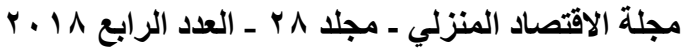

نعترف اعتر افا صريحا بالسلوك الذى يسبب لنا الألم و نصححه و أن نعيد وضع هذه العلاقات

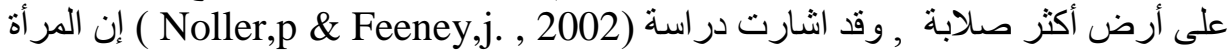

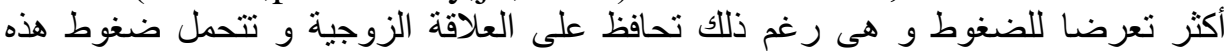

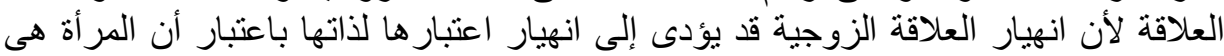

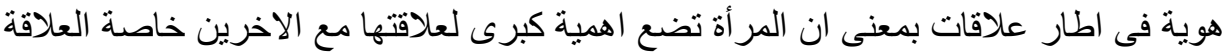

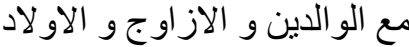

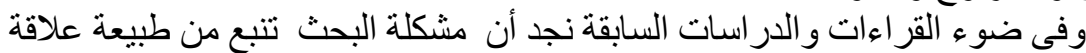

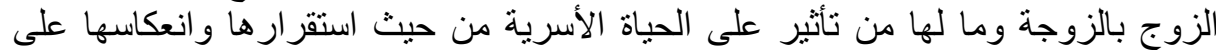

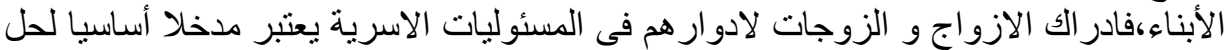

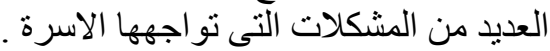

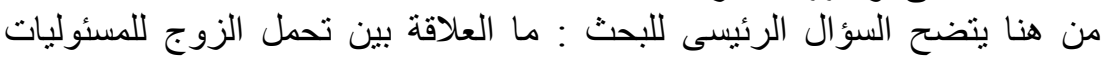

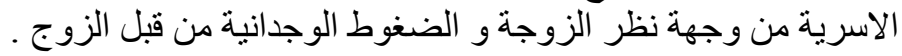

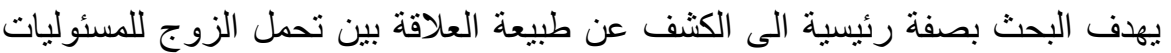

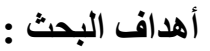

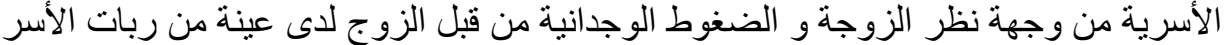

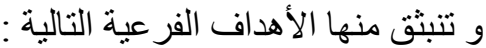

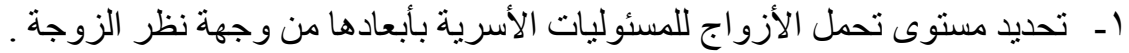

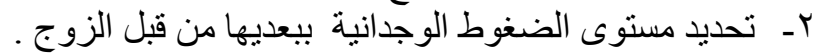

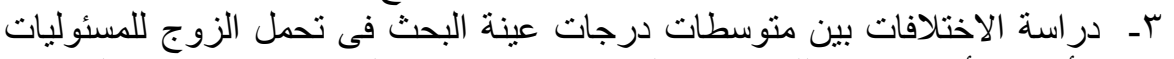

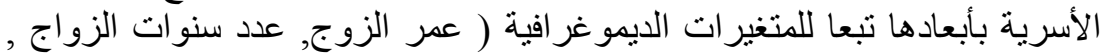

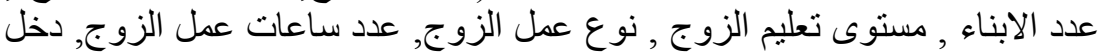

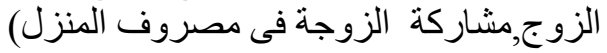

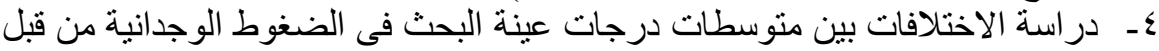

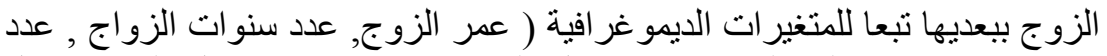

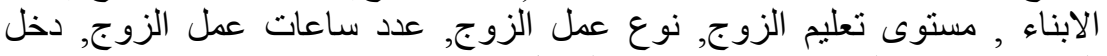

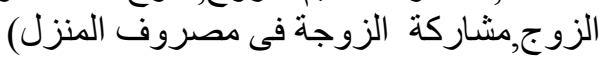

$$
\text { ا اهمية البحث : التأكيد على أهمية إدر اك الزوجين للمسئوليات الأسرية و الالتزام بأدائها . }
$$

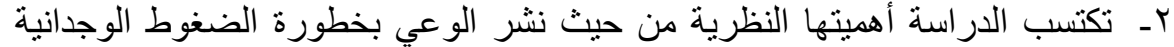

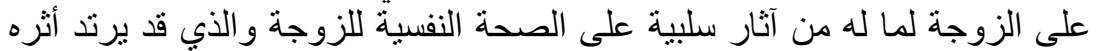

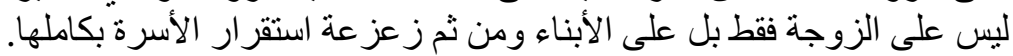

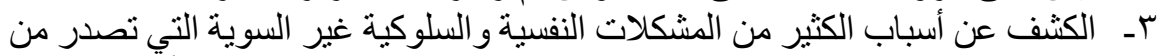
بعض الزوجات و التي قد يكون الزوج هو الفاعل الحقيقي والسبب الأساسي فئهان 


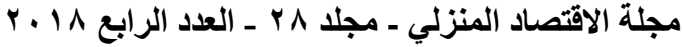

وذللك من خلال شكل من التفاعل بعتمد على الابنزاز الوجدانى وهو أسلوب في بي

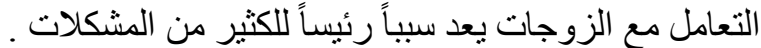

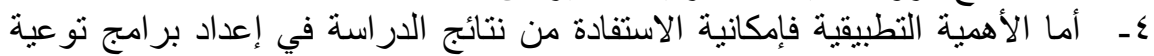

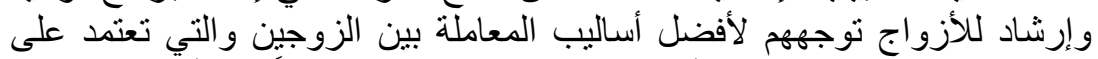

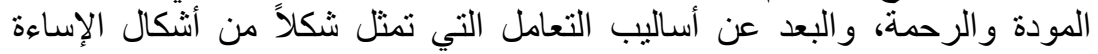

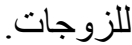

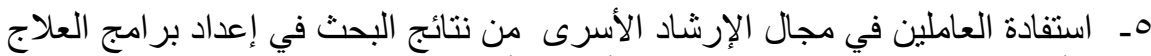

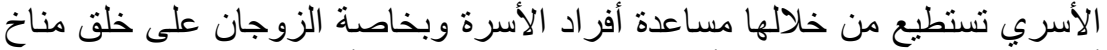

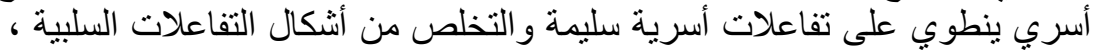
وكذللك مساعدة الزوجات على التخلص من التاعلى التار النفسية و السلوكيات السلبية الناتجة عن التعرض للضغوط الزوجات على الوجدانية.

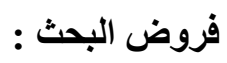

ا ـ توجد علاقة ارتباطية دالة إحصائيا بين تحمل الزوج للمسئوليات الأسرية بأبعادها

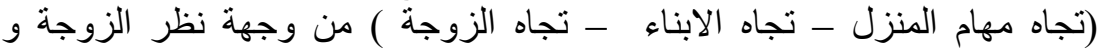

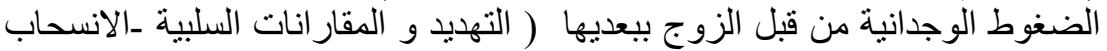

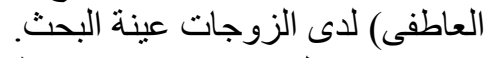

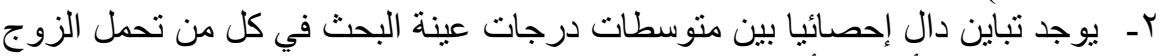

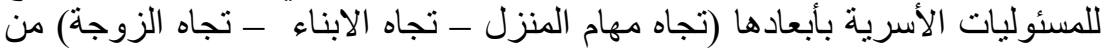

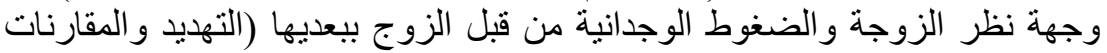

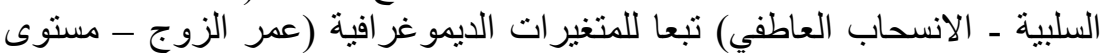

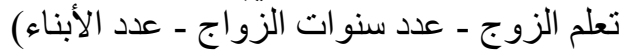

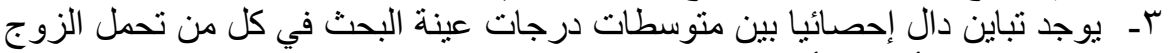

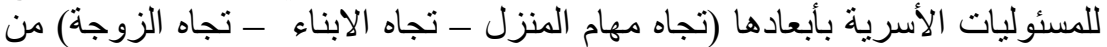

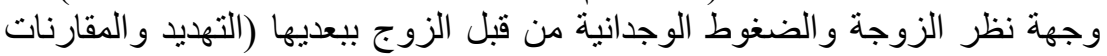

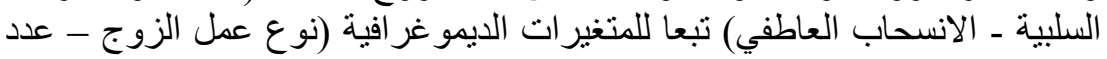

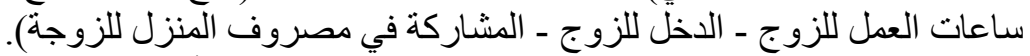

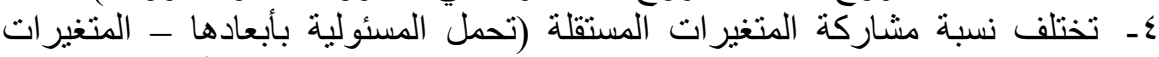

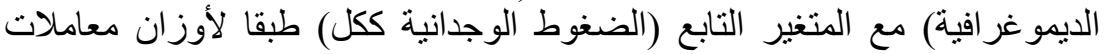
الانحدار ودرجة الارنباط مع المتغير التابع.

$$
\text { الاسلوب البحثى : منهج البحث }
$$

يتبع هذا البحث المنهج الوصفى التحليلى لمناسبته لطبيعة البحث . ثانيا : المصطلحات العلمية و المفاهيم الاجر ائية : 


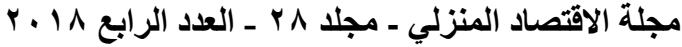

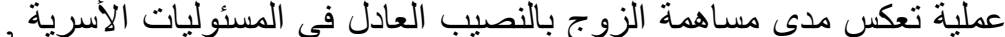

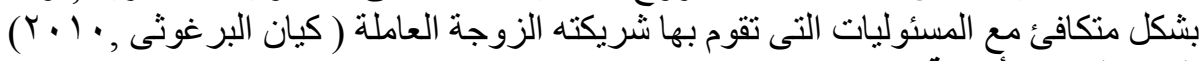

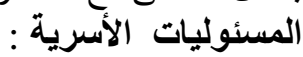

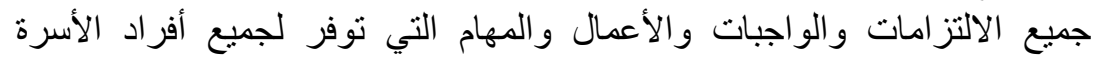

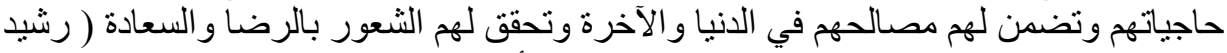

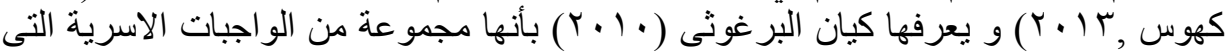

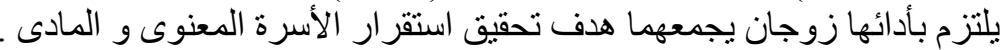

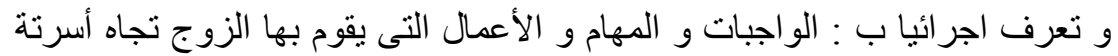

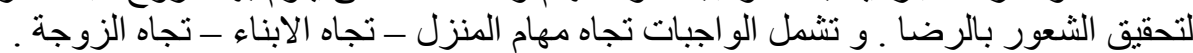

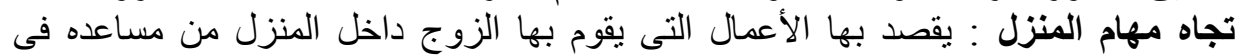

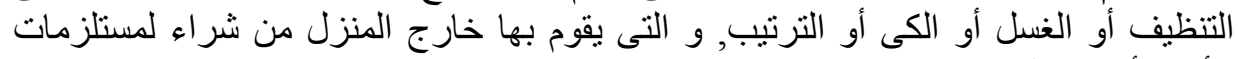

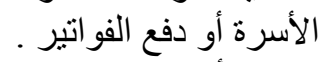
تجاه الأبناء : يقصد بها العنائل العناية بالأبناء و رعايتهم الاهتمام بدراستهم و بحالتهم الصحية و النفسية

تجاه الزوجة : يقصد بها التو اصل العاطفى مع الزوجة من الحب و التفاهم و الود و الرعاية .

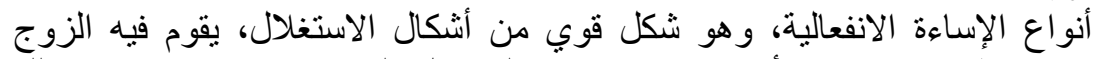

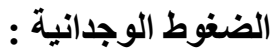

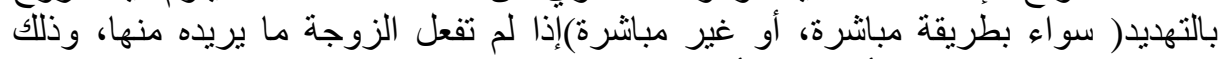

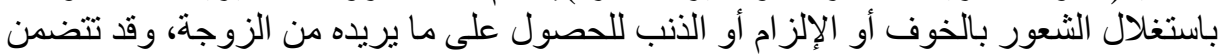

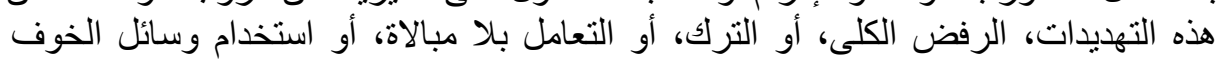

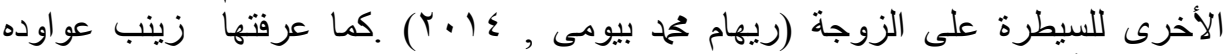

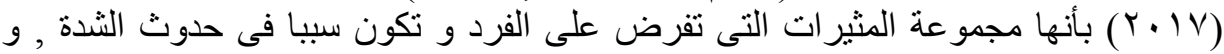

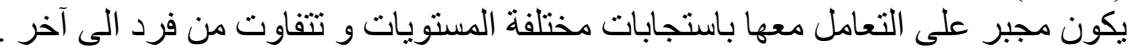

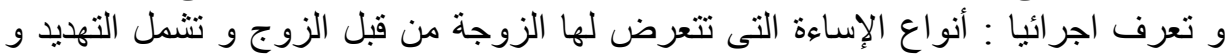

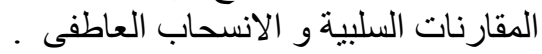

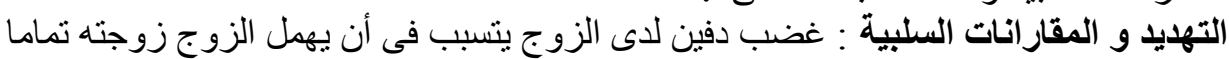

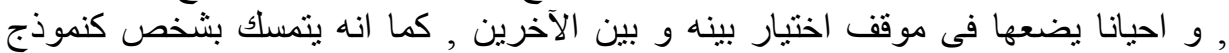

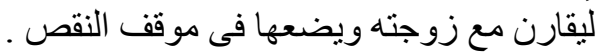

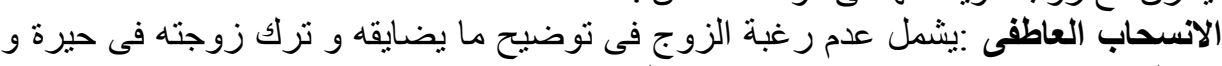

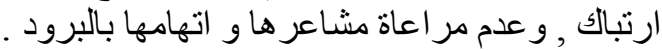

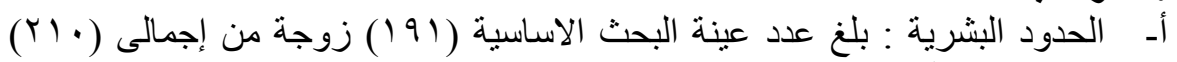

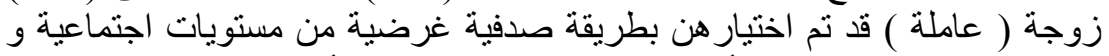

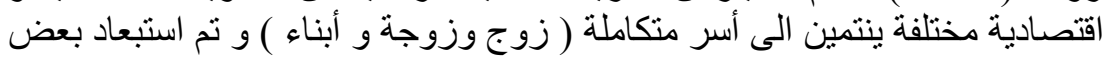


الاستمارات بسبب عدم استكمال الاستجابات على بنود الاستبيان أو لعدم إستيفاء

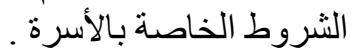

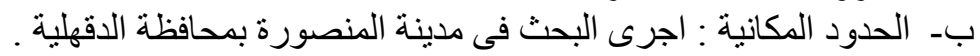

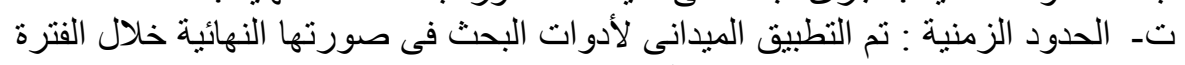

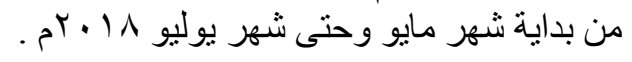

$$
\begin{aligned}
& \text { رابعا : أدوات البحث ( إعداد الباحثتان ) } \\
& \text { اشتملت أدو ات البحث على : البحث إعال }
\end{aligned}
$$

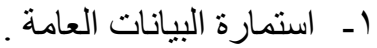

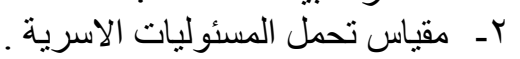

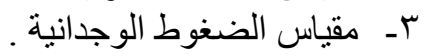

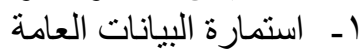

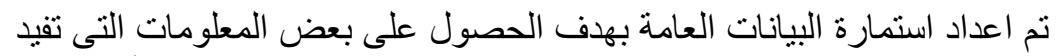

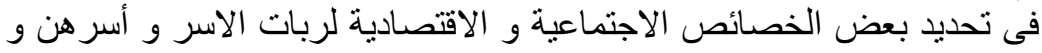

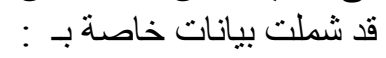

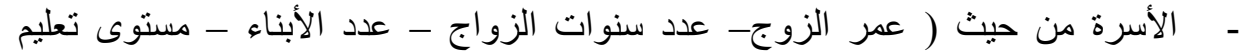

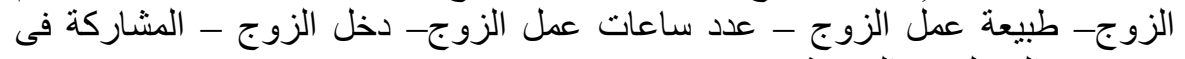

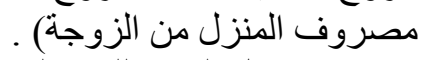

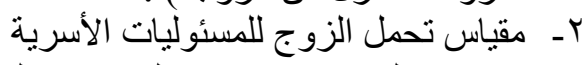

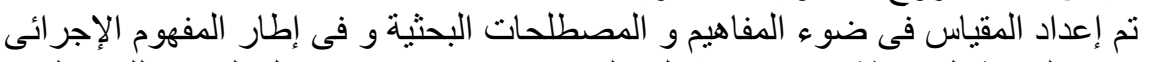

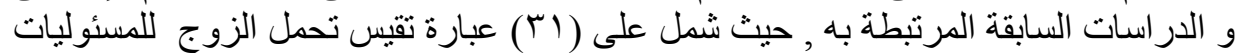

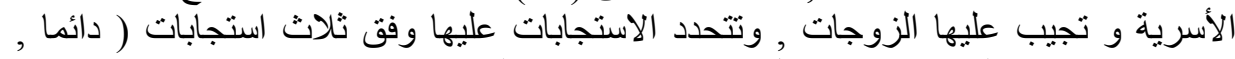

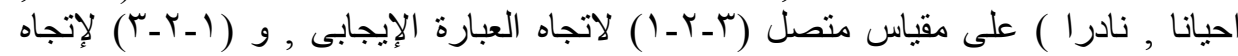

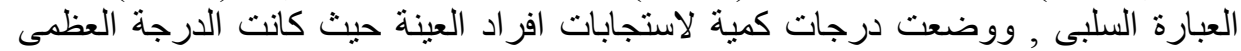

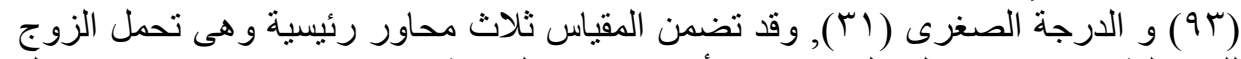

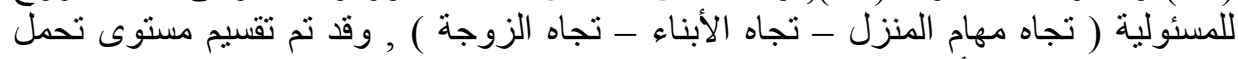

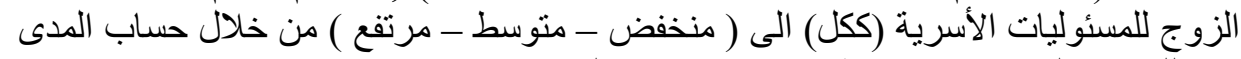

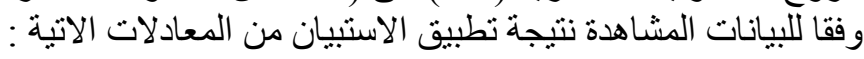

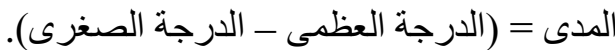

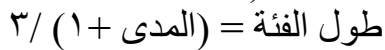

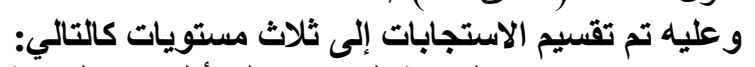

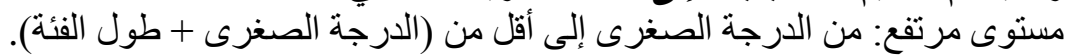

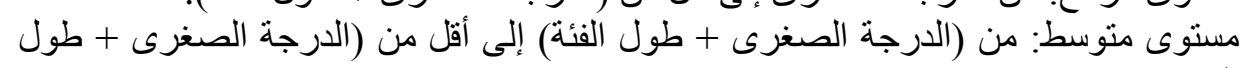

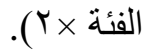
مستوى منخفض: من (الدرجة الصغرى + طول الفئة × آ) فأكثر. 


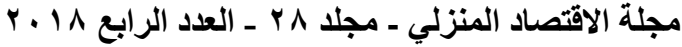

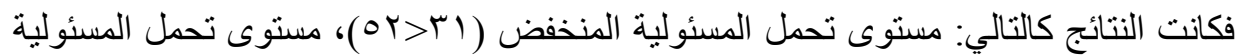

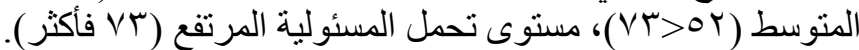

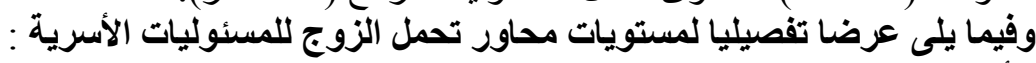

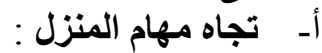

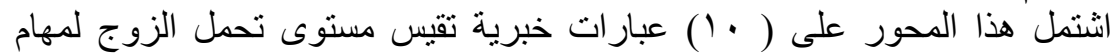

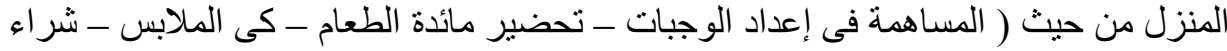

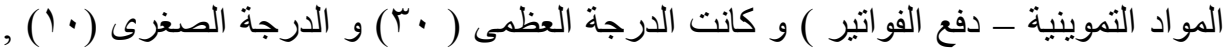

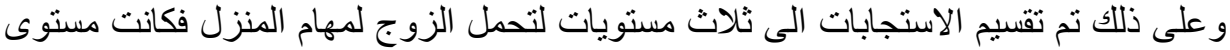

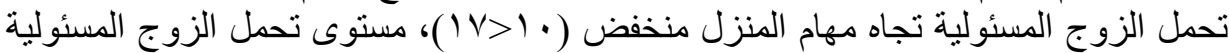

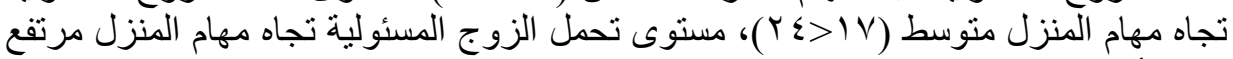

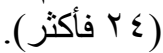

اشتمل هذا المحور على ( • (1) عبار ات خبرية تقبس مستوى تحمل الزوج لمسئولية

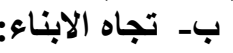

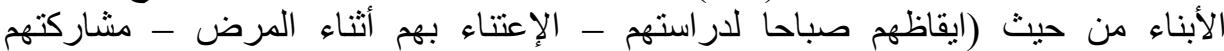

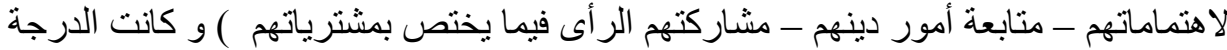

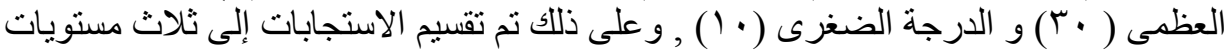

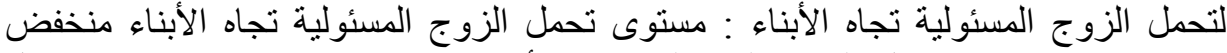

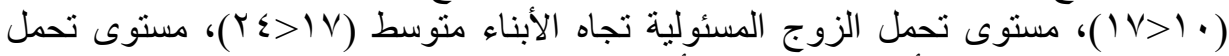

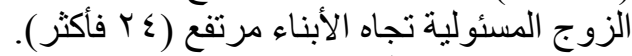

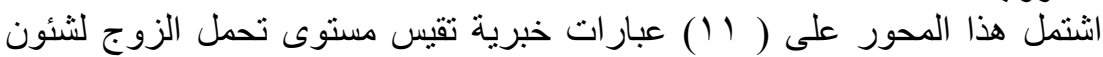

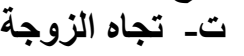

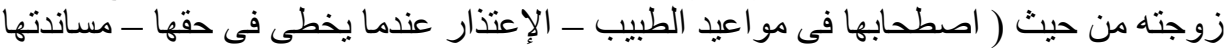

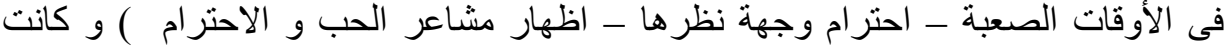

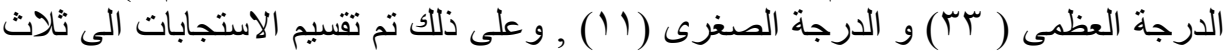

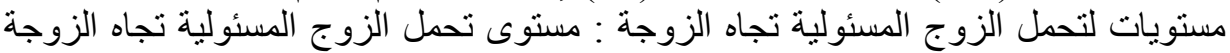

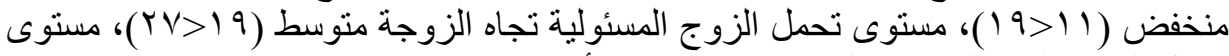

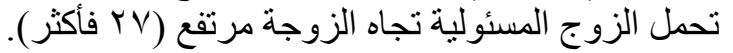

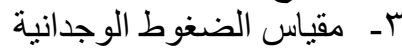

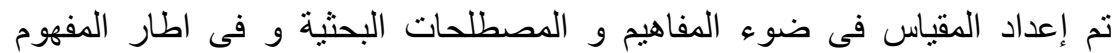

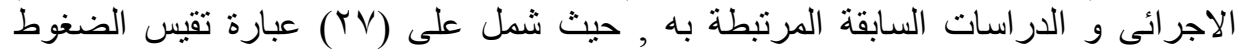

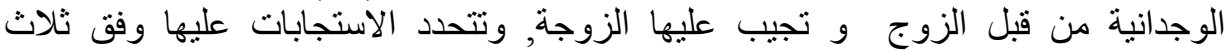

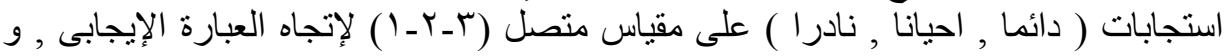

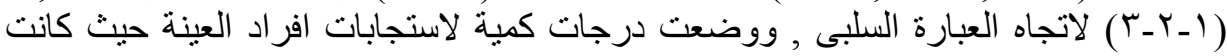

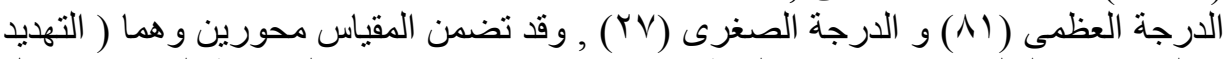

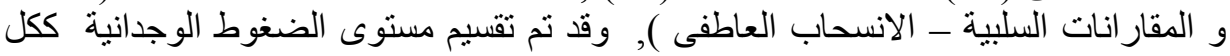


الى ( منخفض - متوسط - مرتفع ) من خلال حساب المدى و وأبعاده تبعا للبيانات المشاهدة

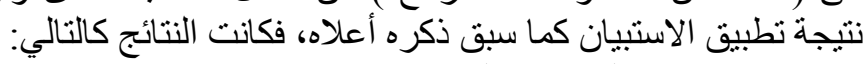

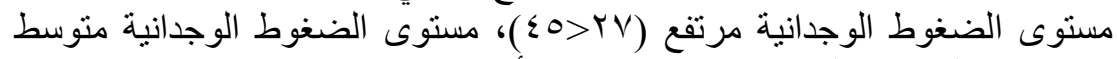

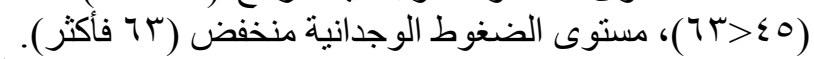

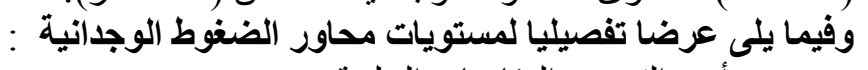

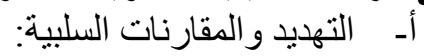

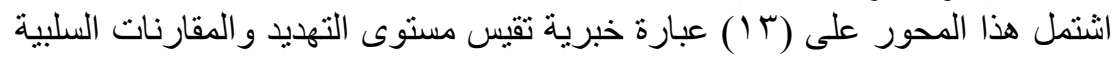

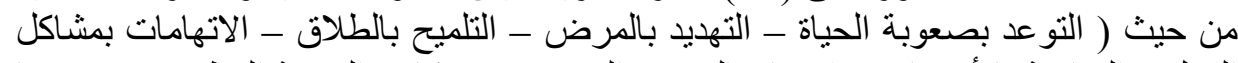

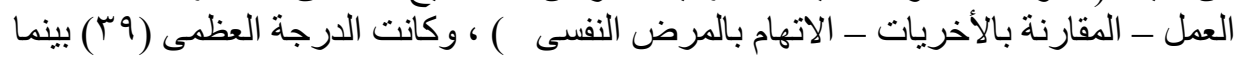

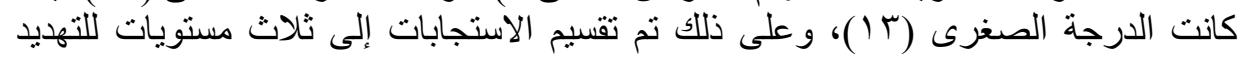

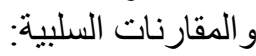

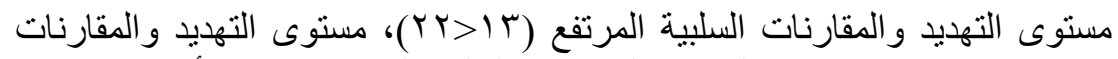

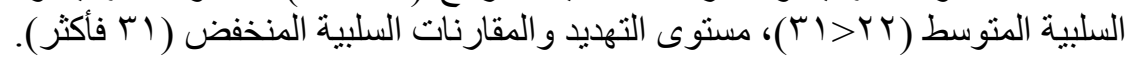

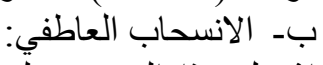

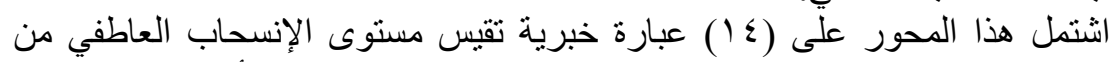

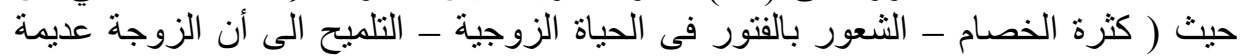

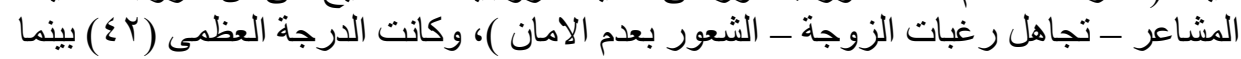

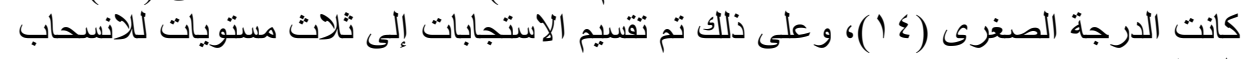

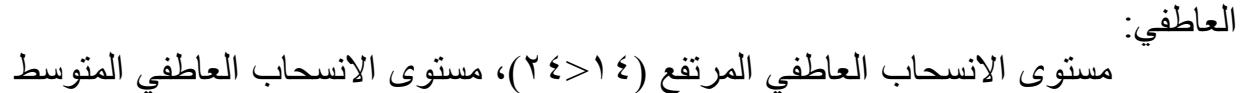

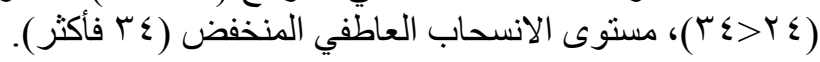

$$
\text { تقنتين أدوات البحث }
$$

اعتمد البحث الحالي في التحقق من صدق المقاس المقاييس Validity على طريقتين: أـ صدق المحتوى:

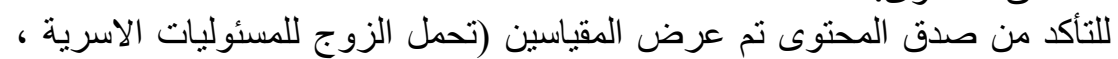

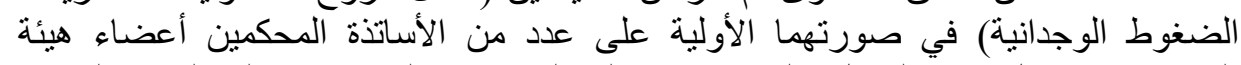

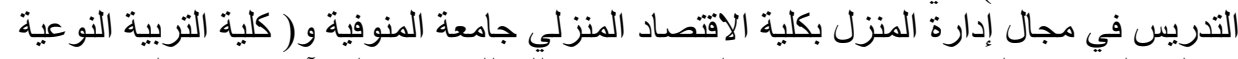

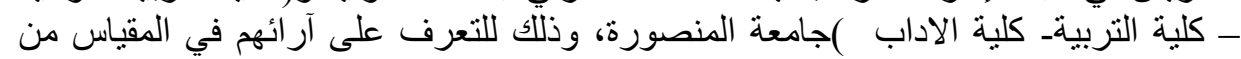

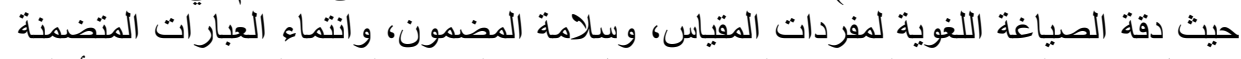

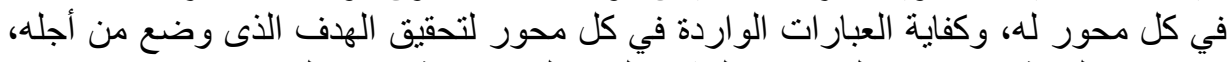

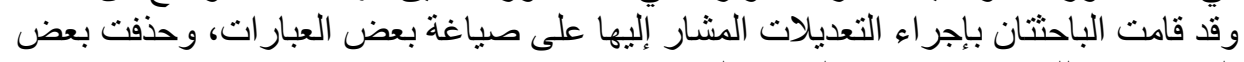

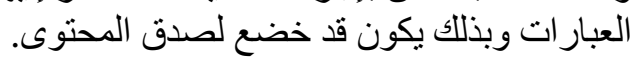


بـ صدق الاتساق الداخلي لمقياس تحمل الزوج للمسئوليات الأسرية :

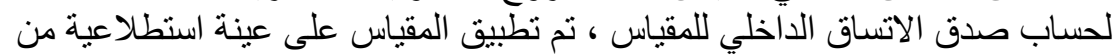

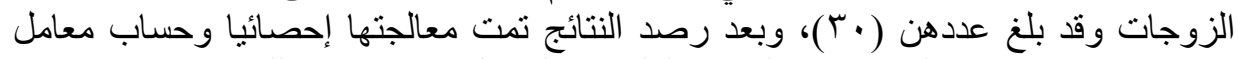

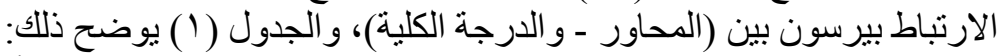

\begin{tabular}{|c|c|c|c|}
\hline مستوى الدلالة & الارتباط & عدد العبار ات & للمقئسوليات تحمل الأسروية \\
\hline$\because \cdot 1$ & *..^r० & 1. & مهام المنزل \\
\hline$\because \cdot 1$ & $* .917$ & 1. & تجاه الأبناء \\
\hline$\because+1$ & $* \cdot . \wedge \vee I$ & 11 & تجاه الزوجة \\
\hline
\end{tabular}

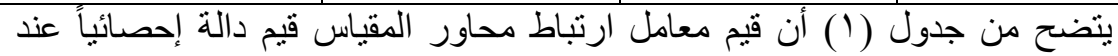

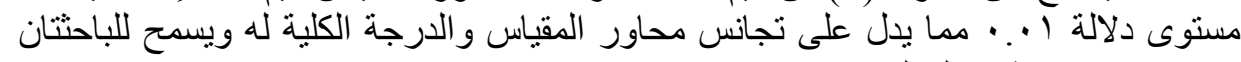
باستخدامه في بحثهما الحالي.

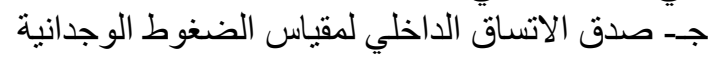

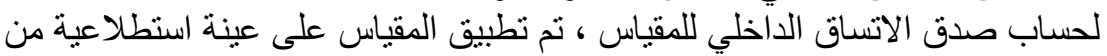

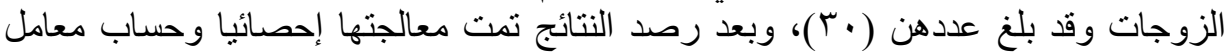

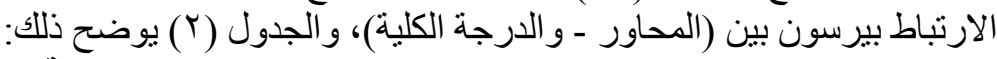

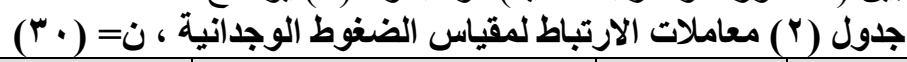

\begin{tabular}{|c|c|c|c|}
\hline مستوى الدلالة & معامل الارتباط & العبار ات & مقياس الضنغوط \\
\hline$\because \cdot 1$ & $* .9 \leq \leqslant$ & $\pi$ & التهديد و المقارنات \\
\hline$\because \cdot 1$ & *. & $1 \leq$ & الانسحاب العاطفي \\
\hline
\end{tabular}

يتضح من جدول (r) أن قيم معامل ارتباط محاور المقياس قيم دالة إحصائياً عند

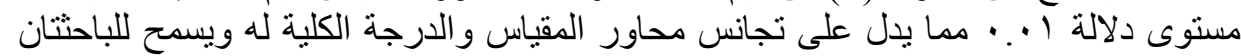

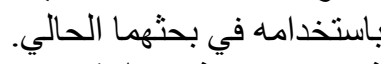

Reliability ثُانيا: حساب ثُبات المقياس

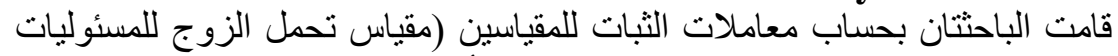

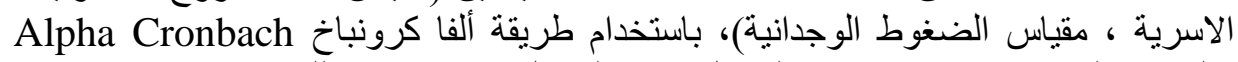

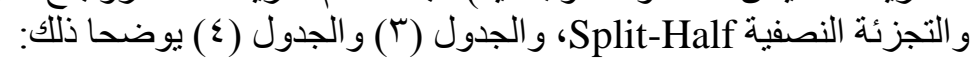




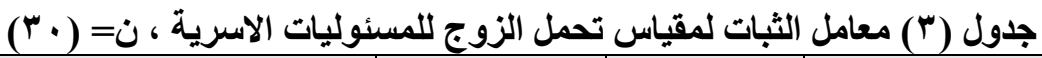

\begin{tabular}{|c|c|c|c|c|}
\hline \multicolumn{2}{|c|}{ التجزئة النصفية } & \multirow{2}{*}{ معامل ألفا } & \multirow{2}{*}{ العبار ات } & \multirow{2}{*}{ للمقئوليات الأسرية الزوج } \\
\hline جتمان & سبيرمان & & & \\
\hline.$\vee 199$ & $\cdot V \cdot 1$ & $\because 1990$ & 1. & مهام المنزل \\
\hline$\cdot V \cdot \varepsilon$ &.$V Y M$ & $\cdot . \wedge \mu r$ & 1 . & تجاه الابناء \\
\hline $.9 Y V$ & $.9 r \wedge$ & $\cdot .941$ & 11 & تجاه الزوجة \\
\hline. VOr & $\because \vee 9$ & .911 & T & ككل \\
\hline
\end{tabular}

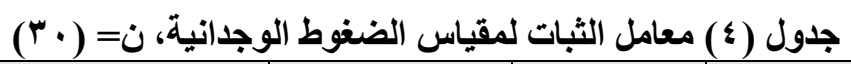

\begin{tabular}{|c|c|c|c|c|}
\hline \multicolumn{2}{|c|}{ التجزئة النصفية } & \multirow{2}{*}{ معامل ألفا } & \multirow{2}{*}{ العبار ات } & \multirow{2}{*}{ مقياس الضيغوط الوجدانية } \\
\hline جتمان & سبيرمان & & & \\
\hline$\cdot V Y I$ & VYYY & $\cdot \Lambda \cdot r$ & IT & السلبية والتهايد والمقارنات \\
\hline$\cdot \Delta 1 \pi$ & $\cdot . \wedge 1 \mathrm{~V}$ & $\cdot . \wedge \wedge$ & $1 \varepsilon$ & الانسحاب العاطفي \\
\hline$\because \wedge 91$ & $\therefore \wedge 9 Y$ & .917 & TV & ككل \\
\hline
\end{tabular}

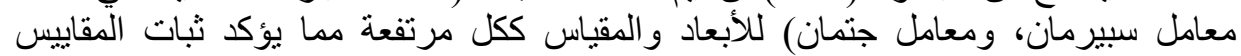

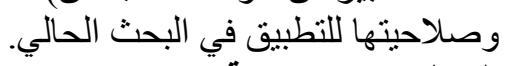
المعالجات الإحصائية

بعد جمع البيانات وتفريغها تم تحليل البيانات و إجر اء المعالجات الإحصائية باستخدام

برنامج (SPSS) وفيما يلي بعض الأساليب الإحصائية المستخدمة لكثف العلاقة بين متغيرات الاتئ

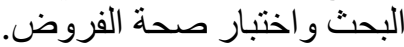

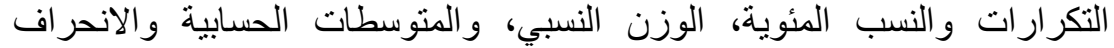

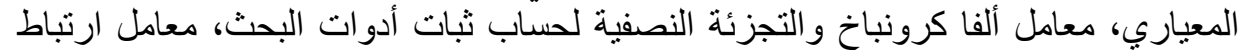

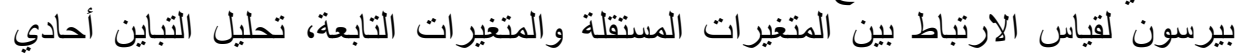

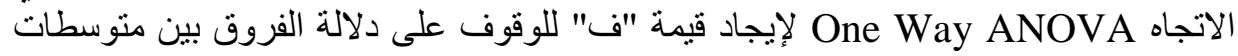
درجات عينة البحث، اختبار LSD للمقارنات المتعددة لتحديد اتجاه الدالة للة ولاد الانحدار.

\section{النتائج ومناقشتها أولا: خصائص عينة البحث :}

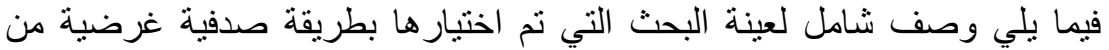
الزوجات العاملات من مدينة المنصورة بمحافظة الدقهلية وينتمين إلى مستويات التئة اجتماعية و اقتصادية مختلفة. 


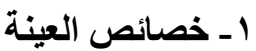

جدول (ه) التوزيع النسبي للزوجات عينة البحث وفقا للخصائص الاقتصادية

\begin{tabular}{|c|c|c|c|c|c|}
\hline$\%$ & العدد الع & ○ـعمل الزوج & $\%$ & العدد الع & ا ـعمر الزوج \\
\hline$\varepsilon \wedge .791$ & 94 & مهني & rA.r & $V T$ & من •ro>r \\
\hline $7 . \wedge \cdot 7$ & 11 & حرفي & $07 .+Y$ & $1 \cdot V$ & من 0"> \\
\hline$\varepsilon \varepsilon .0 . T$ & 10 & أعمال حرة & $0 . \vee 7$ & 11 & من •0 فأكثر \\
\hline $1 \cdots$ & 191 & المجموع & $1 \cdots$ & 191 & المجموع \\
\hline$\%$ & العدد الع & 7 1 -عدد ساعات الزوج & $\%$ & العدد الع & 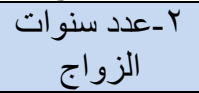 \\
\hline T.YAY & ir & أقل من ^ ساعات & T. TY. & 79 & من إ >> \\
\hline $0 . V \wedge$ & $9 V$ & من 1> 1 1 & $\varepsilon r .9 \vee 9$ & $\Lambda \varepsilon$ & من 0>0 \\
\hline$\varepsilon r . q$ & Ar & من • ا فأكثر & 19.190 & rᄉ & من 10 فأكثر \\
\hline $1 \cdots$ & 191 & المجموع & $1 \ldots$ & 191 & المجموع \\
\hline$\%$ & العدد & Vـ - دخل الزوج & $\%$ & العدد & آ-عدد الابناء \\
\hline $1 Y . E Y$ & r & أقل من . . . ب & IY.OV & $r \varepsilon$ & من ا> \\
\hline $70 . \leqslant \leq 0$ & Iro & من ...>r..>r & $\Lambda \cdot .1$ & 104 & من r \\
\hline TY.01T & $\varepsilon r$ & من · . . ع فأكثر & V.TH & $1 \varepsilon$ & من 0 فأكثر \\
\hline $1 \cdots$ & 191 & المجموع & $1 \cdots$ & 191 & المجموع \\
\hline$\%$ & العدد العد & مصروالمشاركة في المنزل & $\%$ & العدد الع & ع ـمستوى تعليم \\
\hline $7 . \mathrm{r} \wedge$ & ir & أقل من \%Y\%\% & 0.17 & 11 & متوسط \\
\hline rq. KV & Vo & من 0Y\%> \% \% & $\varepsilon Y . q T$ & Ar & فوق المتوسط \\
\hline $0 \leqslant \leqslant 0$ & $1 \cdot \varepsilon$ & من • 0\% فأكثر & 01.11 & 91 & جامعي \\
\hline $1 \ldots$ & 191 & المجموع & $1 \cdots$ & 191 & المجموع \\
\hline
\end{tabular}

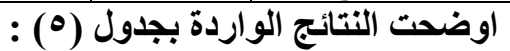

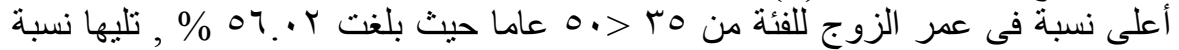

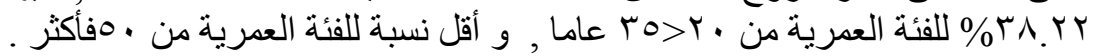

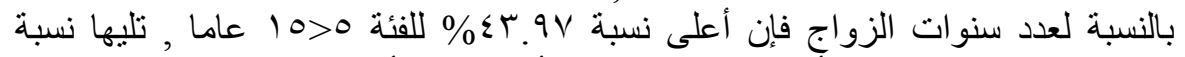

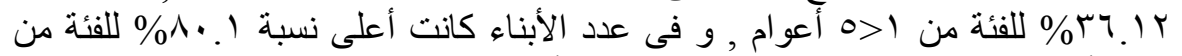

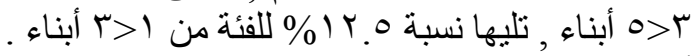

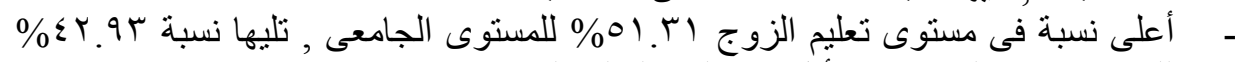

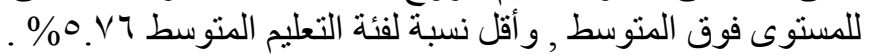




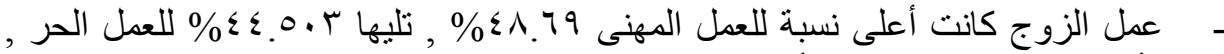

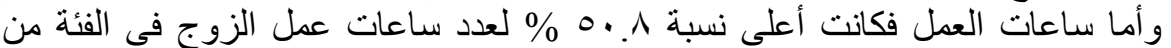

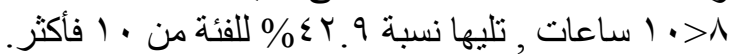

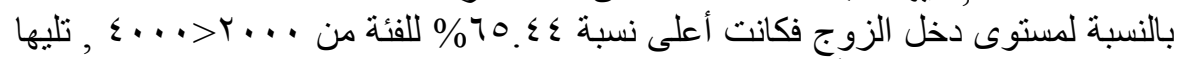

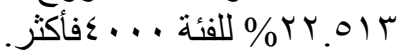

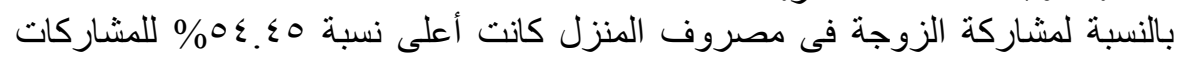

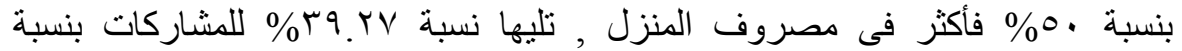
$\% 0 \cdot>r 0$

ثانياً: نتائج وصف العينة في ضوء أبو الاستجابات على أدوات البحث

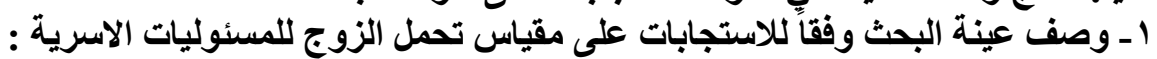

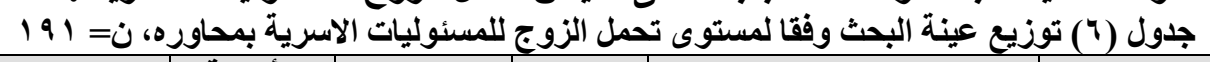

\begin{tabular}{|c|c|c|c|c|c|}
\hline الترتيب & الأهبية & $\%$ & العدد الع & المستوى & المحاور \\
\hline \multirow{3}{*}{ الثاني } & \multirow{3}{*}{$r r . r \leq 0$} & or.AN & 1.1 & مستوي منذفض (· l > l & \multirow{3}{*}{ مهام المنزل } \\
\hline & & rQ.YTV & Vo & مستوي متوسط (V > Y ؛ Y) & \\
\hline & & V.AOT & 10 & مستوي مرتفع ( ؟ ب فأكثر) & \\
\hline \multirow{3}{*}{ الثالث } & \multirow{3}{*}{ rY. $0 \leqslant Y$} & rY. ET & $7 Y$ & مستوي منخفض (· > IV (IV) & \multirow{3}{*}{ تجاه الابناء } \\
\hline & & $\sum 9 . Y 10$ & $9 \varepsilon$ & مستوي متوسط (Y > Y \& Y) & \\
\hline & & IN.rYO & ro & مستوي مرتفع ( ؟ ب فأكثر) & \\
\hline \multirow{3}{*}{ الأول } & \multirow{3}{*}{$r \leq . r \mid r$} & $r \cdot r 47$ & $0 \wedge$ & مستوي منخفض (11 > 19 (1) & \multirow{3}{*}{ الزوجة } \\
\hline & & Or.9YV & $1 \cdot r$ & مستوي متوسط (YV > 19) & \\
\hline & & $10 . V \cdot V$ & $r \cdot$ & مستوي مرتفع (V ب فأكثر) & \\
\hline \multirow{4}{*}{\multicolumn{2}{|c|}{$\% 1 \ldots$}} & rY.\{TI & $7 r$ & مستوي منخفض (O > Y Y r) & \multirow{4}{*}{ ككل } \\
\hline & & Or.rot & $1 \cdots$ & مستوي متوسط (Yr > > (VY) & \\
\hline & & $10.11 \mu$ & rq & مستوي مرتفع ( V V فأكثر) & \\
\hline & & $\% 1 \ldots$ & 191 & المجموع & \\
\hline
\end{tabular}

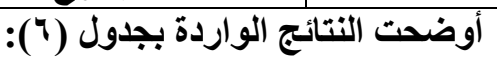

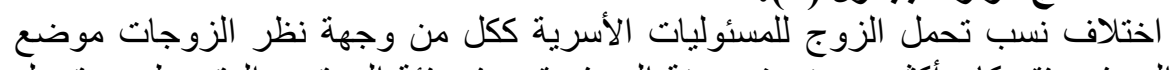

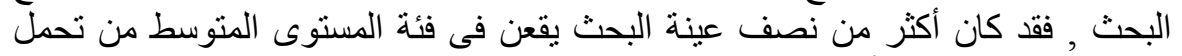

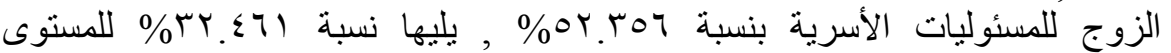

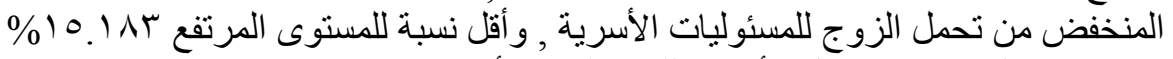

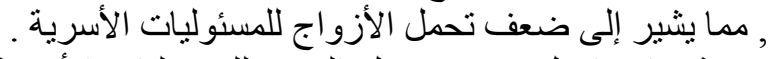

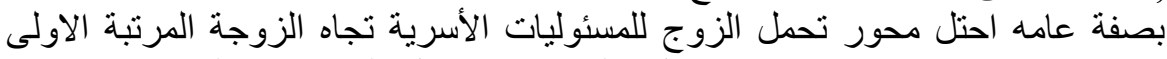

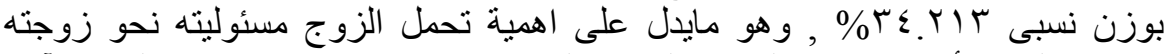

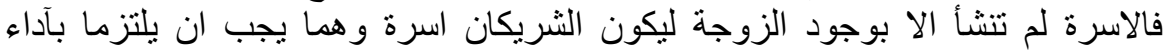
و اجباتهما نحو بعضهما ليحققا استقرار الاسرة المعنوى و المادى لـون , و هذه الو اجبات منبادلة 


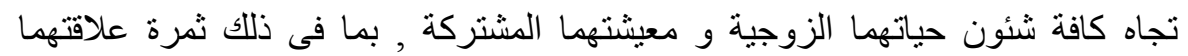

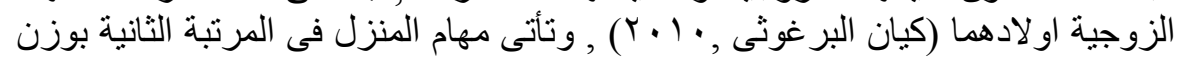

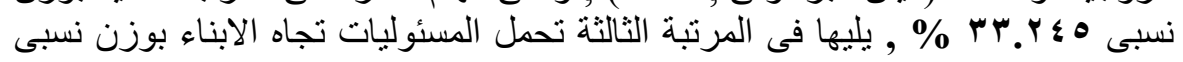

Y - وصف عينة البحث وفقاً للاستجابات على مقياس الضغوط الوجدانية:

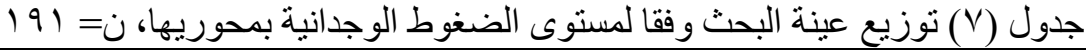

\begin{tabular}{|c|c|c|c|c|c|}
\hline الترتيب & الأهبية & $\%$ & العدد & المستوى & المحاور \\
\hline \multirow{3}{*}{ الأول } & \multirow{3}{*}{$0 \wedge . Y \leqslant$} & Or.AVq & 1.1 & 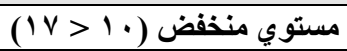 & \multirow{3}{*}{ والمقارنيات } \\
\hline & & rq.YTV & Vo & مستوي متوسط (V > Y צ Y) & \\
\hline & & V.A०r & 10 & مستوي مرتفع ( ؟ ف فأكثر) & \\
\hline \multirow{3}{*}{ الثاني } & \multirow{3}{*}{$\& 1 . \vee 7$} & TY.\&Y. & $\pi T$ & مستوي منخفض (· > l ( IV) & \multirow{3}{*}{ العاطفي } \\
\hline & & $\{9 . Y 1 \leqslant$ & $9 \varepsilon$ & مستوي متوسط (Y > Y ؟ Y) & \\
\hline & & IN.rY & ro & مستوي مرتفع (؛ Y فأكثر) & \\
\hline \multirow{4}{*}{\multicolumn{2}{|c|}{$\% 1 \ldots$}} & $r \cdot .474$ & 01 & مستوي منغفض (11 > 19 (1) & \multirow{4}{*}{ ككل } \\
\hline & & $0 \% .9 Y 4$ & 1.4 & مستوي متوسط (YV > 19) & \\
\hline & & $10.8 \cdot 7$ & $r \cdot$ & مستوي مرتفع (rV فأكثر) & \\
\hline & & $1 \cdots$ & 191 & 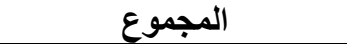 & \\
\hline
\end{tabular}

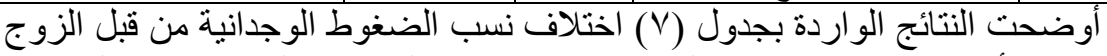

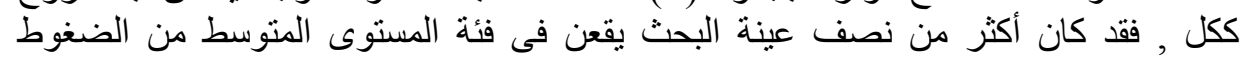

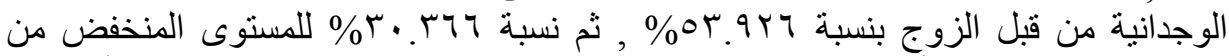

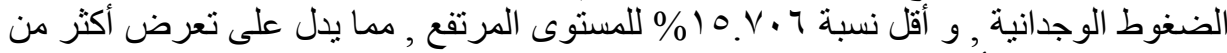

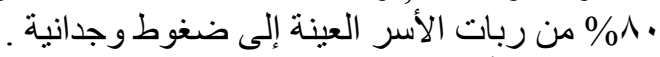

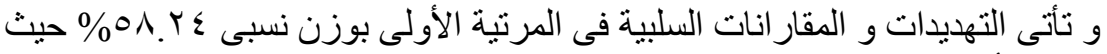

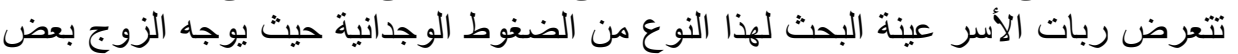

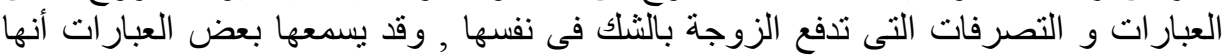

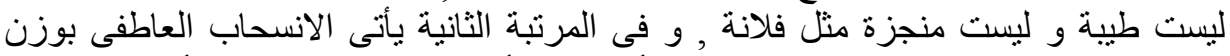

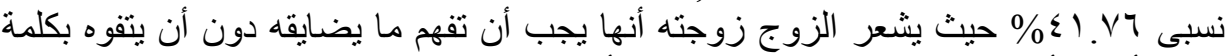

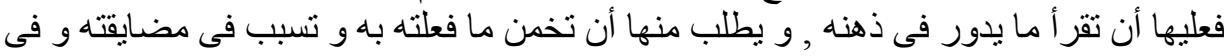

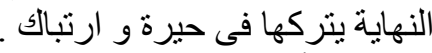

ينص الفرض على أنه توجد علاقة ارتباطية دالة احصائيا بين تحمل الزوباه

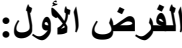

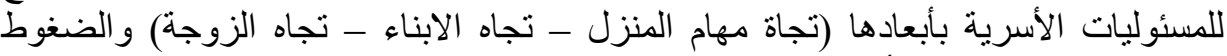

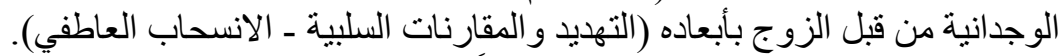

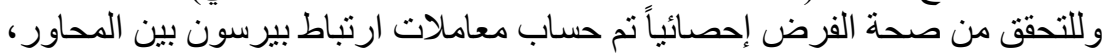
وجدول (^) يوضح ذللك: 
جدول(^)معاملات الارتباط بين تحمل الزوج للمسئوليات الأسرية بأبعادها و الضغوط الوجدانية

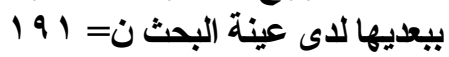

\begin{tabular}{|c|c|c|c|c|}
\hline 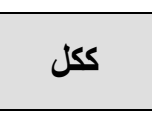 & تجاه الزوجة & تجاه الابناء & مهام المنزل & الضغوط الوجدانية تحمل المسئولية \\
\hline$* ., \vee \leqslant 9$ & $* . \wedge 11-$ & $* . \wedge r V_{-}$ & $* \cdot \wedge \leq \tau_{-}$ & التهديد والمقارنات السلبية \\
\hline *. . Tr & $* . \wedge \cdot 1-$ & $* . \wedge 1 q_{-}$ & *.ArT_ & الانسحاب العاطفي \\
\hline$* .7 \leq 0_{-}$ & $* \cdot V \cdot v_{-}$ & $* . V Y \varepsilon_{-}$ & $* . V \varepsilon_{-}$ & ككل \\
\hline
\end{tabular}

يوضح جدول (^) : (^)

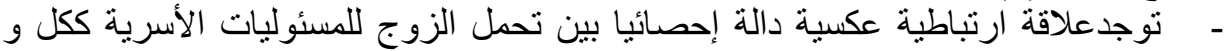

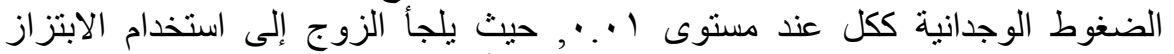

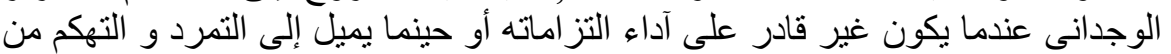

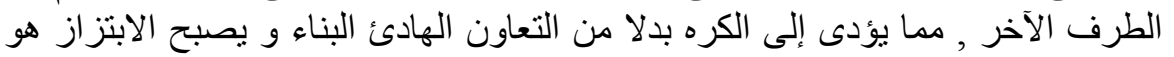

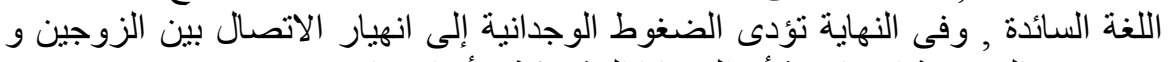

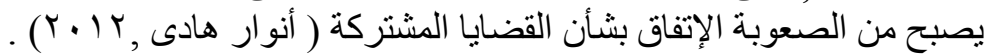

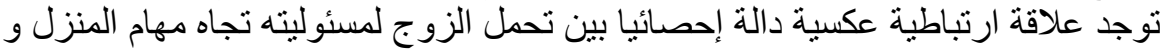

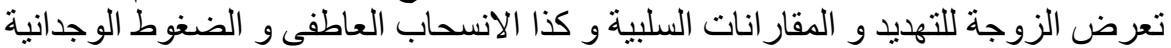

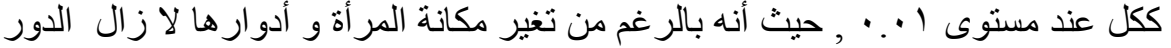

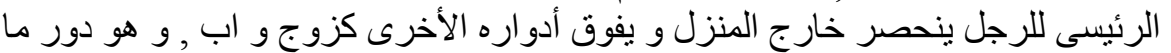

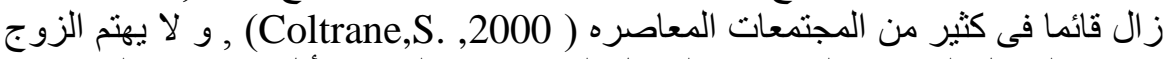

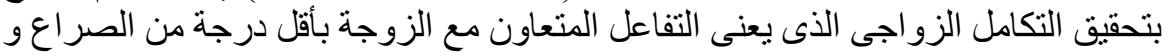

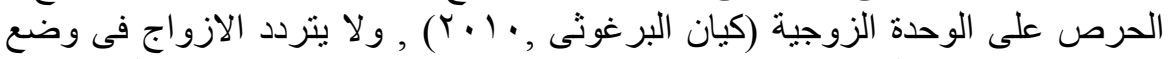

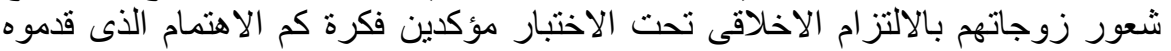

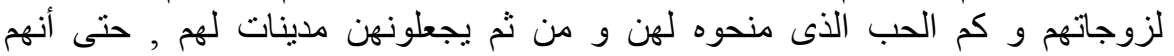

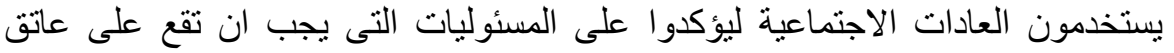

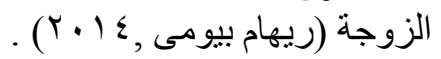

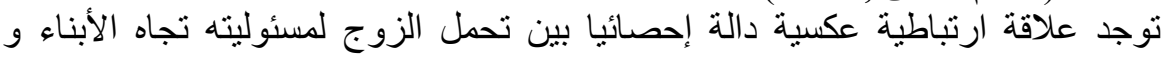

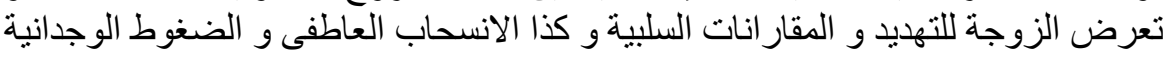

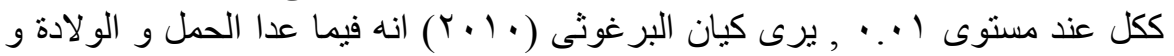

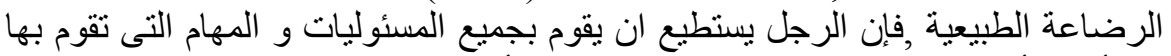

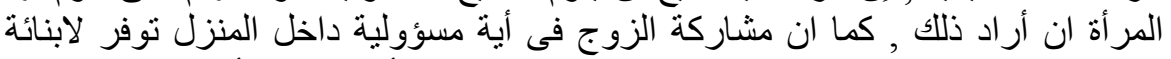

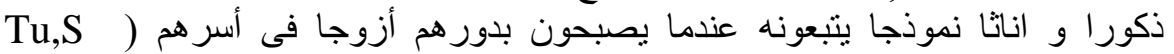
, (.\&Liao,p., 2006 


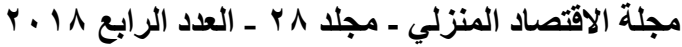

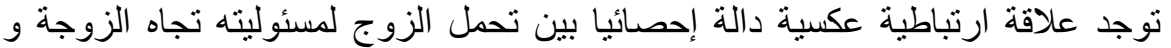

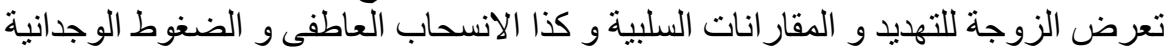

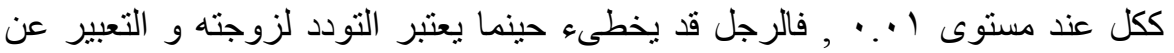

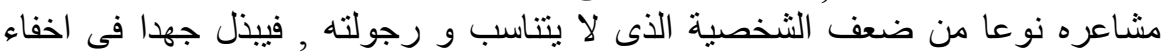

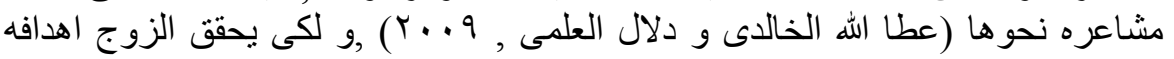

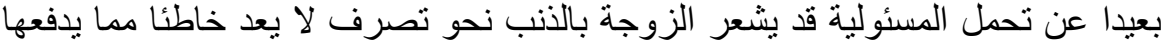

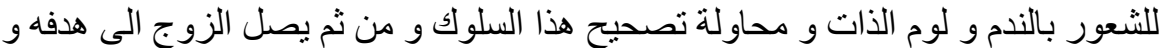

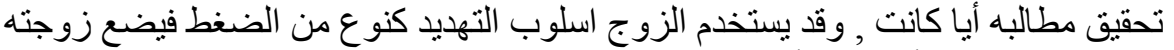

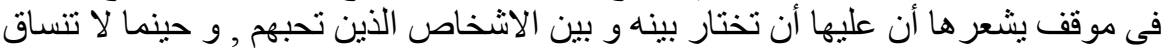

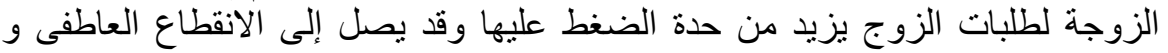

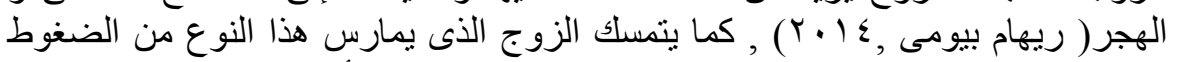

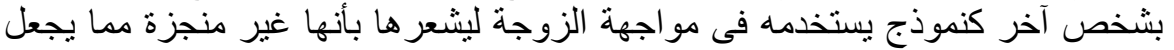

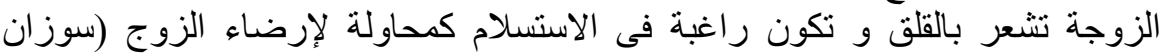

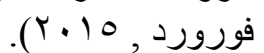

\section{وبذللك يكون الفرض الأول قد تحقق}

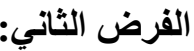

ينص الفرض الثانى على أنه يوجد تباين دال إحصائيا بين متوسطات درجات عينة

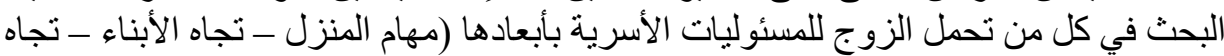

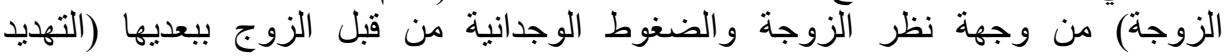

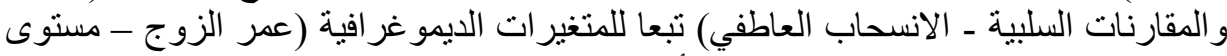

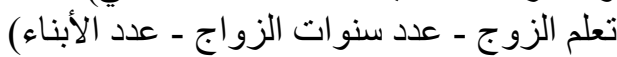

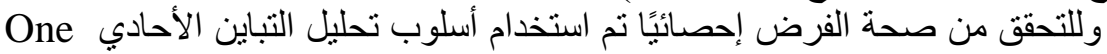

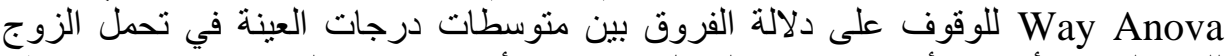

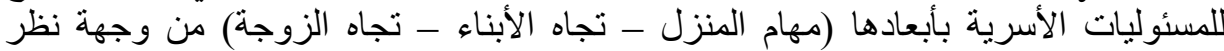

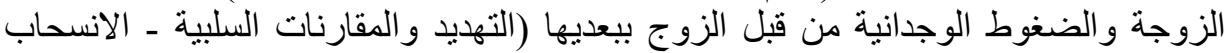

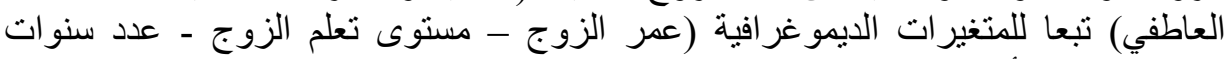

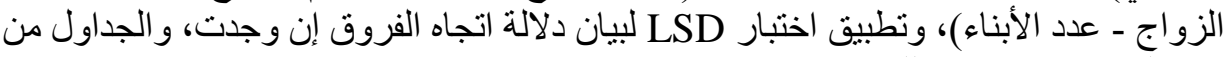

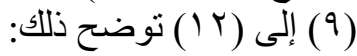




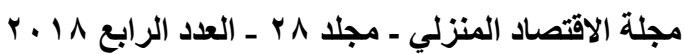

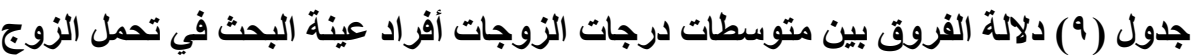

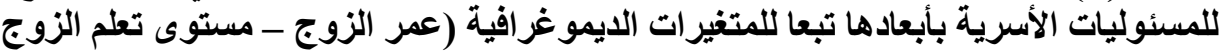

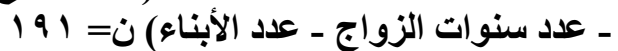

\begin{tabular}{|c|c|c|c|c|c|c|c|}
\hline مستوى & قيمة & متوسط المربعات & الحرية & المربعات & مصدر & المقئول & المتغير \\
\hline$\because 0$ & $\varepsilon r .9 r$ & $\begin{array}{l}V \leq 0 . M T Y \\
\text { IV.V.T }\end{array}$ & $\begin{array}{l}\text { r } \\
111 \\
19 .\end{array}$ & 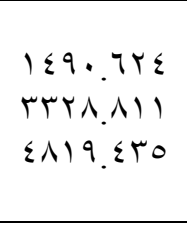 & 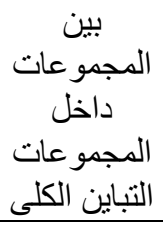 & المنزل & \multirow{4}{*}{$\begin{array}{l}\frac{y}{3} \\
\overline{3} \\
1\end{array}$} \\
\hline$\because 0$ & $r \varepsilon .0 \wedge T$ & $\begin{array}{l}7 \leq 9.9 .0 \\
11 . \vee 94\end{array}$ & $\begin{array}{l}\text { r } \\
111 \\
19 .\end{array}$ & 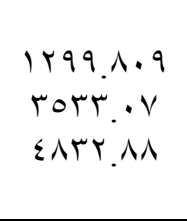 & المجمو المبات & الأبناء & \\
\hline$\because 0$ & $\leq 1.97 \varepsilon$ & $\begin{array}{l}\text { MVT.ArA } \\
\text { rA.E } \varepsilon \varepsilon\end{array}$ & $\begin{array}{l}\text { r } \\
111 \\
19 .\end{array}$ & $\begin{array}{l}\text { rror.707 } \\
\text { orVT.rT9 } \\
\text { VTro.190 }\end{array}$ & المجمو المجات & الزوجة & \\
\hline$\because .0$ & $\Sigma T . Y \mid T$ & $\begin{array}{l}\text { vorq.7rq } \\
17 r .940\end{array}$ & $\begin{array}{l}\text { r } \\
111 \\
19 .\end{array}$ & $\begin{array}{l}10.09 . \mathrm{VV} \\
r .7 \mu 1 . V \wedge 1 \\
\leqslant 0791.01\end{array}$ & 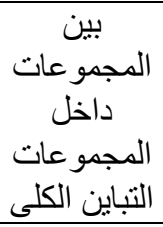 & ككل & \\
\hline غير & $.0 V Y$ & מוד & $\begin{array}{l}r \\
111 \\
19 .\end{array}$ & $\begin{array}{l}\because v 1 . \\
117.204 \\
118.574\end{array}$ & 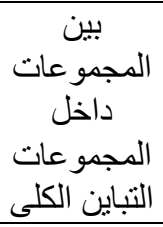 & مهام & \multirow{2}{*}{$\begin{array}{l}3 \\
3 \\
y \\
3 \\
-1 \\
\overline{3} \\
\frac{3}{2}\end{array}$} \\
\hline غير & و & $\begin{array}{l}.0 \leq 7 \\
.701\end{array}$ & $\begin{array}{l}r \\
111 \\
19 .\end{array}$ & 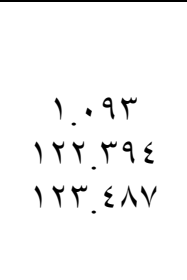 & المجمو المجات & الأبناء & \\
\hline
\end{tabular}




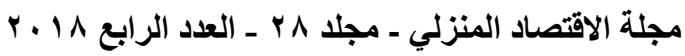

\begin{tabular}{|c|c|c|c|c|c|c|c|}
\hline الدلالة & قيمة & متوسط المربعات & درجات & المربعات & التباين & المسئولية & المتغير \\
\hline غير & $.70 \mathrm{~V}$ & $\begin{array}{l}\ddots \leqslant \leqslant \varepsilon \\
\because 7 \vee 0\end{array}$ & $\begin{array}{l}r \\
111 \\
19 .\end{array}$ & $\begin{array}{l}\because A \wedge V \\
\text { IrY.qro } \\
\text { IrV.Arr }\end{array}$ & المجمو المبات & الزوجة & \\
\hline غير & $\because 180$ & $\begin{array}{l}. .198 \\
1.791\end{array}$ & $\begin{array}{l}r \\
111 \\
19 .\end{array}$ & $\begin{array}{r}.09 \varepsilon \\
r 19 . r 1 r \\
r 19.9 .7\end{array}$ & المجمو عات المبن & ككل & \\
\hline$\because .0$ & M.rVו & $\begin{array}{c}1104.0 \leq \varepsilon \\
0.91 V\end{array}$ & $\begin{array}{l}r \\
111 \\
19 .\end{array}$ & 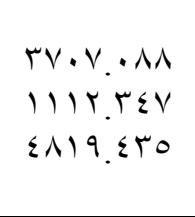 & المجمو المجات & المنزل & \multirow{4}{*}{$\begin{array}{l}\frac{9}{1} \\
.3 \\
\frac{3}{3} \\
\overline{3} \\
\frac{1}{10}\end{array}$} \\
\hline$\because .0$ & rqV.) & $\begin{array}{l}\text { INTO.TVT } \\
\text { T.IVA }\end{array}$ & $\begin{array}{l}r \\
111 \\
19 .\end{array}$ & 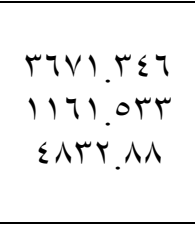 & المجمو المبات & الأبناء & \\
\hline$\because .0$ & $1 \leqslant 1.00 \%$ & $\begin{array}{l}\text { rTHO.YTE } \\
10 . \mathrm{KT}\end{array}$ & $\begin{array}{l}r \\
111 \\
19 .\end{array}$ & $\begin{array}{l}\Sigma T V \cdot .0 Y V \\
Y 900 . r T \Lambda \\
V T Y 0.190\end{array}$ & 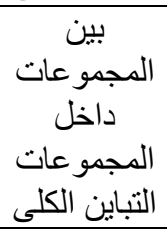 & الزوجة & \\
\hline$\because .0$ & 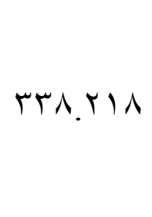 & $\begin{array}{l}\text { IVAVY. IA } \\
\text { Or.AOV }\end{array}$ & $\begin{array}{l}r \\
111 \\
19 .\end{array}$ & $\begin{array}{l}\text { rovos. ro } \\
99 T V . \text { rr } \\
\text { s0791..01 }\end{array}$ & المجمو المات & ككل & \\
\hline$\because .0$ & $V O . V T$ & $\begin{array}{l}\text { 1.79.9人r } \\
\text { IE. YOr }\end{array}$ & $\begin{array}{l}r \\
111 \\
19 .\end{array}$ & $\begin{array}{l}r 1 r q .974 \\
r 7 \vee 9 . \leqslant 79 \\
\leqslant 119 . \leqslant 40\end{array}$ & 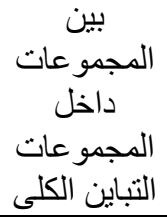 & المنزل & $\frac{y}{7}$ \\
\hline
\end{tabular}




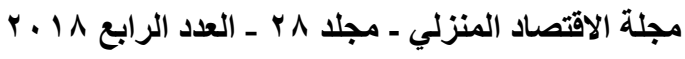

\begin{tabular}{|c|c|c|c|c|c|c|c|}
\hline الدلالة & قنمة & متوسط المربعات & درجات & المربعوات & مصدر & المسئملية & المتغير \\
\hline$\because .0$ & $V Y . \leqslant 7$. & $\begin{array}{l}1.91 .779 \\
15.99\end{array}$ & $\begin{array}{l}r \\
111 \\
19 .\end{array}$ & 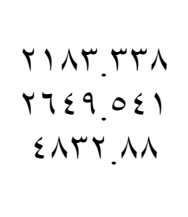 & المجمو المات التبات & الأبناء & \\
\hline$\because .0$ & $\leqslant \Lambda . \leqslant O r$ & 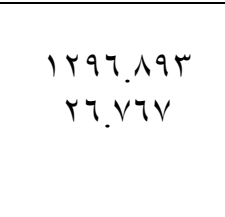 & $\begin{array}{l}r \\
111 \\
19 .\end{array}$ & 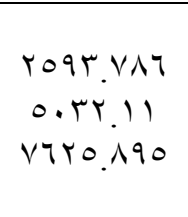 & المجمو المجات & الزوجة & \\
\hline$\because .0$ & $V \vee . q \cdot \Lambda$ & 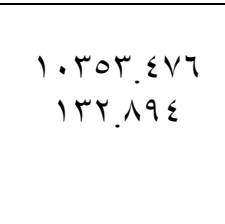 & $\begin{array}{l}r \\
111 \\
19 .\end{array}$ & $\begin{array}{l}r \cdot V \cdot T .90 r \\
r \leqslant 91 \leq .1 .7 \\
\Sigma 0791 . .01\end{array}$ & 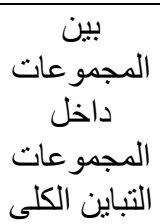 & ككل & \\
\hline
\end{tabular}

\section{يتضح من جدول (9): (9)}

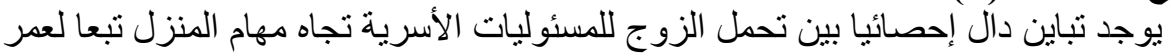

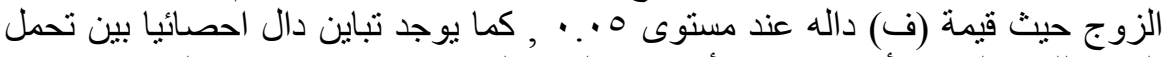

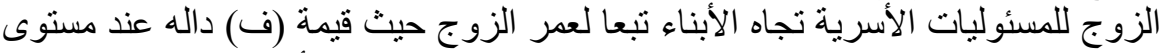

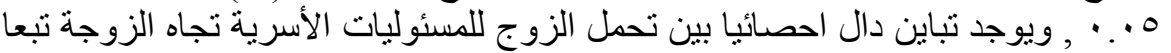

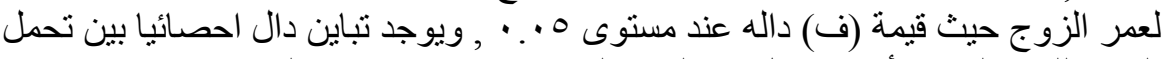

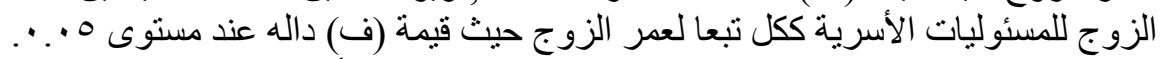

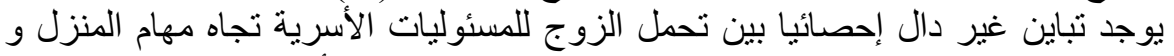

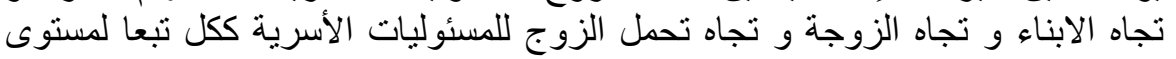

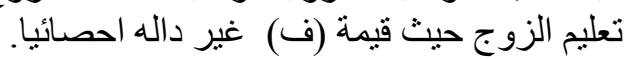

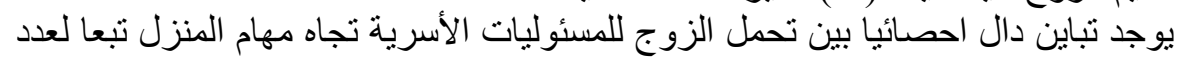

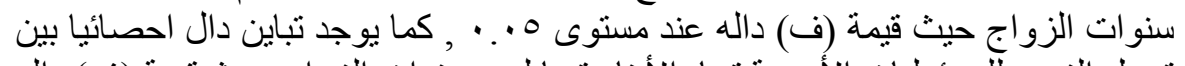

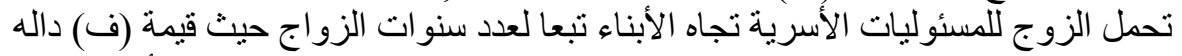

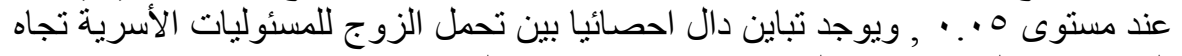

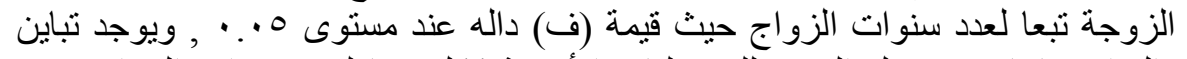

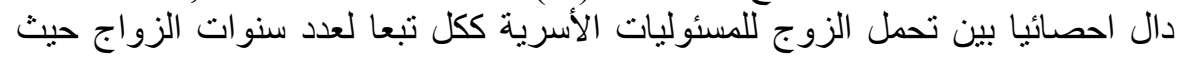

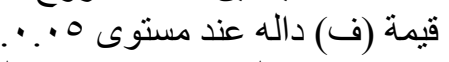

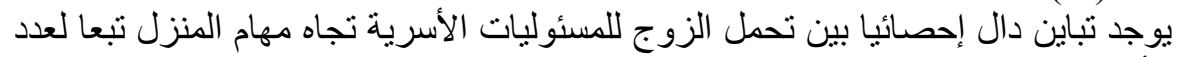

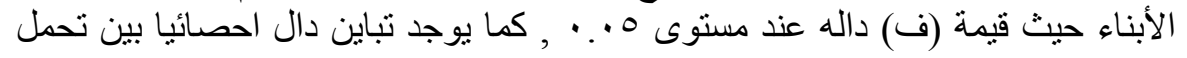




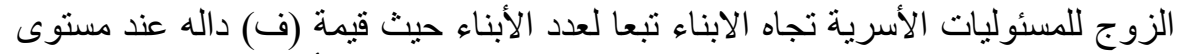

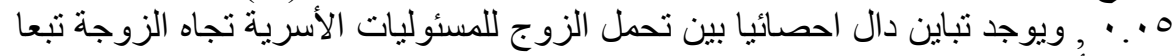

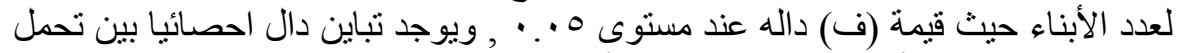

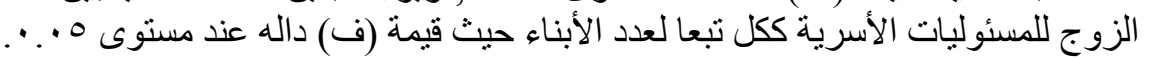

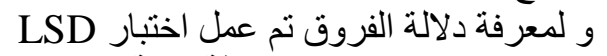

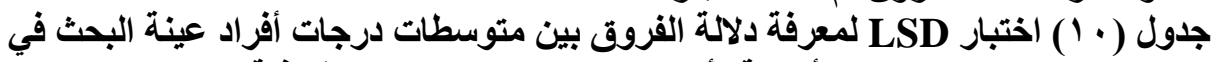

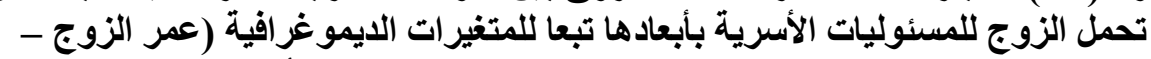

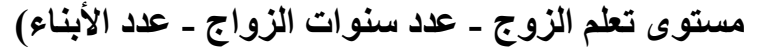

\begin{tabular}{|c|c|c|c|c|c|}
\hline ن= & 1. $V=\dot{~}$ & $v r=\dot{~}$ & الحسابي & عمر الزوج & تحمل \\
\hline- & - & - & $18 . \leqslant 790$ & من •ro>r & \multirow{3}{*}{ المنزل } \\
\hline- & - & *T.VTrO _ & $r l . r \leqslant r$ & من 0ب>> 0 & \\
\hline- & *V.าフォ1- & $\begin{array}{c}- \\
* 11 . \leqslant \text { }\end{array}$ & $r \wedge .9 .91$ & من • 0 فأكثر & \\
\hline- & - & - & $1 \vee .91 \vee A$ & من •ro>r & \multirow{3}{*}{ الأبناء } \\
\hline- & - & $* \Psi .19 \leqslant r \leqslant-$ & $r 1.11 Y 1$ & من 0"> 0.0 & \\
\hline- & *V.V৭79 & *1. $\overline{991 Y \Lambda}$ & $r \wedge .9 .91$ & من • ه فأكثر & \\
\hline- & - & - & 19.511 & من •ro>r & \multirow{3}{*}{ الزوجة } \\
\hline- & - & $*_{0 . \leqslant Y T \backslash 9}$ & $Y \leq \_T V T$ & מن 0"> 0.0 & \\
\hline- & *V.qAVYY_ & $\begin{array}{c}- \\
*|r . \leq| r \leqslant 0\end{array}$ & $T T_{.} \leqslant 0 \leqslant 0$ & من • 0 فأكثر & \\
\hline- & - & - & $0 \leqslant . \leqslant \mu \wedge \leqslant$ & من •ro>r & \multirow{3}{*}{ ككل } \\
\hline- & - & $\begin{array}{c}- \\
* \mid r . r \wedge \varepsilon \cdot V\end{array}$ & II.AYYE & من 0Y>>0 & \\
\hline- & $* Y r_{.} \leqslant 0 . r_{-}$ & $\begin{array}{c}- \\
* 0 . \wedge \mu \leqslant \mu V\end{array}$ & Q. YVYV & من • 0 فأكثر & \\
\hline
\end{tabular}




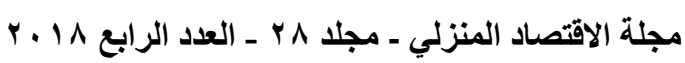

تابع جدول (• 1) اختبار LSD لمعرفة دلالة الفروق بين متوسطات درجات أفراد عينة البحث

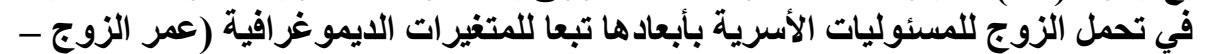

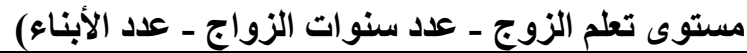

\begin{tabular}{|c|c|c|c|c|c|}
\hline ن & $\wedge \varepsilon=\dot{ }$ & $79=\dot{~}$ & المتوسطابي & عدد سنو ات عات & تحملور \\
\hline - & - & - & $1 V . \leqslant T \leqslant \Lambda$ & من ا>>0 & \multirow{3}{*}{ المنزل } \\
\hline- & - & $* 1.1 \leqslant 100_{-}$ & IN.ONKT & من 0>0 & \\
\hline - & *). $5 \leqslant$. & *11.09101 & rq. rqr & من 1 فأكثر & \\
\hline - & - & - & $1 V .9070$ & من ا>>0 & \multirow{3}{*}{ الأبناء } \\
\hline- & - & . $14 \leq 91-$ & IA.TYE & من 0>0 & \\
\hline - & $* 1 . \wedge 1.10$ & $* 11.1 \vee 0.7$ & $r q . r \leq \cdot r$ & من 0 ا فأكثر & \\
\hline - & - & - & $11.9 \vee 1$ & من ا>>0 & \multirow{3}{*}{ الزوجة } \\
\hline- & - & $* Y . \vee 19 \leq 7_{-}$ & 11.79 .0 & من 0>0 & \\
\hline- & *). & * & Tr.EVTV & من 0 فأكثر & \\
\hline- & - & - & 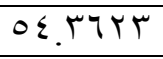 & من ا>>0 & \multirow{3}{*}{ ككل } \\
\hline- & - & *E.YrYqY_ & $01.090 Y$ & من 0> & \\
\hline - & ع - & צ' & 9.7177 & من 0 ف فأكثر & \\
\hline
\end{tabular}


تابع جدول ( • 1) اختبار LSD لمعرفة دلالة الفروق بين متوسطات درجات أفراد عينة البحث

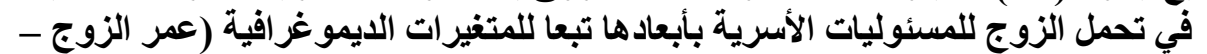

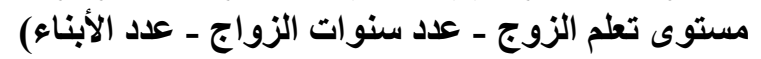

\begin{tabular}{|c|c|c|c|c|c|}
\hline ن & ن & $r \xi=\dot{ }$ & الحسابي & عدد الابناء & تحملور \\
\hline- & - & - & $r \wedge .90 \wedge r$ & من ا>> & \multirow{3}{*}{ المنزل } \\
\hline- & - & $* q . \vee \wedge \wedge \varepsilon$ & 19.1799 & من ro> & \\
\hline- & $* r_{.} .9 \wedge 01$ & $* 11 . \wedge \wedge 79$ & $\mid V . V 1 \leq$ & من ه فأكثر & \\
\hline- & - & - & r9.177V & من l> & \multirow{3}{*}{ الأنباء } \\
\hline- & - & $* 9.94 \vee 91$ & $19 . Y Y \wedge \Lambda$ & من r >>0 & \\
\hline- & I.AVITY & $* 11 . \wedge .90 Y$ & IV.roVI & من 0 فأكثر & \\
\hline- & - & - & TY.ZITV & sن > r & \multirow{3}{*}{ الزوجة } \\
\hline- & - & *1. .VYT人T & YI.79YA & من r> & \\
\hline- & $r .0 \leqslant 990$ & *IT.YVTNI & $19.1 \leqslant Y 9$ & من ه فأكثر & \\
\hline- & - & - & $9.0 \leqslant 1 \mathrm{~V}$ & من ا>r & \multirow{3}{*}{ ككل } \\
\hline- & - & $* r . . \leq 0.17$ & $7 . .910$ & من س>>0 & \\
\hline- & $* 7.0 Y . . V$ & $* r \neg .9 V \cdot Y \varepsilon$ & or.ovIs & من 0 فأكثر & \\
\hline
\end{tabular}

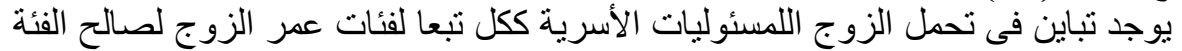

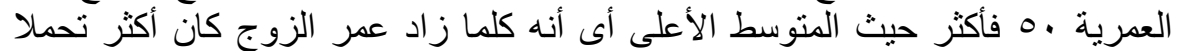

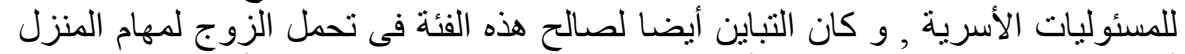

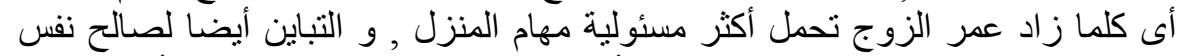

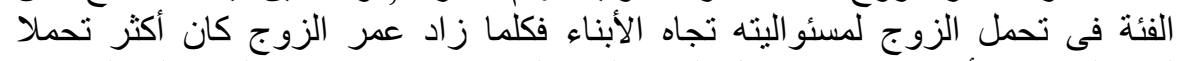

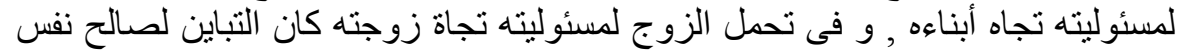

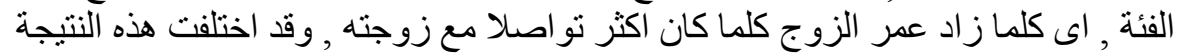

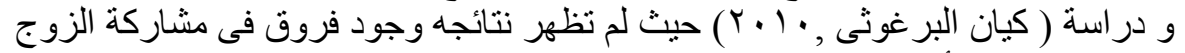

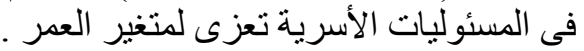

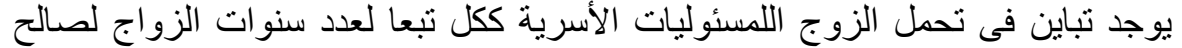

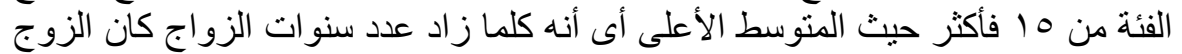

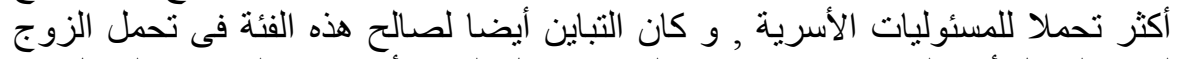

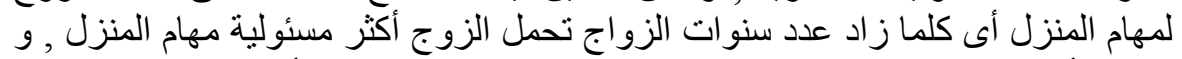

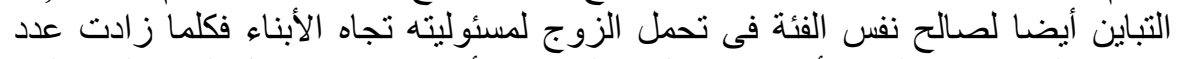

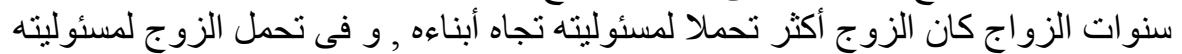

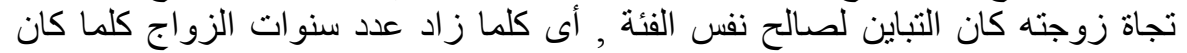




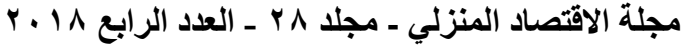

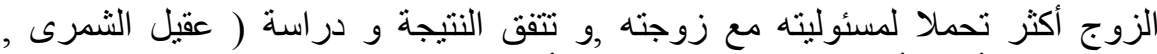

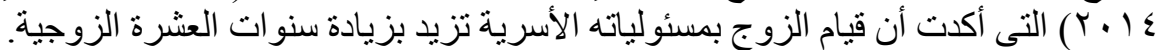

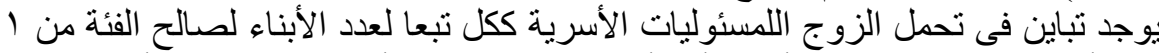

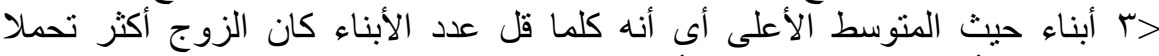

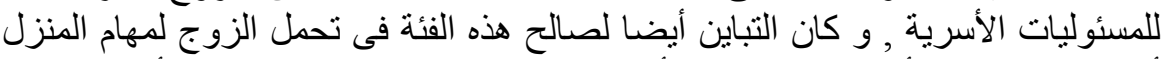

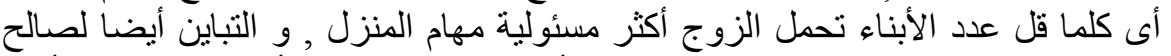

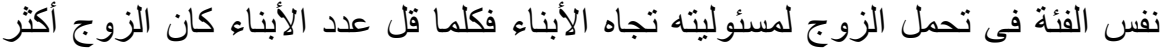

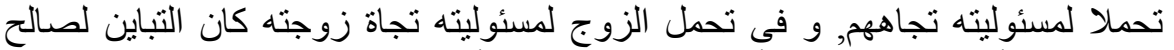

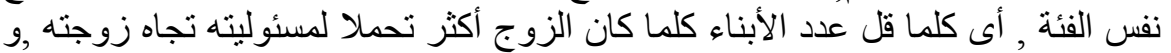

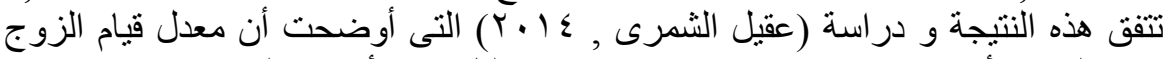

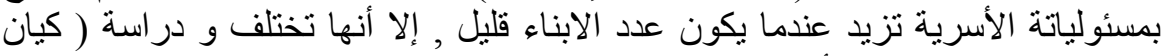

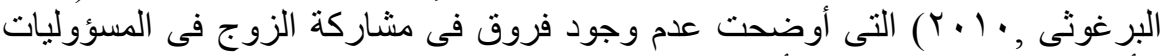

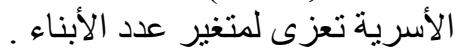

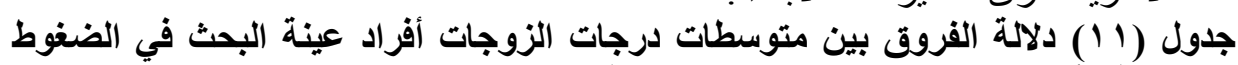

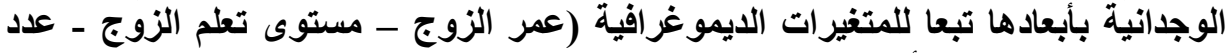

\begin{tabular}{|c|c|c|c|c|c|c|c|}
\hline \multicolumn{8}{|c|}{ سنوات الزواج - عدد الابناء)ن= 191} \\
\hline مستوى الدلالة & قفية & المربعات & الحرجية & المربعات & مصدر & الوحاور الضغوط & المتغير \\
\hline$\because 0$ & ro.r & $\begin{array}{r}1097 . \mathrm{rV} \\
50.110\end{array}$ & $\begin{array}{l}r \\
111 \\
19 .\end{array}$ & $\begin{array}{l}M 19 r .0 \leq \\
1 \leq 9 \leq . \wedge .8 \\
11714.109\end{array}$ & المان النجمو عات & التهلية المقارنات & $\begin{array}{l}\frac{9}{3} \\
\overline{3}\end{array}$ \\
\hline$\because 0$ & or. 7199 & $\begin{array}{r}Y Y V \varepsilon . \wedge V T \\
\varepsilon Y . M V I\end{array}$ & $\begin{array}{l}r \\
111 \\
19 .\end{array}$ & $\begin{array}{l}\leqslant 0 \leqslant 9 . V 0 Y \\
V 970 . V 74 \\
1 Y 010.011\end{array}$ & البين النجموعات & الانسحاب & \\
\hline$\because 0$ & Or.VYY & $\begin{array}{l}V \leqslant r r . V \cdot 1 \\
1 K \Lambda .1 \wedge T\end{array}$ & $\begin{array}{l}r \\
111 \\
19 .\end{array}$ & $\begin{array}{l}l \leqslant \Lambda \leqslant V . \varepsilon \cdot r \\
r 0 q V \Lambda . q \wedge 0 \\
\varepsilon \cdot \Lambda r T . r \wedge V\end{array}$ & المجنين المجوعات & ككل & \\
\hline
\end{tabular}




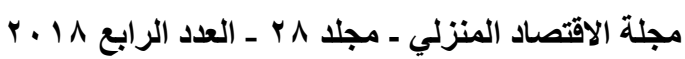

\begin{tabular}{|c|c|c|c|c|c|c|c|}
\hline غير & $\because$ Vo & $\begin{array}{l}\because \leq 9 \\
.77\end{array}$ & $\begin{array}{l}r \\
111 \\
19 .\end{array}$ & $\begin{array}{l}\because .99 \\
|r \leq .| r \mid \\
\mid r \leq . r T\end{array}$ & 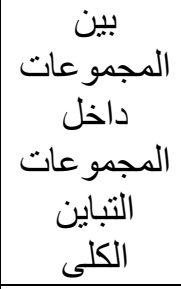 & و المقارنات & \multirow{3}{*}{$\begin{array}{l}3 \\
3 \\
y \\
3 \\
7 \\
\overline{3} \\
? \\
?\end{array}$} \\
\hline غاله & $r .79$ & $\begin{array}{l}1 . \varepsilon r \\
. T \wedge V\end{array}$ & $\begin{array}{l}r \\
111 \\
19 .\end{array}$ & $\begin{array}{l}r . \wedge \leq 1 \\
1 r^{\prime} . v_{0} \\
|r| .917\end{array}$ & 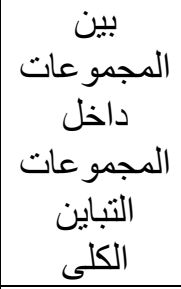 & الانسحاب & \\
\hline غاله & 1.004 & $\begin{array}{l}1.9 V 7 \\
1 . r V Y\end{array}$ & $\begin{array}{l}r \\
111 \\
19 .\end{array}$ & $\begin{array}{l}r .901 \\
r r q .109 \\
r \leq r .11\end{array}$ & 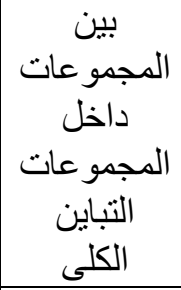 & ككل & \\
\hline$\because .0$ & |rr. & 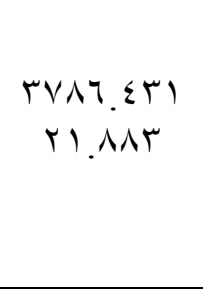 & $\begin{array}{l}r \\
111 \\
19 .\end{array}$ & $\begin{array}{l}\text { VOVY.ATY } \\
\Sigma 11 T .997 \\
11717.109\end{array}$ & 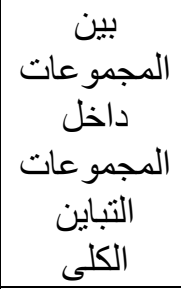 & و المقارنات & \multirow{3}{*}{$\begin{array}{l}\frac{y}{1} \\
\frac{3}{3} \\
\overline{3} \\
\overline{3} \\
\frac{7}{N}\end{array}$} \\
\hline$\because .0$ & $9 \leqslant . \vee .0$ & $\begin{array}{c}r \leq .07 V \\
r .17 r\end{array}$ & $\begin{array}{l}r \\
111 \\
19 .\end{array}$ & 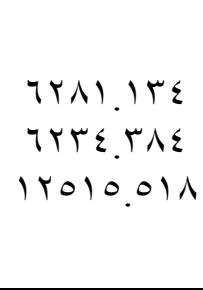 & 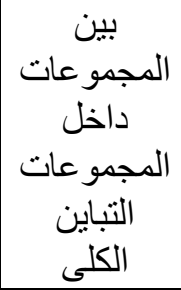 & الانسحاب & \\
\hline$\because .0$ & IVA.TY & $\begin{array}{c}I r r u . \cdot r r \\
V \leqslant .9 \leqslant 9\end{array}$ & $\begin{array}{l}r \\
111 \\
19 .\end{array}$ & 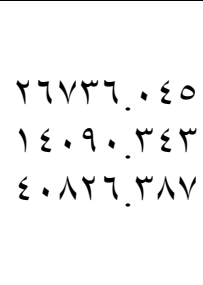 & المجموعات المبل التبوعات & ككل & \\
\hline
\end{tabular}




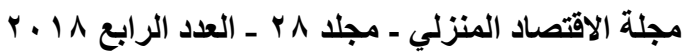

\begin{tabular}{|c|c|c|c|c|c|c|c|}
\hline$\because 0$ & 00.717 & $\begin{array}{c}r \mid V Y .1 \leq 0 \\
r 9 . .07\end{array}$ & $\begin{array}{l}r \\
111 \\
19 .\end{array}$ & $\begin{array}{l}\varepsilon r \leqslant \varepsilon . r q 1 \\
V r \leqslant r .071 \\
117 \wedge 7.109\end{array}$ & المجمو التمبو التباتين & و المقارنات & \\
\hline$\because 0$ & $r 1.0 \mathrm{Vr}$ & $\begin{array}{l}\text { lovr. } \varepsilon .0 \\
\leqslant 9 . \wedge \mu \leqslant\end{array}$ & $\begin{array}{l}r \\
111 \\
19 .\end{array}$ & $\begin{array}{l}r 1 \leq 7.1 .9 \\
9471 . v .9 \\
15010.011\end{array}$ & 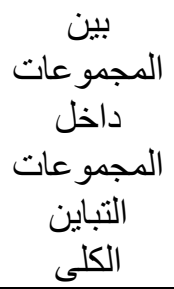 & الانسحاب & $\frac{9}{7}$ \\
\hline$\because 0$ & 0 or.0 $0 \leq 7$ & $\begin{array}{l}V \varepsilon \cdot \Lambda . r \cdot \varepsilon \\
\mid r \Lambda . r 01\end{array}$ & $\begin{array}{l}r \\
111 \\
19 .\end{array}$ & 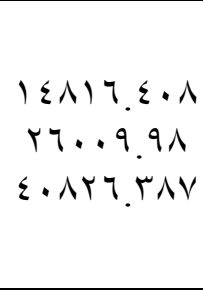 & 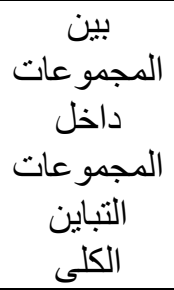 & ككل & \\
\hline
\end{tabular}

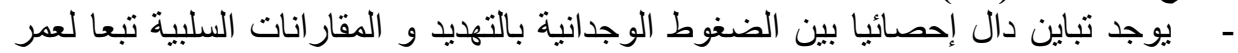

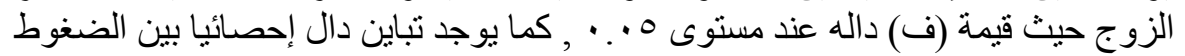

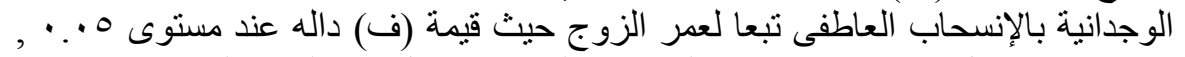

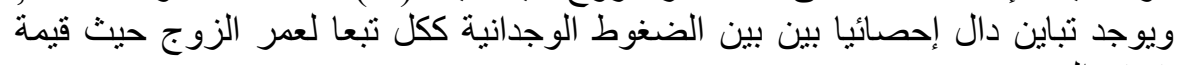

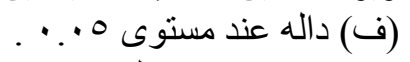

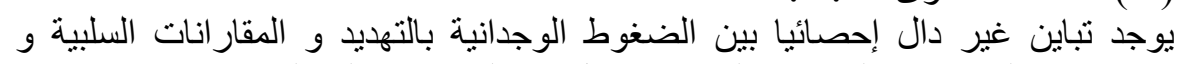

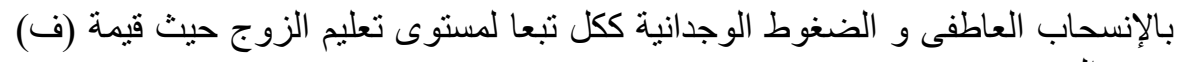
يوجد تباين دال إحصائيا بين بين الضغوط الوجدانية بالتهديد و المقار انات السلبية تبعا لعدد

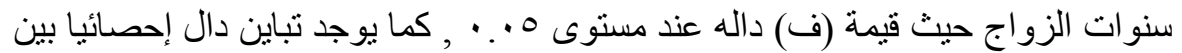

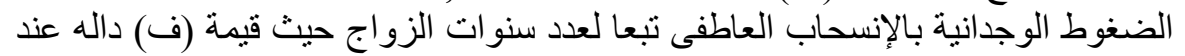

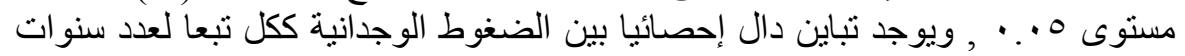

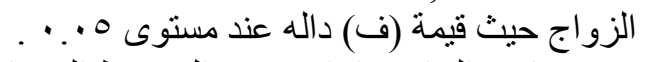

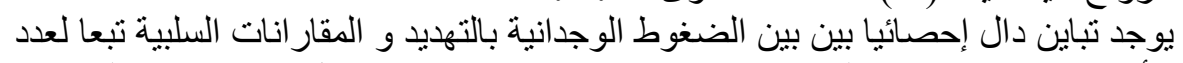

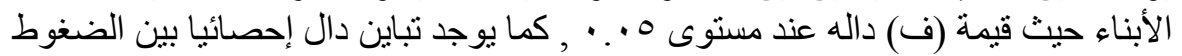

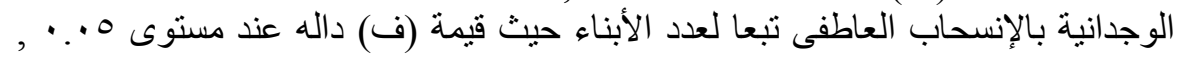


ويوجد تباين دال إحصائيا بين الضغوط الوجدانية ككل تبعا لعدد الأبناء حيث قيمة (ف)

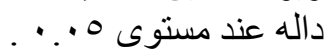

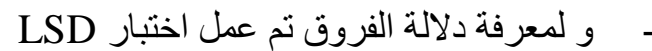

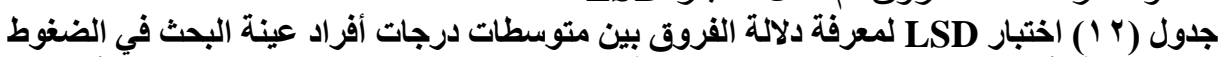

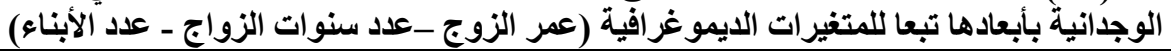

\begin{tabular}{|c|c|c|c|c|c|}
\hline ن & $1 \cdot V=\dot{ }$ & $V r=\dot{~}$ & المتوسط الحسابي & عمر الزوج & محاور الضنغانية \\
\hline- & - & - & rE.YAVV & من •ro>r & \multirow{3}{*}{ التهديد والمقارنات } \\
\hline- & - & *0.YMIT & 19.071 & من 0ب>> 0 & \\
\hline- & *II.VATKO & $* 1 V .1 \leq 9 \leq$ & IV.YVYV & من •0 فأكثر & \\
\hline- & - & - & $r \varepsilon .10 . \mathrm{V}$ & من •ro>r & \multirow{3}{*}{ الانسحاب العاطفي } \\
\hline- & - & $* \Lambda . \vee 0 \wedge 17$ & ro.rqTo & من 0ب>> 0. & \\
\hline- & $* V . r \cdot 171$ & $* 17.09 \vee \wedge$ & 11.9 .9 & من • 0 فأكثر & \\
\hline- & - & - & $\neg \wedge . \varepsilon \Gamma \wedge \varepsilon$ & من •ro>r & \multirow{3}{*}{ ككل } \\
\hline- & - & $* 11.9 \wedge 9 \vee 7$ & $0 \leqslant \leqslant \leqslant \wedge 7$ & من 0ب>> 0.0 & \\
\hline- & $* 19 . \wedge \leqslant 97$ & $* T r . V \Sigma V Y$ & 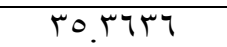 & من •0 فأكثر & \\
\hline$r \Lambda=\dot{ }$ & $\wedge \varepsilon=\dot{ن}$ & $79=\dot{0}$ & المتوسط الحسابي & 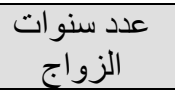 & محاور الضنغوط الوجدية \\
\hline- & - & - & TE.MTM & من ا>> & \multirow{3}{*}{$\begin{array}{c}\text { التهديد والمقارناتية السلبية } \\
\text { التبية }\end{array}$} \\
\hline- & - & *I.OYT人I & r. .1 .90 & من 0>10 & \\
\hline- & $* 1 \leq .99 \mathrm{VV}$ & $* 17.01 \vee 0 \varepsilon$ & $1 V .1101$ & من 10 فأكثر & \\
\hline- & - & - & $r \varepsilon . \wedge V$ & من ا>> & \multirow{3}{*}{ الانسحاب العاطفي } \\
\hline- & - & $* 0 . \wedge V Y T V$ & $r \wedge . Y I \leqslant r$ & من 0>0 & \\
\hline- & 1. ITOTE & $* 17 . .1 .1$ & $1 \wedge . \vee \wedge \wedge$ & من 10 فأكثر & \\
\hline- & - & - & $7 \Lambda . \varepsilon Y \cdot r$ & من ا>>0 & \multirow{3}{*}{ ككل } \\
\hline- & - & $* \vee . \Upsilon 97 \leqslant \Lambda$ & 7I. & من & \\
\hline- & *ro.1 rq.V & *YY.0Y000 & $r 0 . \wedge 9 \leqslant V$ & من 10 فأكثر & \\
\hline ن & ن & $r \varepsilon=\dot{ }$ & المتوسط الحسابي & عدد الابناء & محاور الضنغوط الوجية \\
\hline- & - & - & $1 V .90 \wedge r$ & من ا> & \multirow{3}{*}{ التهديد و المقارنات } \\
\hline- & - & $* 1 T .907 V_{-}$ & 11.910 & من Tro & \\
\hline- & r.9ะYा1- & $* 17 . \wedge 9 \wedge \wedge 1$ - & $r \varepsilon . \wedge 0 V 1$ & من 0 فأكثر & \\
\hline- & - & - & 11..ATr & من l> & \multirow{3}{*}{ الانسحاب العاطفي } \\
\hline- & - & $* 11 . r(19$ & rq.5.0r & من r & \\
\hline- & $\varepsilon .09 \leqslant V V_{-}$ & $* 10.9177 V_{-}$ & $r \varepsilon$ & من ه فأكثر & \\
\hline- & - & - & M. & من > & \multirow{3}{*}{ ككل } \\
\hline- & - & *Y०. YVA० & $T I . T \cdot T$ & من س> & \\
\hline- & 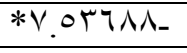 & $* *_{Y} \wedge_{\text {N }} 0 \leq \Lambda_{-}$ & $71 . \wedge 0 \mathrm{VI}$ & من 0 فأكثر & \\
\hline
\end{tabular}




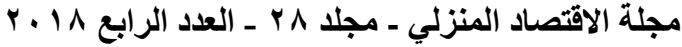

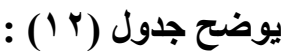

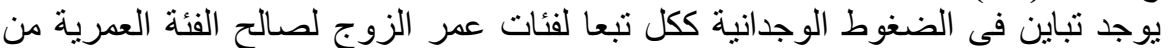
• .

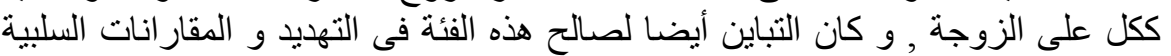

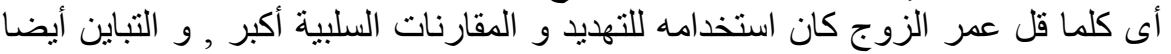

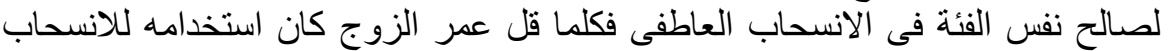

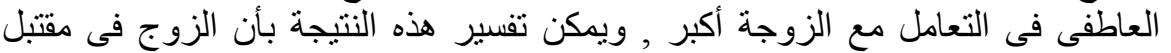

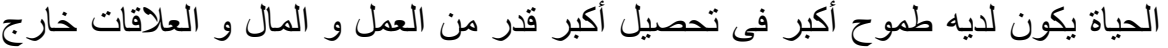

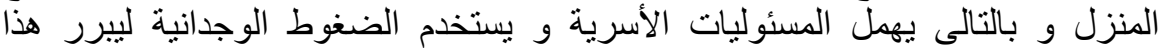

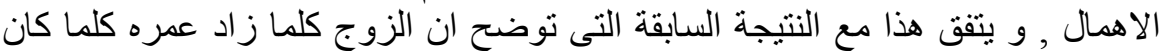

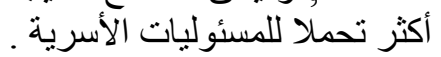

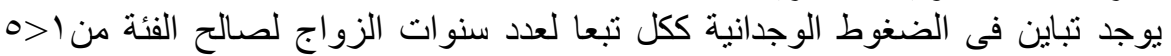

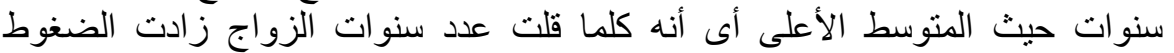

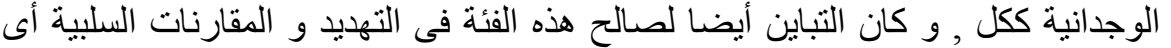

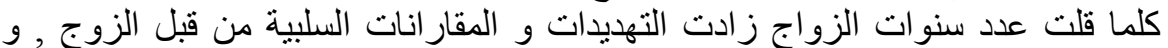

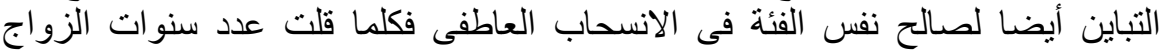

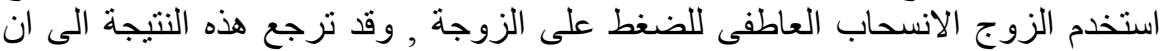

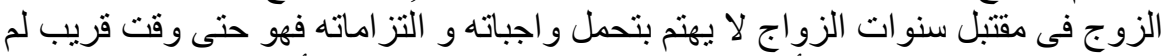

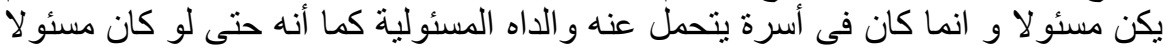

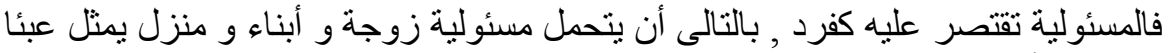

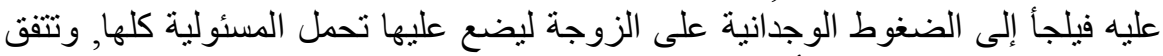

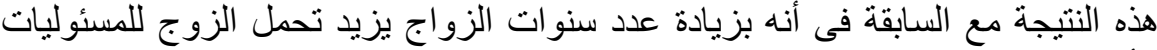

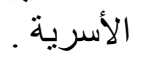

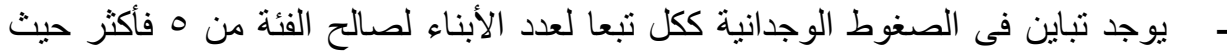

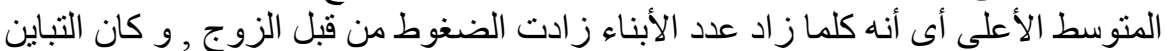

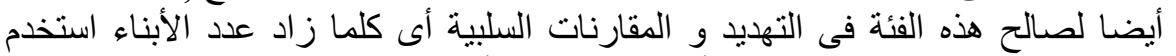

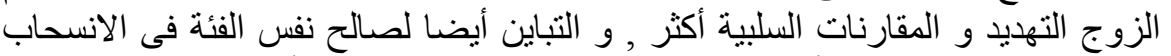

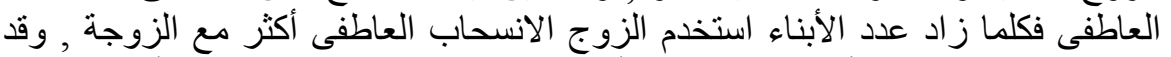

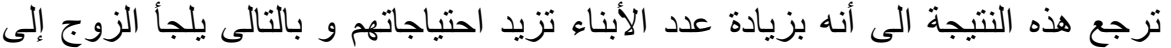

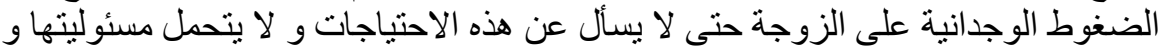

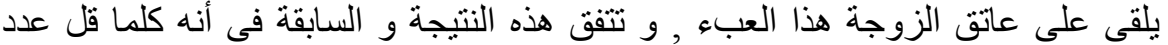

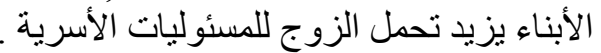

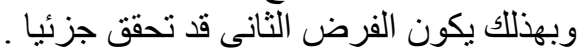

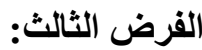

ينص الفرض الثالث على أنه يوجد تباين دال إحصائيا بين متوسطات درجات عاد عينة البحث في كل من تحمل الزوج للمسئوليات الأسرية بأبعادها (مهام المنزل ـ ـ تجاه الأبناء ـ تجاه 
الزوجة) من وجهة نظر الزوجة والضغوط الوجدانية من قبل الزوج بيعاتئيها (التهديد

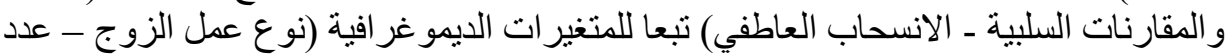

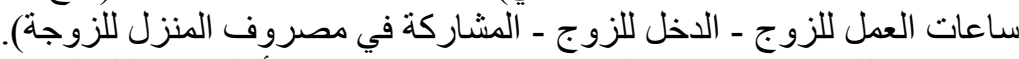

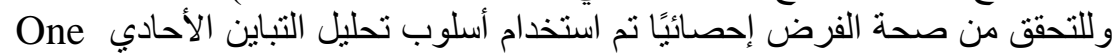

Way Anova

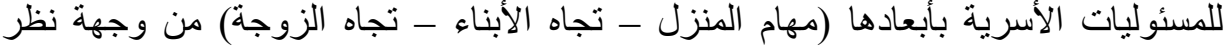

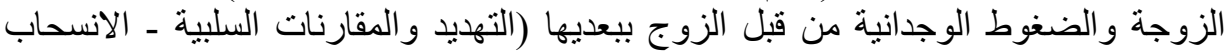

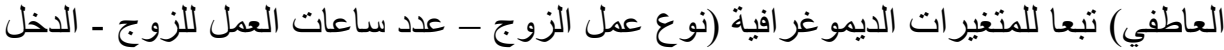

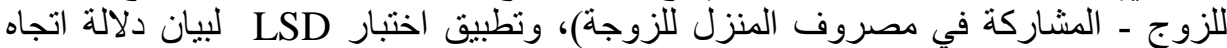

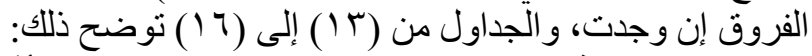

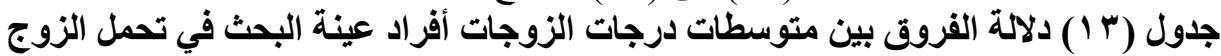

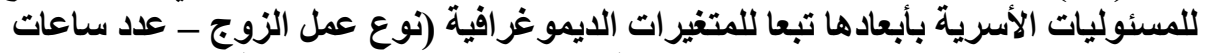

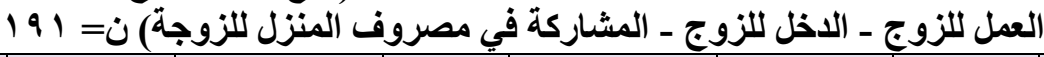

\begin{tabular}{|c|c|c|c|c|c|c|c|}
\hline مستوى & قبمة & المربعات & الحرجات & المربعوات & مصدر & مقياس & المتغير \\
\hline غير & $\cdot .7 / V$ & מוזr & $\begin{array}{l}r \\
111 \\
19 .\end{array}$ & 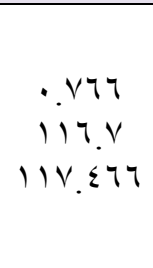 & المجمو المات التبل & المنزل & \\
\hline غير & $.01 \mathrm{~V}$ & $\begin{array}{l}\text { אT". } \\
.70 \%\end{array}$ & $\begin{array}{c}r \\
111 \\
19 .\end{array}$ & 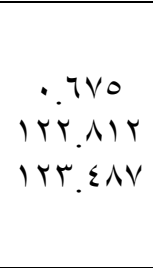 & المجمو المات التبات & الأجناء & $\begin{array}{l}3 \\
3 \\
y \\
3 \\
\bar{z}\end{array}$ \\
\hline غاله غير & E & $\begin{array}{l}\theta Y K \\
\cdot T Y \Lambda\end{array}$ & $\begin{array}{c}r \\
111 \\
19 .\end{array}$ & $\begin{array}{l}\ddots \leqslant r q \\
\text { IrV.rAr } \\
\text { Irv.Arr }\end{array}$ & المجمو عات التجمو عات & الزوجة & . \\
\hline غاله & $\because \vee \wedge r$ & $\begin{array}{l}1.419 \\
1.711\end{array}$ & $\begin{array}{l}r \\
111 \\
19 .\end{array}$ & $\begin{array}{c}r .7 q \\
r \text { r. } \\
r \text { rq. } 9.9\end{array}$ & المجموعات & ككل & \\
\hline
\end{tabular}




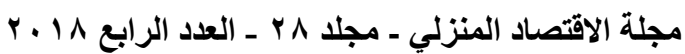

\begin{tabular}{|c|c|c|c|c|c|c|c|}
\hline & & & & & التباين & & \\
\hline$\because .0$ & $\{9.07\}$ & $\begin{array}{l}1 \mu 1.9 \cdot r \\
17 . \vee 10\end{array}$ & $\begin{array}{l}r \\
111 \\
19 .\end{array}$ & $\begin{array}{l}177 r . \wedge . r \\
r 100.7 r \mid \\
\varepsilon \wedge 19 . \varepsilon r 0\end{array}$ & المجمو النمات & المنزل & \multirow{4}{*}{$\begin{array}{l}y \\
y \\
3 \\
3 \\
y \\
\vdots \\
\overline{3} \\
3 \\
3 \\
3 \\
5 \\
\omega\end{array}$} \\
\hline$\because 0$ & $\varepsilon r .0 V Y$ & $\begin{array}{l}\text { רשr. } \\
\text { 1V.070 }\end{array}$ & $\begin{array}{l}r \\
111 \\
19 .\end{array}$ & 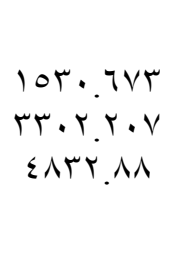 & المجمو عات النبل & الأبناء & \\
\hline$\because .0$ & $01.9 \varepsilon$ & $\begin{array}{c}|r \leqslant r . v \|| \\
r q . r v q\end{array}$ & $\begin{array}{l}r \\
111 \\
19 .\end{array}$ & $\begin{array}{l}r 710 . \leqslant Y 1 \\
\sum 9 \leqslant \cdot . \Sigma V \leqslant \\
V 7 r 0 . \wedge 90\end{array}$ & المجمو المات & الزوجة & \\
\hline$\because .0$ & $07.9 \vee \leqslant$ & 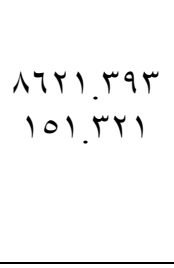 & $\begin{array}{l}r \\
111 \\
19 .\end{array}$ & $\begin{array}{l}\text { IVY } Y Y . V A O \\
r \wedge \leqslant \leqslant \Lambda . r V Y \\
\varepsilon 0791 . .01\end{array}$ & المجمو المبل التبوعات & ككل & \\
\hline$\because .0$ & $79 . .091$ & $\begin{array}{c}r|r| . \cdot 10 \\
r . v 1\end{array}$ & $\begin{array}{l}r \\
111 \\
19 .\end{array}$ & $\begin{array}{l}\leqslant Y \leqslant Y . P Q \\
O V Y . \leqslant \cdot 0 \\
\leqslant \Lambda \mid 9 . \leqslant T 0\end{array}$ & المجمو النات & المنزل & \multirow{2}{*}{$\begin{array}{l}\overline{7} \\
3 \\
3 \\
3 \\
2\end{array}$} \\
\hline$\because .0$ & VOV.T.V & $\begin{array}{l}r) \leqslant 9.019 \\
r . \wedge r q 9\end{array}$ & $\begin{array}{l}r \\
111 \\
19 .\end{array}$ & $\begin{array}{l}\varepsilon r q 9 . \mid V \Lambda \\
\text { Orr.V.r } \\
\varepsilon \wedge r r . \wedge \Lambda\end{array}$ & المجمو النمات & الأبناء & \\
\hline
\end{tabular}




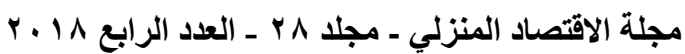

\begin{tabular}{|c|c|c|c|c|c|c|c|}
\hline$\because 0$ & 19V.VTI & $\begin{array}{c}\text { rOAE. rOA } \\
1 T . \cdot V\end{array}$ & $\begin{array}{l}r \\
111 \\
19 .\end{array}$ & $\begin{array}{l}0171 . V 17 \\
\text { YSOV.1V9 } \\
\text { VTYO.190 }\end{array}$ & المجمو النات & الزوجة & \\
\hline$\because .0$ & $\Lambda \nmid \wedge . \leqslant Y \Lambda$ & $\begin{array}{l}r .01 V . \leqslant O V \\
\text { rE.VTV }\end{array}$ & $\begin{array}{l}r \\
111 \\
19 .\end{array}$ & $\begin{array}{l}\leq 1 . r \leq .91 r \\
\leq 707.1 \leq \varepsilon \\
\leq 0791.01\end{array}$ & المجمو النمات & ككل & \\
\hline$\because .0$ & $v \cdot$. sor & 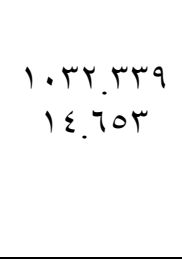 & $\begin{array}{l}r \\
111 \\
19 .\end{array}$ & $\begin{array}{l}\text { Y.TE.TVV } \\
\text { TVOI.VOV } \\
\leqslant N 19 . \text { STO }\end{array}$ & المجمو المبل & المنزل & \\
\hline$\because .0$ & TV. 911 & $\begin{array}{l}1.1 \leqslant .4 \cdot 7 \\
1 \leqslant .9 \mid V\end{array}$ & $\begin{array}{l}r \\
111 \\
19 .\end{array}$ & $\begin{array}{l}r \cdot r \wedge . \Sigma l r \\
r \wedge . \Sigma . \Sigma T \Lambda \\
\Sigma \wedge r r . \wedge \Lambda\end{array}$ & المجمو المات & الأنباء & 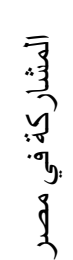 \\
\hline$\because .0$ & NA.TVY & $\begin{array}{c}110 . \text {. AT9 } \\
r \cdot . \wedge V T\end{array}$ & $\begin{array}{l}r \\
111 \\
19 .\end{array}$ & $\begin{array}{l}r V .1 . V T V \\
r 9 Y \leq .101 \\
V 7 Y 0.190\end{array}$ & المجمو النمات & الزوجة & 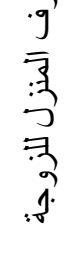 \\
\hline$\because .0$ & 95.470 & $\begin{array}{l}\| r \wedge \varepsilon . A \\
|r| .94\end{array}$ & $\begin{array}{l}r \\
111 \\
19 .\end{array}$ & $\begin{array}{l}\text { rYVTA.171 } \\
\text { rYqYT.A9V } \\
50791 . .01\end{array}$ & المجمو النمات & ككل & \\
\hline
\end{tabular}

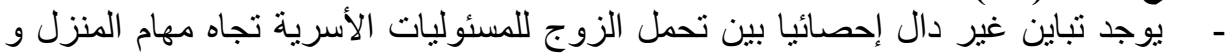

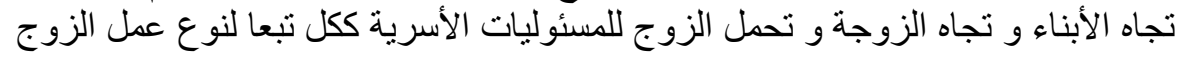




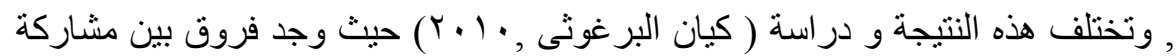

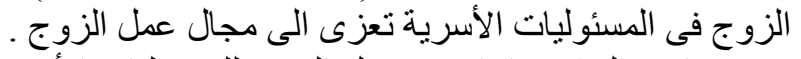

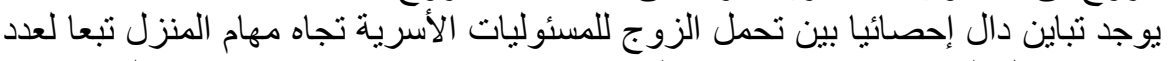

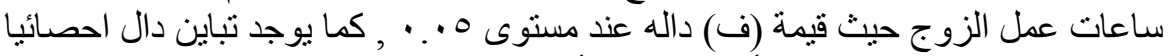

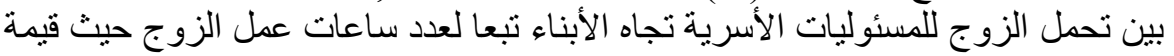

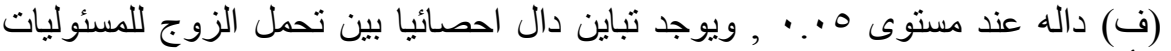

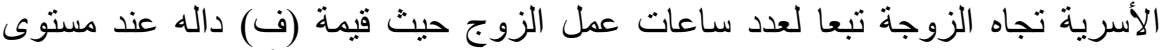
•..

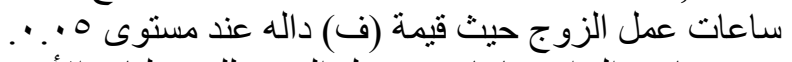

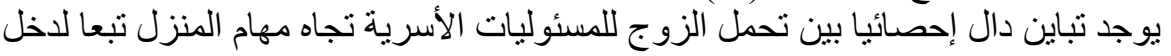

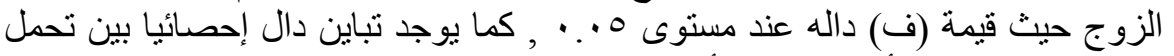

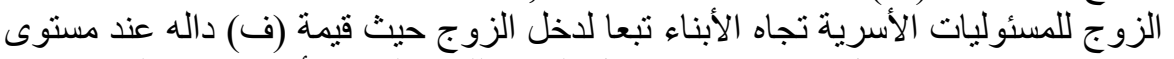

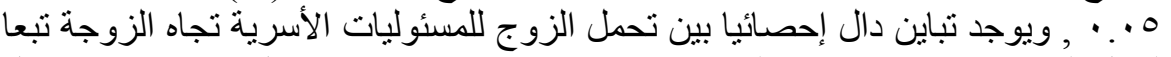

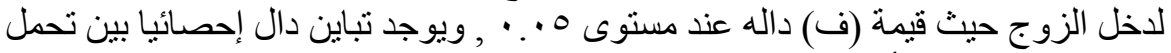

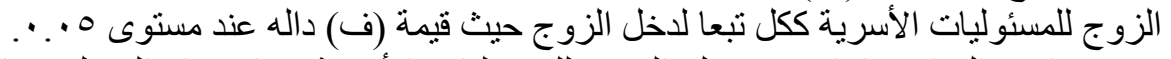

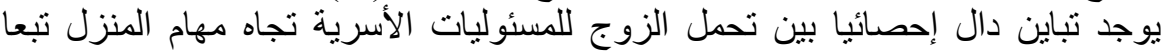

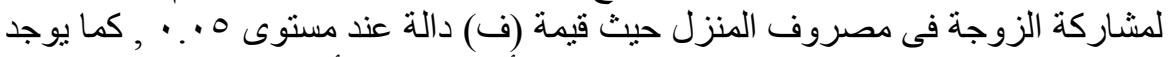

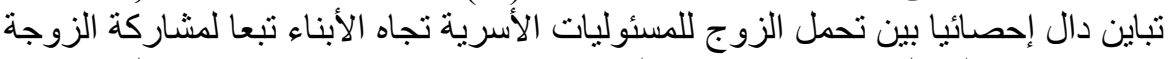

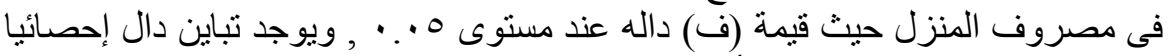

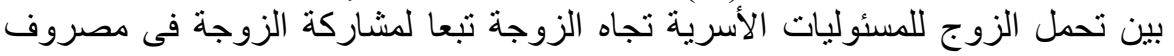

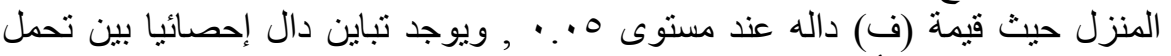

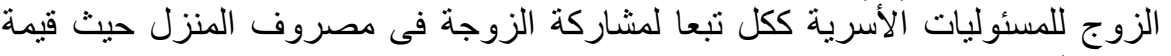

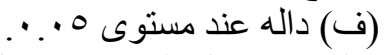

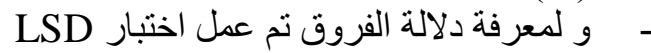

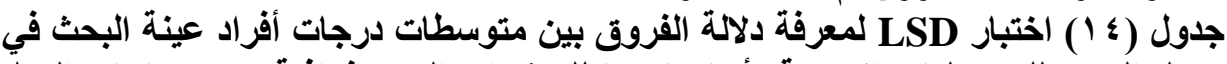

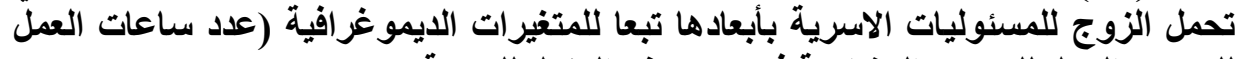

\begin{tabular}{|c|c|c|c|c|c|}
\hline$\Lambda r=\dot{U}$ & $q V=\dot{U}$ & ن & الحسابي & للزوج ساعات العمل & تحملو \\
\hline- & - & - & TA.917V & أقل من م ساعات & \\
\hline- & - & *V.हTाराT & T. $\varepsilon \wedge \varepsilon 0$ & من & \\
\hline- & *T.qVरTE & $* \|$ *I. & TV.OTYT & من · ا فاكترز & \\
\hline- & - & - & TA.917V & أفل من م ساعات & تجاه الابناء \\
\hline- & - & $* V . \varepsilon \lambda \Gamma 4 \lambda$ & TI.हTए & 1.>1 من & \\
\hline- & $* T .7 \varepsilon \cdot \Gamma 1$ & $* 11.11491$ & TV.VATV & من · (فاكتر & \\
\hline- & - & - & $T Y .817 V$ & أقل من ^ ساعات & تجاه \\
\hline- & - & $* V .0 T \ldots V$ & $T \varepsilon .1174$ & 1.>1 من & الزوجة \\
\hline- & *0.ATVAT & $* 15.17 V 19$ & $19 . \cdot \sum \wedge 1$ & من · ا فاكتر & \\
\hline - & - & - & $9 \cdot .10$ & أقل من ^ ساعات & ككل \\
\hline
\end{tabular}




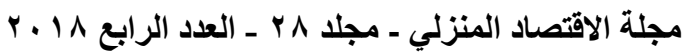

\begin{tabular}{|c|c|c|c|c|c|}
\hline$\wedge Y=\dot{ }$ & $q \vee=\dot{ }$ & ن & الحسابي & للزوج ساعات العمل & تحمل المسئولية \\
\hline- & - & 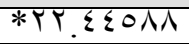 & $7 \vee . \wedge \cdot \sum 1$ & من > & \\
\hline- & $* \| \Gamma . \leqslant 0 . \varepsilon V$ & *Y0.197T\& & OE.TOTV & من • ( فاكتر & \\
\hline$\varepsilon r=\dot{U}$ & ن & ن & الحسابي & الدخل للزوج & المسئولية \\
\hline- & - & - & TV. $.2 Y 0$ & أقل من .... & \multirow{3}{*}{ المنزل } \\
\hline- & - & *. VANOY_ & IV.ATY & هن ...>r... & \\
\hline- & $* 11 . \overline{1} \leqslant \leqslant v \leqslant$ & $11.9 T \times Y V_{-}$ & TA.9V7V & من . . ـ فأكثر & \\
\hline- & - & - & TV.EVAT & أقل من ·... & \multirow[t]{3}{*}{ تجاه الابناء } \\
\hline- & - &. ก & IV.AE & من > ...>r... & \\
\hline- & *11. r990r & $* 11 . \overline{7 T I K V}$ & 19.1190 & من . . ـ فأكثر & \\
\hline - & - & - & 19.17 .9 & أفل من P... & \multirow{3}{*}{ الزوجة } \\
\hline- & - & $.9491 \%-$ & $r \cdot . r$ & من > ...>r... & \\
\hline- & *Ir. YANTV & *IT. irvo. & 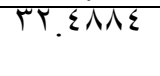 & من . . ع فأكثر & \\
\hline - & - & - & OT.VATY & أقل من ·.... T & \multirow{3}{*}{ ككل } \\
\hline- & - & $1.19949_{-}$ & $00 . \wedge V Y$ & من ? & \\
\hline- & * & *Tr.AYT. & $9 \cdot .7 \cdot \leqslant V$ & من ... فأكثر & \\
\hline ن & $V \theta=\dot{~}$ & $\dot{~ ن}$ & الحسابي & مصروفت المنزّل & المسئولية \\
\hline- & - & & 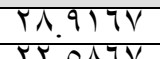 & اقل من 0Y\%\% & \\
\hline- & & *4.rT & TY.0NTV & 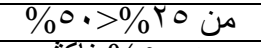 & \\
\hline - & *0. . YरवV & $* 11.1019 \mathrm{~V}$ & TV.00VV & من • •\% فاكتر & \\
\hline- & - & - & $Y \Lambda .917 \mathrm{~V}$ & أقلّل من \%َro\% & \multirow[t]{3}{*}{ تجاه الابناء } \\
\hline- & - & $* 4.10$ & TT.777V & 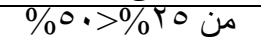 & \\
\hline- & $* \varepsilon .99509$ & $* 11 . r \leqslant r 09$ & IV.TVTI & من • • \% فاكتر & \\
\hline- & - & - & TY.EITV & أقل من \% \% \% & \multirow{3}{*}{ الزوجة } \\
\hline- & 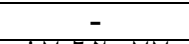 & *0.VV7TV & $17.7 \varepsilon$ & 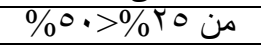 & \\
\hline- & $* V .7 T \cdot V V$ & 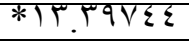 & 19.9197 & من • \% فاكتر & \\
\hline- & - & - & $9 \cdot .10$ & 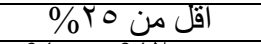 & \multirow{3}{*}{ ككل } \\
\hline- & - & $* 11.1074 \mathrm{~V}$ & VI.19Tा & 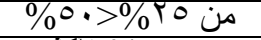 & \\
\hline- & *IV.7ETTा & $* Y 7$ & $0 \leqslant .10$ & من • م\% فاكتر & \\
\hline
\end{tabular}
يوضح جدول (\& 1 ) :

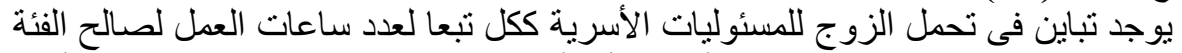

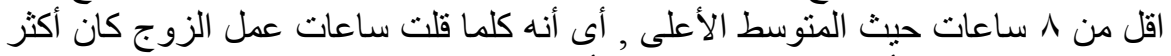

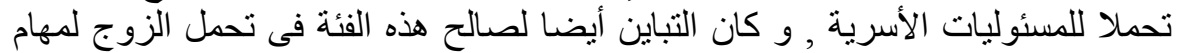

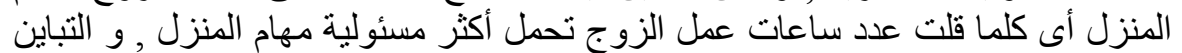

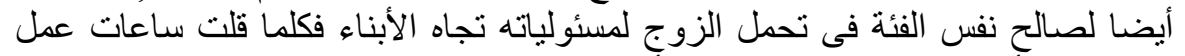

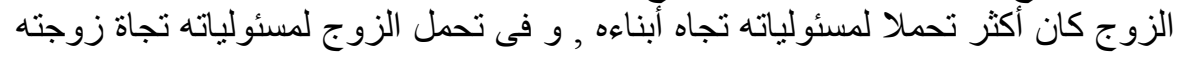




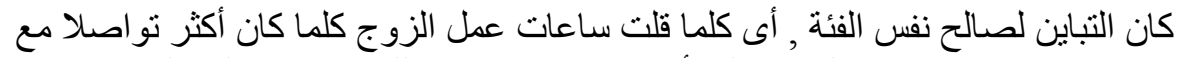

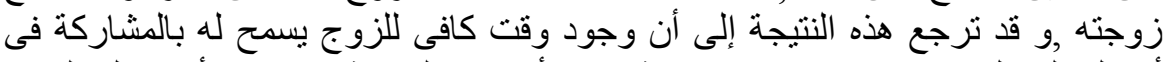

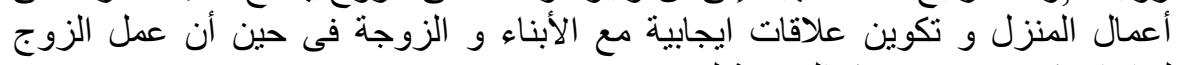

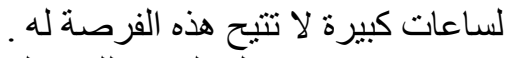

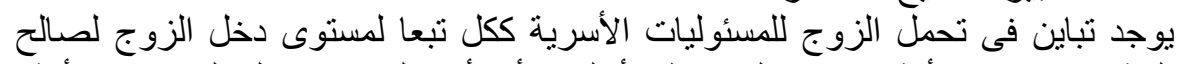

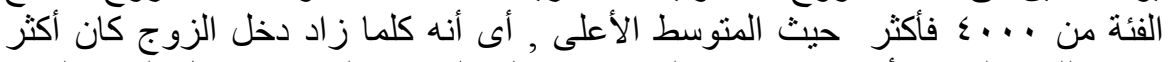

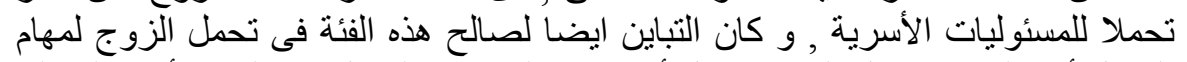

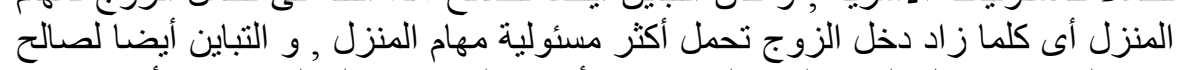

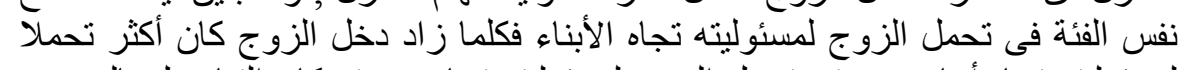

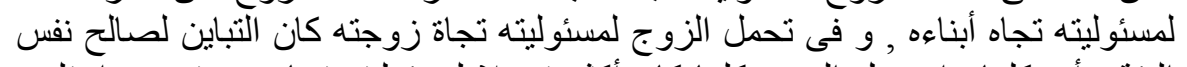

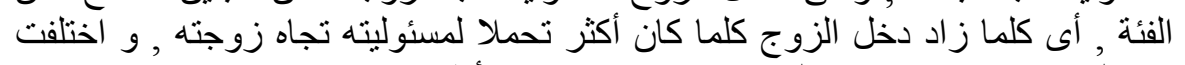

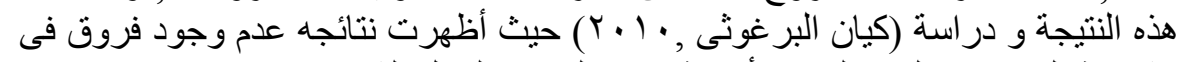

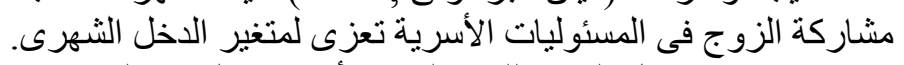

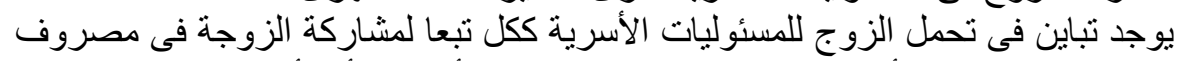

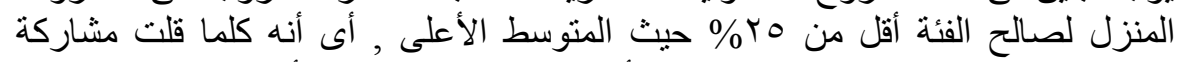

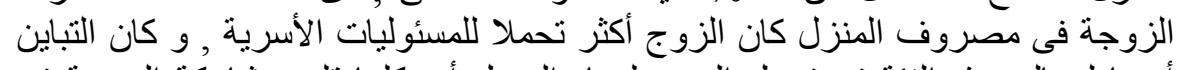

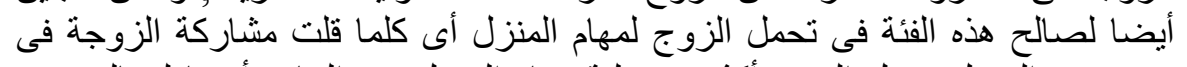

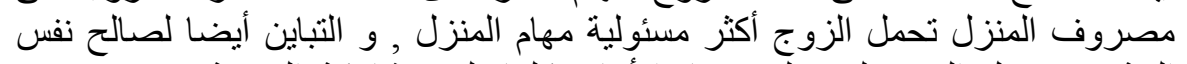

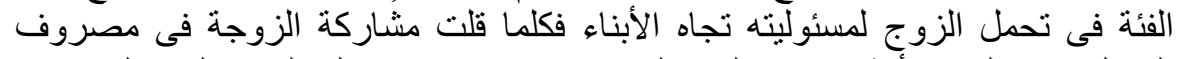

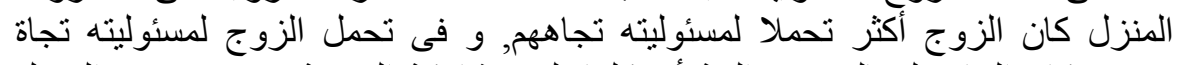

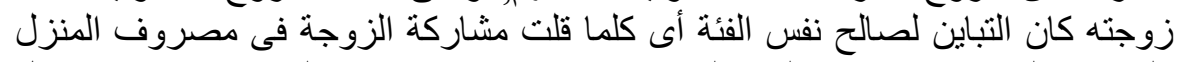

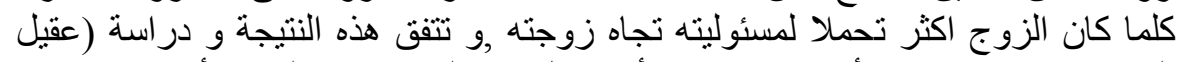

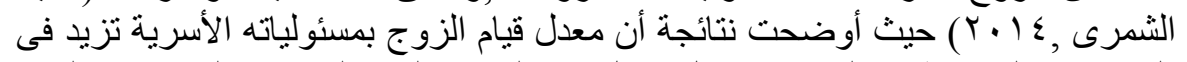

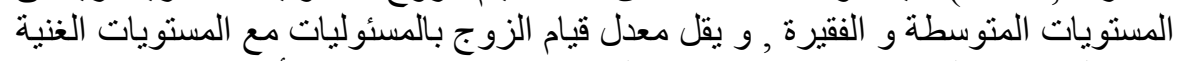

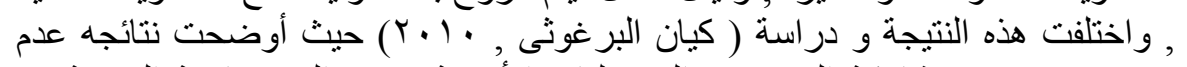

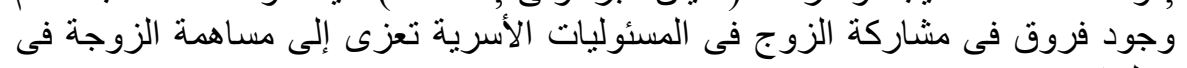
دخل الاسرة . 


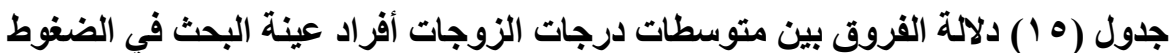

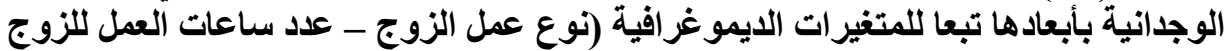

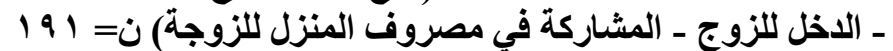

\begin{tabular}{|c|c|c|c|c|c|c|c|}
\hline الدستوي & قُقَمة & المربعات & الحرجية & المربعوات & التباين & الضحغوط & المتغير \\
\hline غالّه & שTYM & $\begin{array}{l}\because 1 \leqslant V \\
.709\end{array}$ & $\begin{array}{l}r \\
191 \\
19 .\end{array}$ & 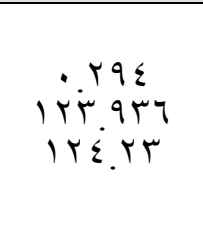 & 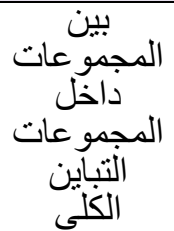 & و المقارنيّات & \multirow{3}{*}{$\begin{array}{l}3 \\
3 \\
y \\
3 \\
\overline{3} \\
\omega\end{array}$} \\
\hline غالَه & r.qr人 & $\begin{array}{l}1.999 \\
.71\end{array}$ & $\begin{array}{l}r \\
111 \\
19 .\end{array}$ & $\begin{array}{l}r .991 \\
1 \% \dot{v} 911 \\
1 \% 1.917\end{array}$ & 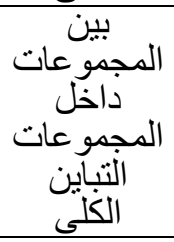 & الانسحابي & \\
\hline غالَهِ & I. ror & $\begin{array}{l}1.091 \\
1.9 V 7\end{array}$ & $\begin{array}{l}r \\
111 \\
19 .\end{array}$ & $\begin{array}{l}r .197 \\
r \mu q .91 \leq \\
r \leq r .11 .\end{array}$ & 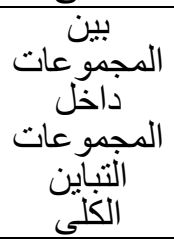 & ككل & \\
\hline$\because 0$ & $\varepsilon \cdot V \mu q$ & 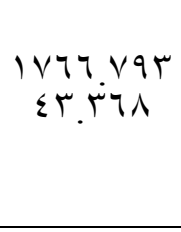 & $\begin{array}{l}\text { r } \\
191 \\
19 .\end{array}$ & 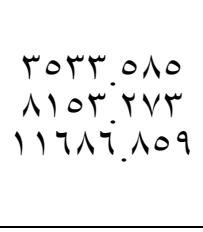 & المجمو النبوعات النبن & و المقارنتاتية & \multirow{3}{*}{$\begin{array}{l}y \\
7 \\
3 \\
3 \\
4 \\
5 \\
\overline{3} \\
3 \\
3 \\
3 \\
0\end{array}$} \\
\hline$\because 0$ & $T V .0 \leqslant 1$ & 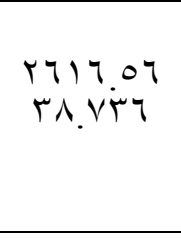 & $\begin{array}{l}r \\
191 \\
19 .\end{array}$ & $\begin{array}{l}\text { OrrT.1199 } \\
\text { VYAY.Y99 } \\
\text { Iro10.011 }\end{array}$ & 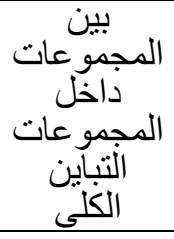 & الإنسحاب & \\
\hline$\because 0$ & $70 . \leqslant 17$ & 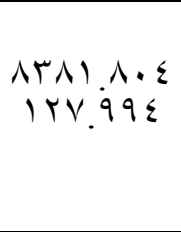 & $\begin{array}{l}\text { r } \\
191 \\
19 .\end{array}$ & 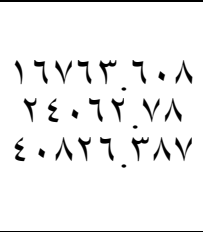 & المجمو النبل التباتين & ككل & \\
\hline$\because 0$ & 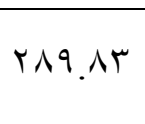 & $\begin{array}{l}\varepsilon E \mid T Y Y O \\
10 . Y T \varepsilon\end{array}$ & $\begin{array}{l}\text { ris } \\
19 .\end{array}$ & 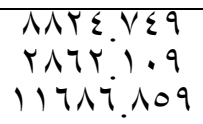 & المجموعات & و المقارنيّات & 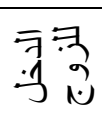 \\
\hline
\end{tabular}




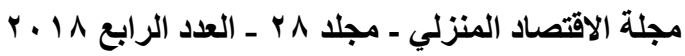

\begin{tabular}{|c|c|c|c|c|c|c|c|}
\hline & & & & & المجمو عاتن الكباتي & & \\
\hline$\because 0$ & 19.001 & r.or.r. & $\begin{array}{l}r \\
111 \\
19 .\end{array}$ & $\begin{array}{l}71.7 .79 \\
7 \leqslant .9 .9 \leq 9 \\
17010.011\end{array}$ & 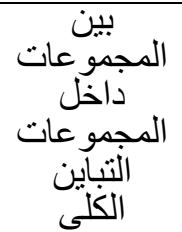 & الانسحاب & \\
\hline$\because 0$ & $r \varepsilon 1.11 r$ & $\begin{array}{l}1 \leqslant T A V \text { KYo } \\
7.910\end{array}$ & $\begin{array}{l}r \\
111 \\
19 .\end{array}$ & $\begin{array}{l}r q \mu v \leqslant . \leqslant 01 \\
11 \leq 01.947 \\
\varepsilon . N r 7 . r \wedge v\end{array}$ & المجموعات النباتين الخبات & ككل & \\
\hline$\because 0$ & $r r .41$ & $\begin{array}{l}r r \leqslant 0, r q r \\
r v . r i \leqslant\end{array}$ & $\begin{array}{l}r \\
111 \\
19 .\end{array}$ & $\begin{array}{l}\varepsilon 79.014 \\
7997.4 V 7 \\
11717.109\end{array}$ & المجمو النمبن التباتين & و المقاريناتي & $\frac{\bar{s}}{3}$ \\
\hline$\because 0$ & 181.711 & 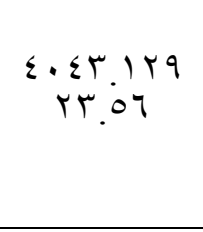 & $\begin{array}{l}r \\
111 \\
19 .\end{array}$ & $\begin{array}{l}\Lambda . \wedge T . r 01 \\
\leqslant \leqslant Y 9 . r 4 \\
1 Y 010.011\end{array}$ & المجمو النبل النباتين & الانسحاب & $\begin{array}{l}y \\
\frac{3}{3} \\
\frac{9}{3}\end{array}$ \\
\hline$\because 0$ & $1 M 9 . \wedge r 4$ & $\begin{array}{c}\text { Kr. } T .9 r \leq \\
\text { NV.r.। }\end{array}$ & $\begin{array}{l}r \\
111 \\
19 .\end{array}$ & 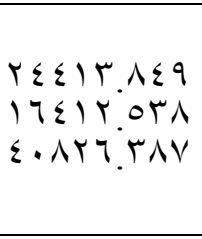 & 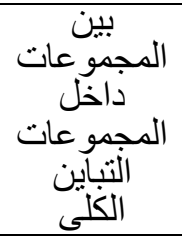 & ككل & 年 \\
\hline
\end{tabular}

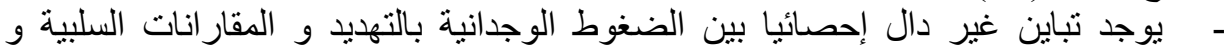

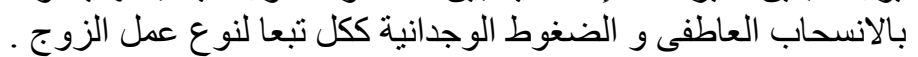

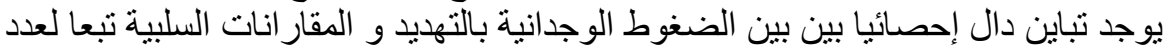

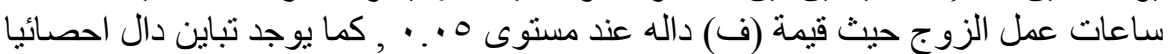

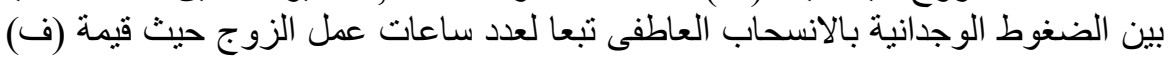

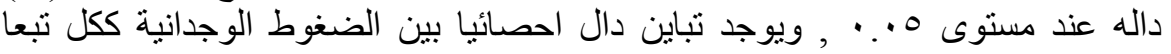

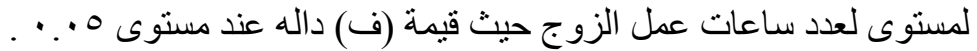

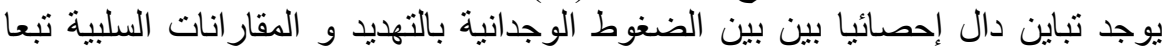

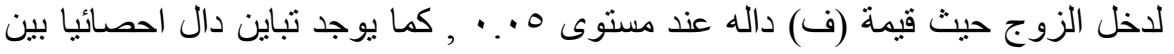




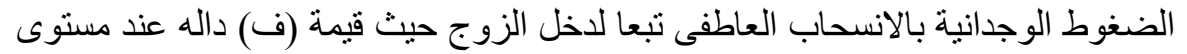

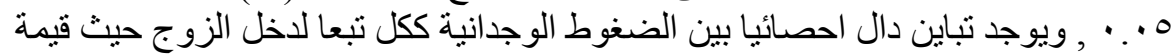

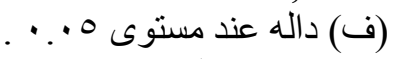

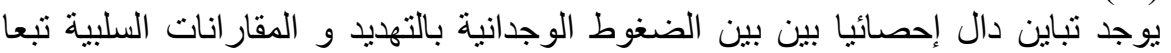

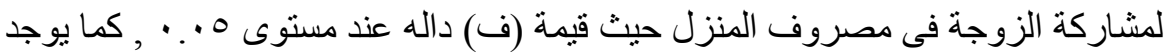

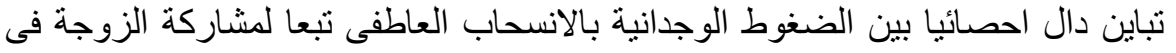

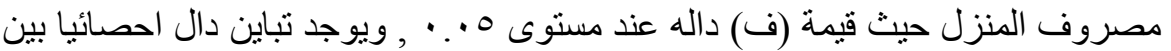

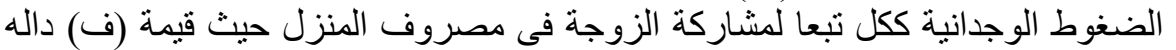

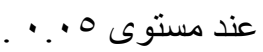

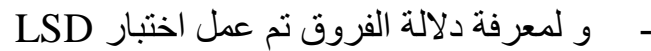

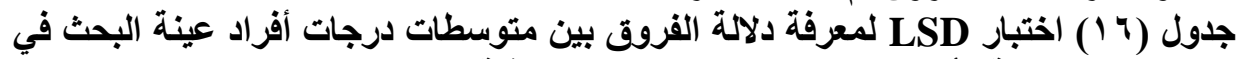

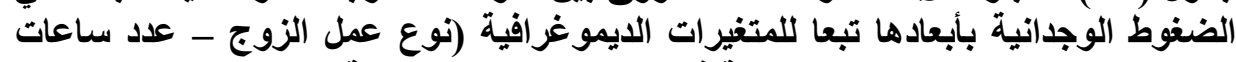

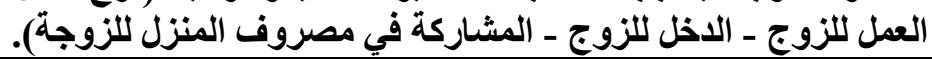

\begin{tabular}{|c|c|c|c|c|c|}
\hline ن & $9 V=\dot{ }$ & ن & الحسابي & عدد ساعات العمل & الضيغوط \\
\hline - & - & - & D.TTRT & أقل من ^ ساعات & \multirow{3}{*}{ والمقارنيات } \\
\hline- & - & * & YA.VYIT & من 1> 1 1 & \\
\hline - & *O.OYYYO_ & *17.91. ov & $r \leqslant . r \leqslant r q$ & من • ا فاكثر & \\
\hline- & - & - & $11.177 \mathrm{~V}$ & اقل من ^ ساعات & \multirow{3}{*}{ الالناطفياب } \\
\hline- & - & 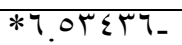 & $r \varepsilon . V \cdot 1$ & 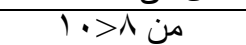 & \\
\hline- & $* q . r \wedge \leqslant r r_{-}$ & $* 10.91 \wedge V_{-}$ & $r \varepsilon .10 \xi$ & من • ( فاكثر & \\
\hline- & - & - & ro.o & أقل من ^ ساعات & \multirow{3}{*}{ ككل } \\
\hline - & - & *IV.व̈Kт人 & OY.ETYV & من 1>> & \\
\hline - & $* 1 \leq \overline{9} .709$ & TY.AlqKV- & T1. TYQT & من · ا فاكثر & \\
\hline$\varepsilon r=\dot{U}$ & ن & ن & الحستوسط & الدخل للزوج & الضحاور \\
\hline- & - & - & rะ.r7. & أقل من ·... & \multirow{3}{*}{ والمقارنات التبيدة } \\
\hline- & - & $\cdot Y T \cdot \wedge V$ & $r \varepsilon$ & 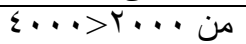 & \\
\hline- & *17. YTYOT & *17. $\varepsilon 94 \leqslant \Gamma$ & TV.VTVE & من ·... فـ فاكثر & \\
\hline- & - & - & rะ. $1 V \Gamma q$ & أقل من ·.... & \multirow{3}{*}{ الانسحاب } \\
\hline - & - & $* r . r \wedge 991$ & $r \cdot . \vee \wedge \varepsilon$ & من > . & \\
\hline- & $* I Y . V 7 . V \varepsilon$ & $* 17.10 .77$ & IA. & من . . . ف فاكثر & \\
\hline- & - & - & $\pi \Lambda . \varepsilon \Gamma \leqslant \lambda$ & أقل من .... T & \multirow{3}{*}{ ككل } \\
\hline- & - & $* Y .70 \cdot V A$ & $7 \varepsilon . V \wedge \varepsilon$ & من >..>r... & \\
\hline- & *Y^.99rT & *TY. T $\leqslant \varepsilon \cdot \wedge$ & ro.va.V & من · . . ـ فاكثر & \\
\hline
\end{tabular}




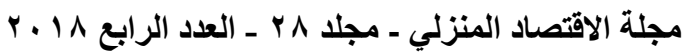

\begin{tabular}{|c|c|c|c|c|c|}
\hline ن & $V 0=\dot{~}$ & ن & الحسابي & مصروف المشناركة في & $\begin{array}{l}\text { الضحاوط } \\
\text { الوجدانية }\end{array}$ \\
\hline - & - & - & DVTRT & أقل من Yro\% & \multirow{3}{*}{ والمقارنيات } \\
\hline- & - & $* 9.0 .77 V_{-}$ & Yๆ.A乏 & 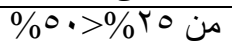 & \\
\hline- & V.09Y79- & *) & TE.ETTV & من •0\% فأكثر & \\
\hline- & - & - & $11.177 \mathrm{~V}$ & أقل من \%ب\% & \multirow{3}{*}{ الانسحاب } \\
\hline- & - & *Y.09TrY_ & YI.V7 & 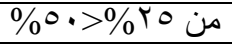 & \\
\hline- & *Ir. $\sum 7110$ & $* 17.0 \leq \leqslant 9$ & TE.YTाY & من •0\% فأكثر & \\
\hline- & - & - & ro. 0 & اقل من 0Y\%\% & \multirow{3}{*}{ ككل } \\
\hline- & - & *iorso & $\leqslant \wedge .7$ & من 0Y\%\%> • \% & \\
\hline- & *r. . . orso & 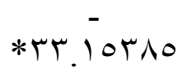 & 71.7041 & من •0\% فأكثر & \\
\hline
\end{tabular}

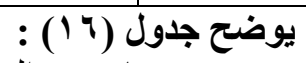

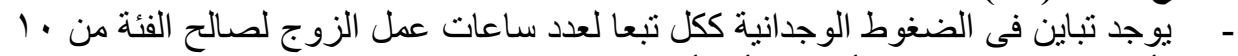

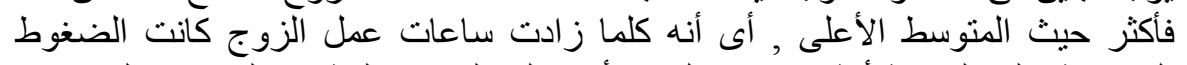

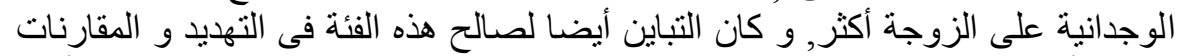

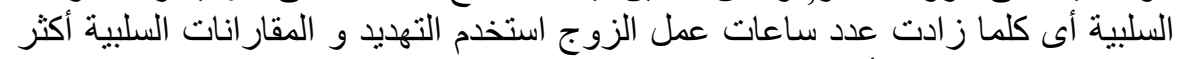

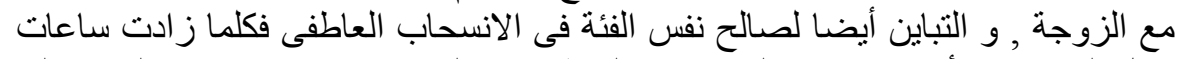

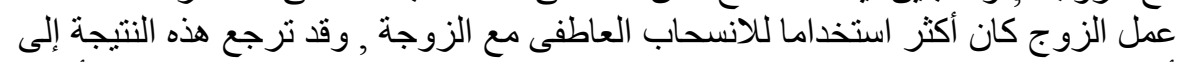

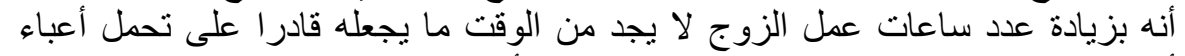

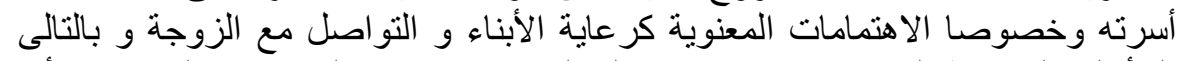

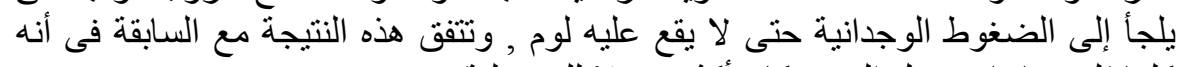

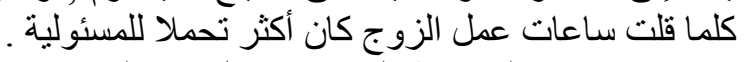

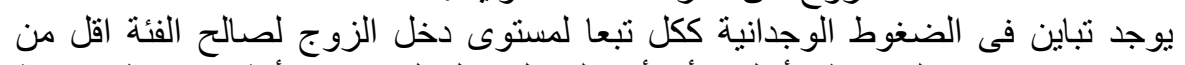

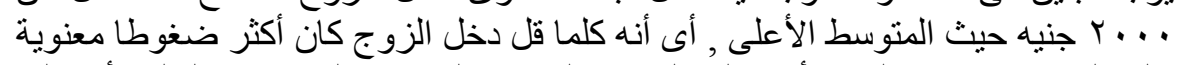

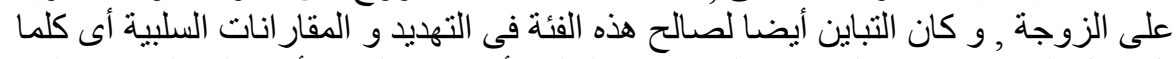

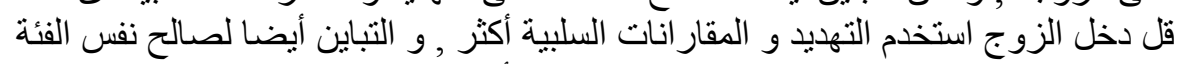

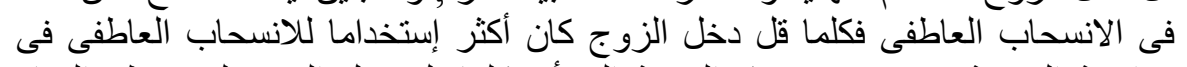

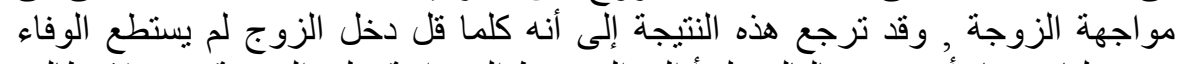

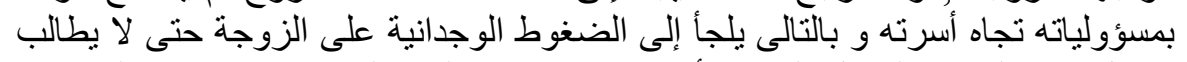

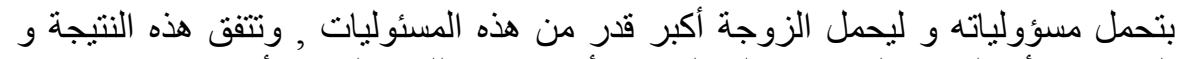

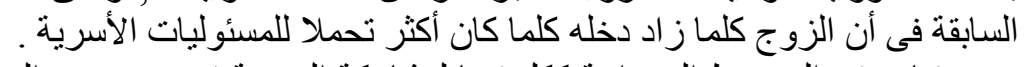

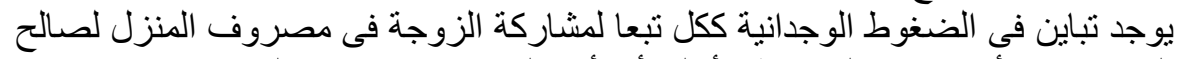

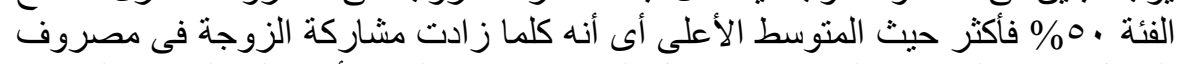

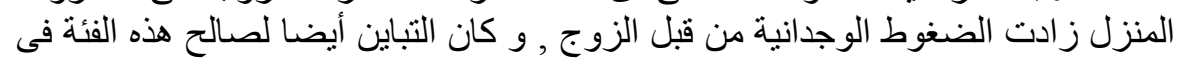




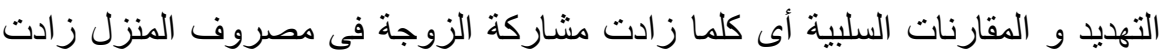

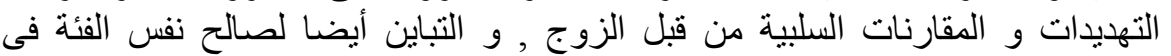

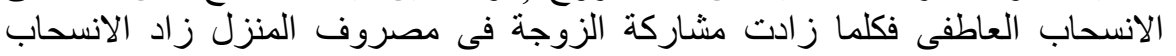

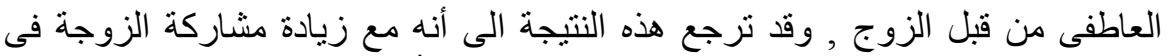

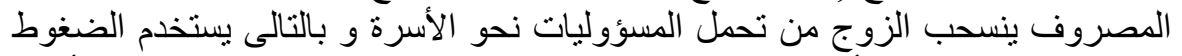

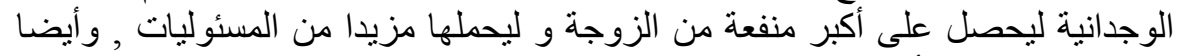

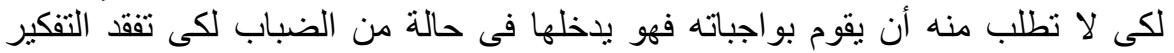

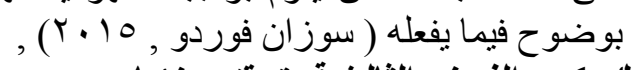
وبذلك يكون الفرض الثالث قد تحقق جزئيا

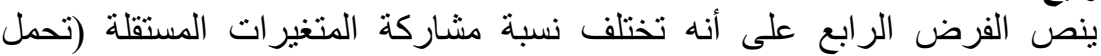

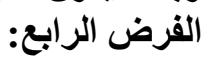

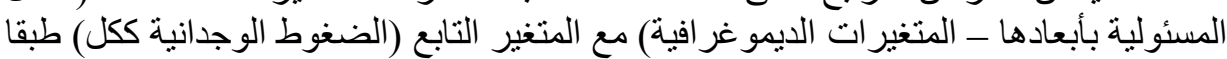

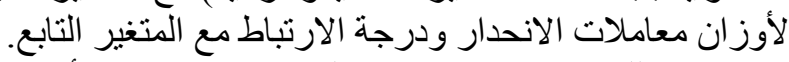
وللتحقق من صحة هذا الفرض ورد الارتباط تم حساب الأهمية النسبية باستخدام معامل الانحدار

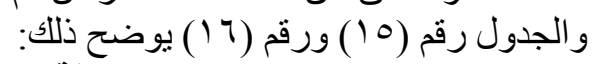

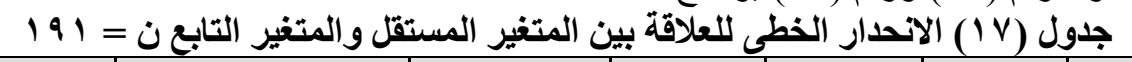

\begin{tabular}{|c|c|c|c|c|c|c|c|}
\hline \multirow{3}{*}{ 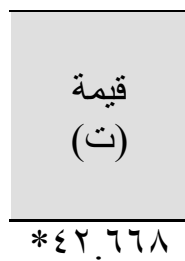 } & \multirow{2}{*}{\multicolumn{2}{|c|}{ معامل الانحدار }} & \multirow[b]{2}{*}{ F } & \multirow{2}{*}{ 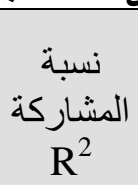 } & \multirow{2}{*}{$\begin{array}{c}\text { الارتباط } \\
\text { R } \\
\text { R }\end{array}$} & \multirow{2}{*}{ المستغير } & \multirow{2}{*}{ التنابع } \\
\hline & & & & & & & \\
\hline & 1.8 .170 & الثابت & \multirow[b]{2}{*}{ ס ק } & \multirow[b]{2}{*}{.$T V V$} & \multirow[b]{2}{*}{$*$. *Ar } & \multirow{2}{*}{ المنزل } & \multirow{6}{*}{$\begin{array}{l}\overline{7} \\
3 \\
-1 \\
\overline{7} \\
\frac{1}{7} \\
: 3\end{array}$} \\
\hline 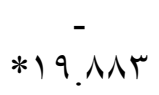 & T. एव _ & B & & & & & \\
\hline$* \leqslant 4.119$ & $1 . V .00 Y$ & الثابت & \multirow[b]{2}{*}{$* \varepsilon \cdot v .117$} & \multirow[b]{2}{*}{ •.TAT } & \multirow[b]{2}{*}{$* . \wedge r \tau$} & \multirow{2}{*}{ الابناء } & \\
\hline *r. ${ }^{-}$ & $T_{.} \varepsilon \cdot r_{-}$ & B & & & & & \\
\hline *or.or & $1 \cdot \varepsilon . V V V$ & الثابت & \multirow[b]{2}{*}{$* 097.7 .9$} & \multirow[b]{2}{*}{$\because \vee 09$} & \multirow[b]{2}{*}{$* . \Delta \vee 1$} & \multirow{2}{*}{ الزوجة } & \\
\hline *r & $r_{.} \cdot 1 r_{-}$ & B & & & & & \\
\hline
\end{tabular}

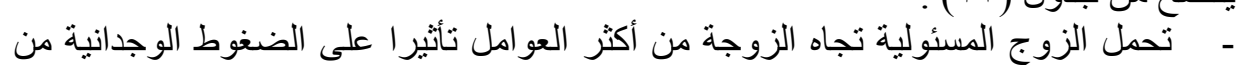

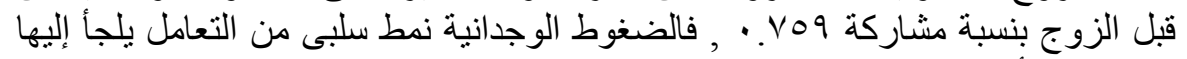

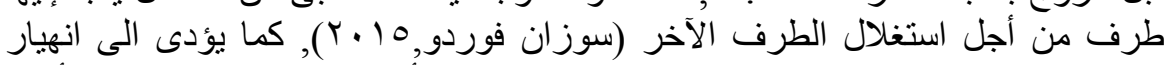

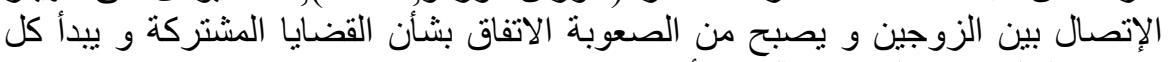

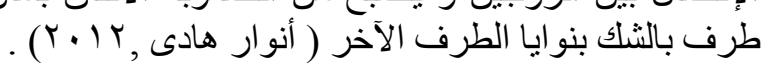




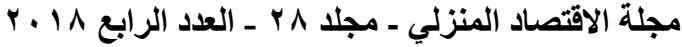

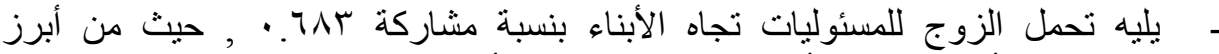

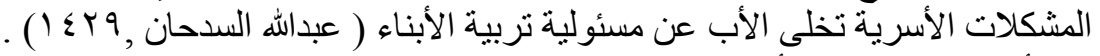

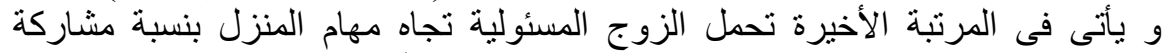

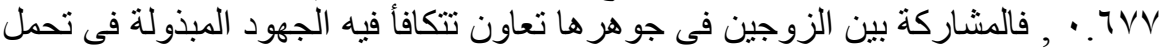

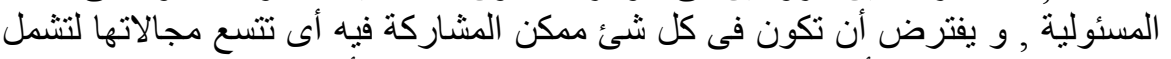

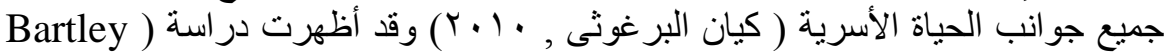

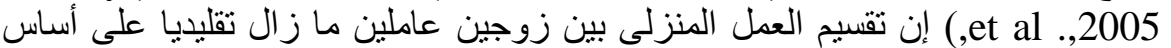

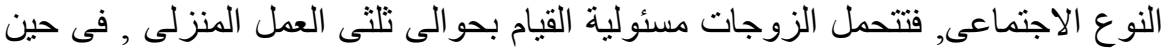

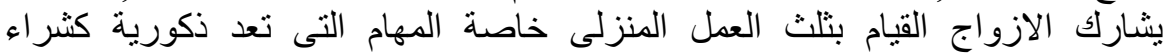

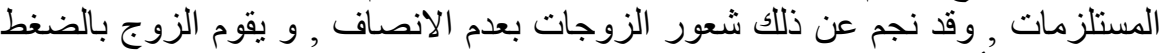

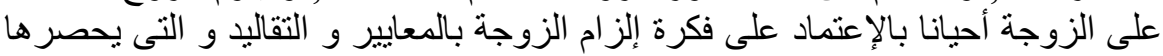

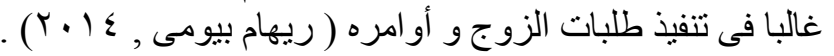
***************************************

\section{جدول (1 1 ا) الاتحدار الخطى للعلاقة بين المتغير التابع والمتغيرات الايموغرافية ن = 19}

\begin{tabular}{|c|c|c|c|c|c|c|c|}
\hline قتيمة & \multicolumn{2}{|c|}{ معامل الانحدار } & $\mathrm{F}$ & المشاركة & الارتباط & المتغيرات & التنتير \\
\hline *YY.YYT & $\Lambda \varepsilon . \wedge r$ & الثنابت & \multirow[b]{2}{*}{$* 1.0 .9 \leq 1$} & \multirow[b]{2}{*}{$\cdot r 09$} & \multirow[b]{2}{*}{$* . .099$} & \multirow[b]{2}{*}{ الزوج عم } & \multirow{13}{*}{ 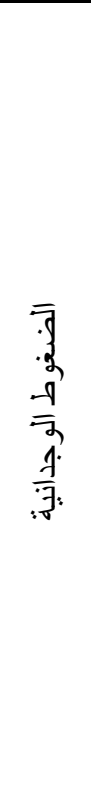 } \\
\hline *1. . rq & $10.10 \%$ & B & & & & & \\
\hline *IVV. 9 Y 9 & 71.171 & الثنابت & \multirow{2}{*}{$\cdot 7 \cdot V$} & \multirow{2}{*}{$\because \cdot r$} & \multirow[b]{2}{*}{$\because .0 \mathrm{~V}$} & \multirow{2}{*}{ تملعنيم } & \\
\hline$\because \vee \vee q_{-}$ & $\cdot 1 \cdot 7_{-}$ & B & & & & & \\
\hline$* \leqslant 0.709$ & $\Lambda 7 . \varepsilon \cdot \varepsilon$ & الثنابت & \multirow{2}{*}{$* r \leqslant \wedge . r \neg q$} & \multirow{2}{*}{.071} & \multirow{2}{*}{$* ., V 0 \leqslant$} & \multirow{2}{*}{ سنو الزواج } & \\
\hline *10, VOV_ & $10 . \overline{V V}$ & B & & & & & \\
\hline *0.VVI & $r r . \cdot \Sigma V$ & الثنابت & \multirow{2}{*}{ 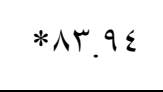 } & \multirow{2}{*}{$\cdot r \cdot \Lambda$} & \multirow{2}{*}{$* .000$} & \multirow{2}{*}{ الالبناء } & \\
\hline$* 9.17 r$ & $1 \Lambda . \Gamma \cdot \varepsilon$ & B & & & & & \\
\hline *YYq.V৭7 & 71.90 & الثابت & \multirow{2}{*}{1.91} & \multirow{2}{*}{$\because \cdots 7$} & \multirow{2}{*}{$\because \vee V 7$} & \multirow{2}{*}{ الزوج } & \\
\hline $1 . \cdot \leqslant \Lambda_{-}$ & $\because \wedge 9_{-}$ & B & & & & & \\
\hline$* 0.0 . V$ & $\bar{Y} 1 . V \cdot \Lambda$ & الثابت & \multirow[b]{2}{*}{$* \mid r . \vee \wedge 0$} & \multirow[b]{2}{*}{$\cdot \varepsilon \cdot q$} & \multirow[b]{2}{*}{$* . .7 \varepsilon$} & \multirow{2}{*}{ ساعات } & \\
\hline *11. & $10.7 \pi$ & B & & & & & \\
\hline$* \mu V .+10$ & $91.01 Y$ & الثابت & $* Y \varepsilon \cdot . V I$ & .07 & $* . V \leqslant \wedge$ & الدخل & \\
\hline
\end{tabular}




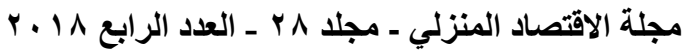

\begin{tabular}{|c|c|c|c|c|c|c|c|}
\hline قتيمة & \multicolumn{2}{|c|}{ معامل الانحدار } & \multirow[t]{2}{*}{$\mathrm{F}$} & \multirow[t]{2}{*}{ 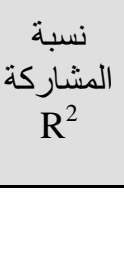 } & \multirow[t]{2}{*}{$\begin{array}{c}\text { الارتباط } \\
\text { R }\end{array}$} & \multirow{2}{*}{ للزئنيرات } & التابع \\
\hline$* 10.010$. & $|\Lambda . q| V$ & B & & & & & \\
\hline$* \varepsilon .7 \leqslant 9$ & $1 Y . Y .9$ & الثنابت & & & & مشار كة & \\
\hline$* 17 . \leqslant \wedge \Lambda$ & $11 . r Y q$ & B & $* Y V I, \wedge 0 \wedge$ & .09 & $* ., \vee \neg \Lambda$ & الزونى & \\
\hline
\end{tabular}

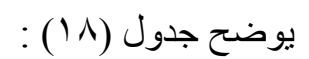

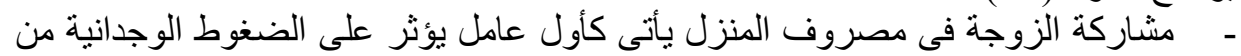

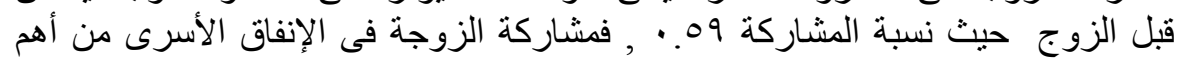

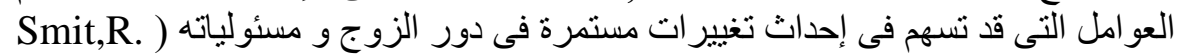

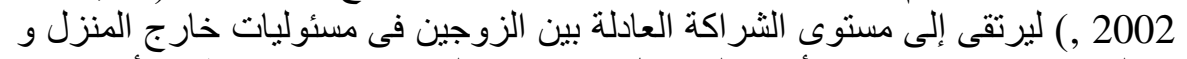

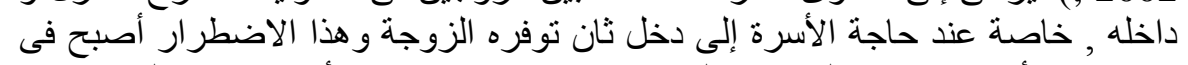

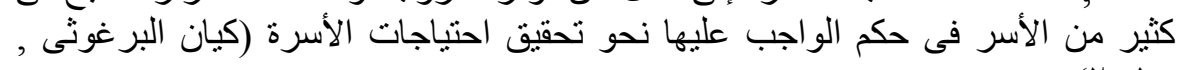
( $($. ) .

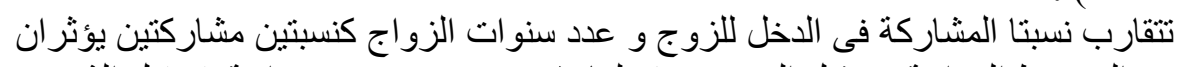

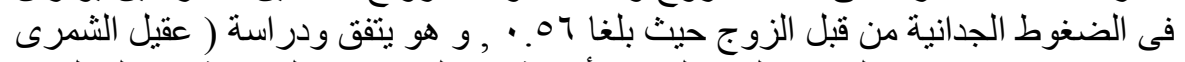

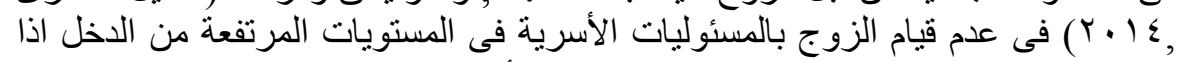

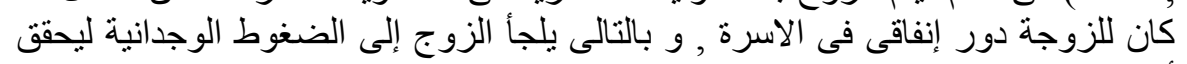

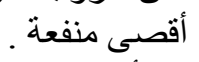

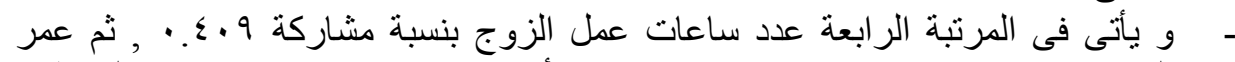

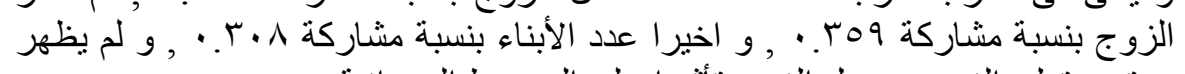

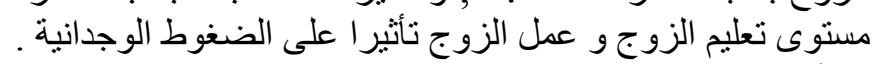

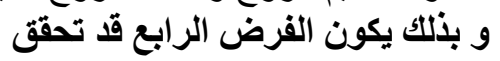
التوصيات : التون الجهات الاعلامية : تصميم و انتاج بر امج أذاعية و تلفزيو نية تستهدف ربات الأسر للتوعية بالضغوط

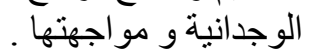

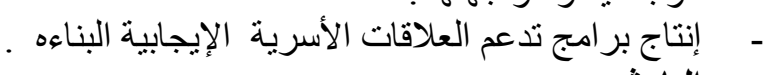

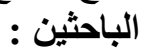
تصميم بر امج إرشادية تستهدف ربات الأسر للتو عية بالمسئوليات الأسرية و تحديد الأدوار

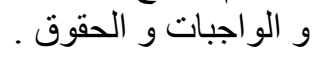


- تصميم بر امج ارشاديه تستهدف ربات الأسر لتحسين قدرتهم على مو اجهة الضغوط

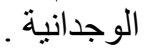
مقترحات بحثية : مقانة

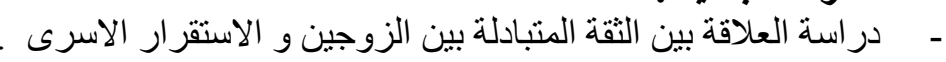

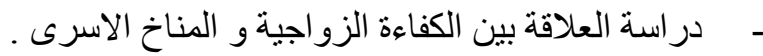

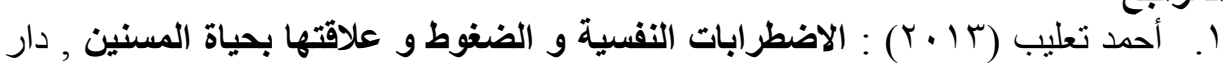

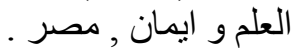

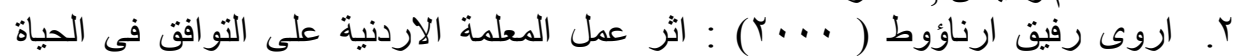

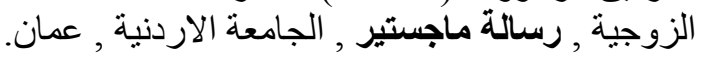

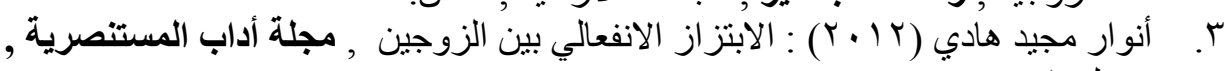
لعراق ألمات

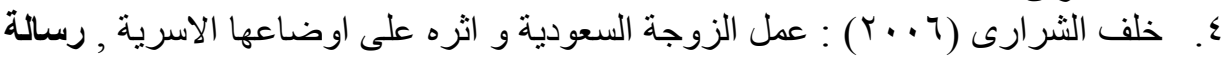

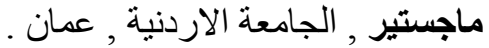

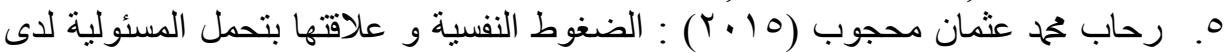

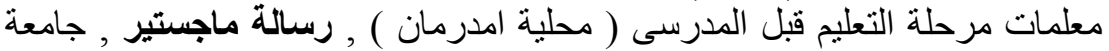

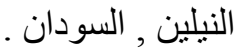

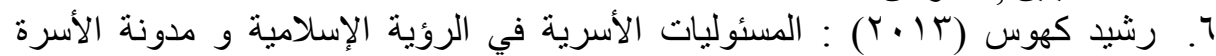

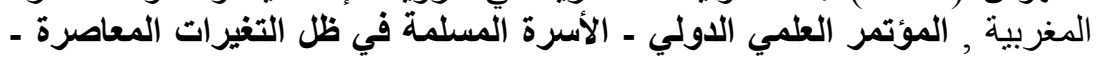

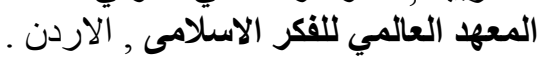

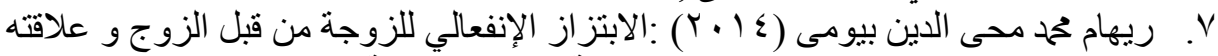

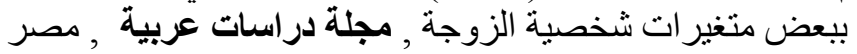

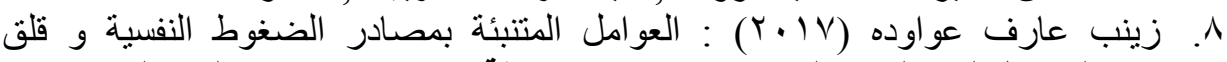
المستقبل لدى النساء المعيلات لاسرهن , رسالة ماجستير , جامعة اليرموك , الاردن

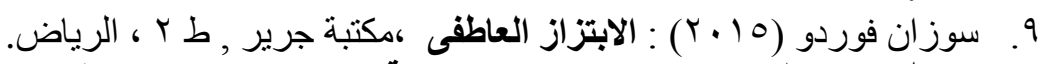

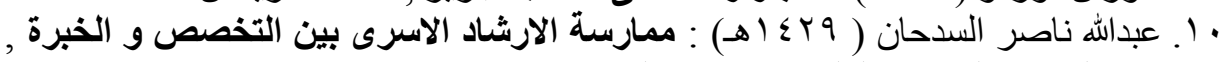

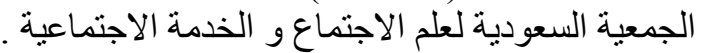

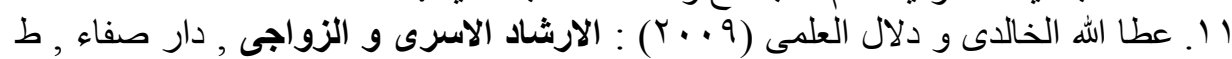
عمان 1

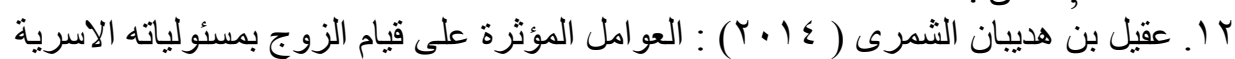

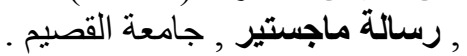

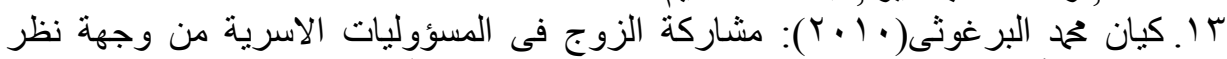

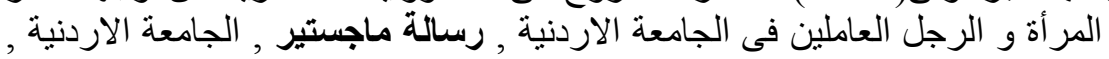




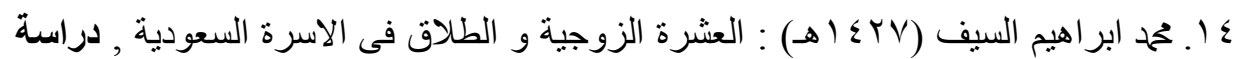

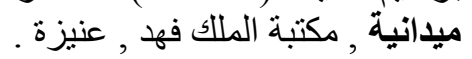

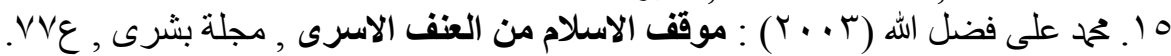

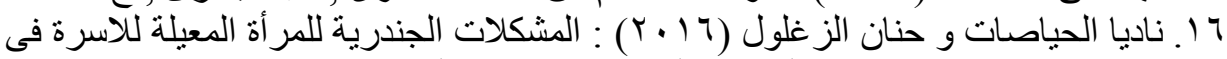

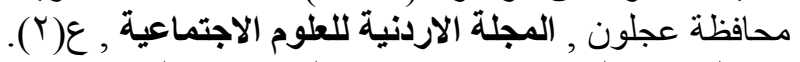

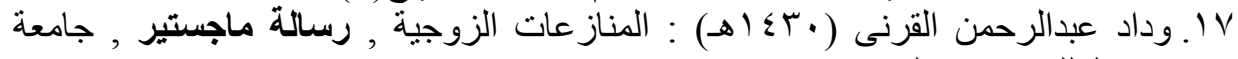

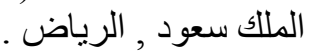

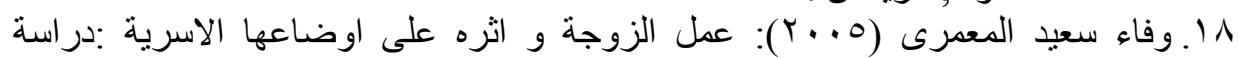

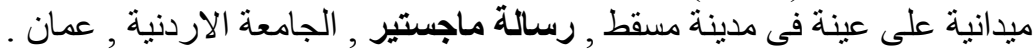

18- Bartley ,Sharon ,Blanton ,Priscilla and Gilliard ,Jennifer (2005) : Husbands and Wives in Dual-Earner Marriages :Decision Making, Gender Role Attitudes, Division of Household Labor ,and Equity, Marriage and Family Review , 37(4)

19- Coltrane, Scott (2000) :Research on Household Labor :Modeling and Measuring the Social Embeddedness of Routine Family Work ,Journal of Marriage and the Family, 62.

20- Noller , P,\&Fenney ,J.(2002) : Understanding marriage developments in the study of couple interaction. New York : Cambridg University .

21-Smit, Ria (2002) : The Changing Role of the Husband/Father in the Dual-Earner Family in South Africa , Journal of Comparative Family Studies, 33(3).

22- Tu,Su-hao and Liao,Pei-shan (2006) : Gender Difference in GenderRole Attitudes :A Comparative Analysis of Taiwan and Coastal China, Journal of Comparative Family Studies, 37(4). 


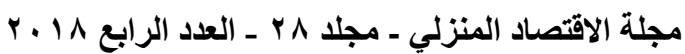

\section{الملاحق}

ملحق (1) استمارة البيانات العامة

البيانات العامة

\begin{tabular}{|l|l|l|r|}
\hline & $0 .>$ ro & ro>r. & العمر \\
\hline & & & \\
\hline
\end{tabular}

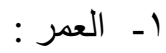

سنوات

\begin{tabular}{|l|l|l|}
\hline r \\
\hline
\end{tabular}

r- ـ عدد الابناء

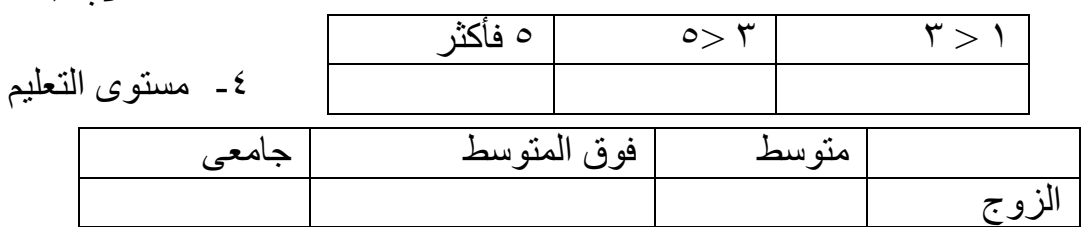

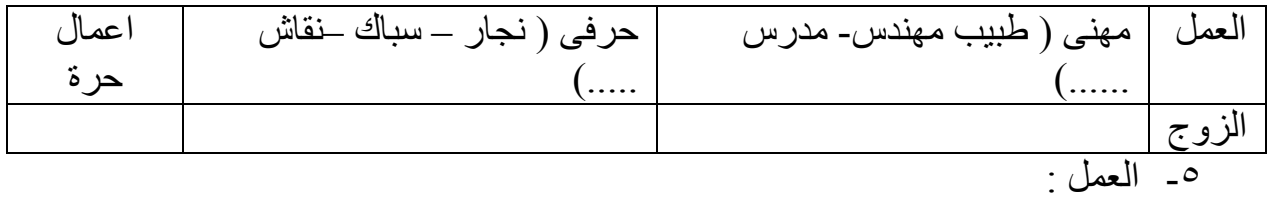

7- عد ساعات العمل

\begin{tabular}{|c|c|c|c|}
\hline • ا أكثر & $1 \cdot>1$ & $\Lambda$ & عدد ساعات العمل \\
\hline & & & لزوج \\
\hline
\end{tabular}

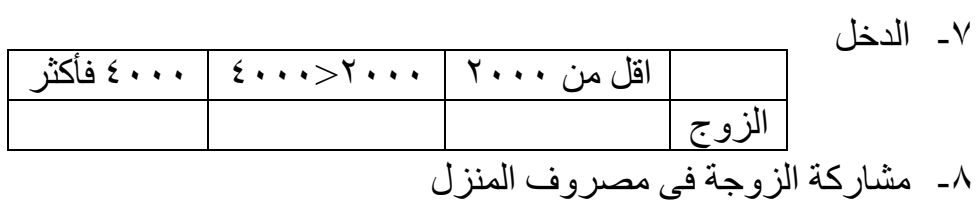

\begin{tabular}{|c|c|c|}
\hline & $\% 0^{0}>r_{0}$ & $\%$ ro \\
\hline
\end{tabular}




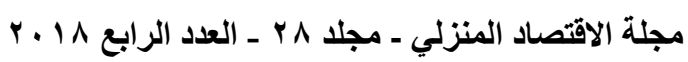

ملحق (r) استبيان تحمل الزوج للمسئوليات الأسرية

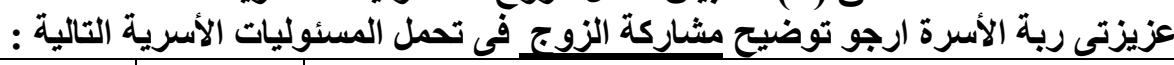

\begin{tabular}{|c|c|c|c|c|}
\hline 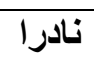 & احيانا & دائما & العبارات & p \\
\hline & & & يساعد فى اعداد وجبات الطعام & 1 \\
\hline & & & يساهم فى تحضير مائدة الطعام & r \\
\hline & & & ينظف المائدة بعد تناول الطعام & $r$ \\
\hline & & & يغسل الصحون و الاوانى ي & $\varepsilon$ \\
\hline & & & يكوى الملابس & 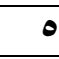 \\
\hline & & & ينظف ارضية المنزل & 7 \\
\hline & & & يرتب غرف المنزل & $\mathrm{V}$ \\
\hline & & & يشترى المواد التموينية ومستلزمات المنزل & $\Lambda$ \\
\hline & & & يدفع الفواتير الشهرية & 9 \\
\hline & & & يتابع صيانة المنزل & 1. \\
\hline & & & يوقظ الابناء فى الصباح & 11 \\
\hline & & & يشارك الأبناء الهتماماتهم & Ir \\
\hline & & & يعتنى بالأبناء اثناء المرض و يعطيهم الدواء & in \\
\hline & & & يشارتك الأبناء بالر أى عند شراء ملابسهم & $1 \varepsilon$ \\
\hline & & & يساعد الأبناء فى استذكار دروسهم & 10 \\
\hline & & & يجلس مع الأبناء و يستمع لهم & 17 \\
\hline & & & يتابع الأبناء فى امور دينهم & IV \\
\hline & & & يتابع تقدم الابناء فى الدراسة & 11 \\
\hline & & & يشارلك الابناء فى وقّت اللعب & 19 \\
\hline & & & يصطحب أبناء فى مواعيد الطبيب & $r$. \\
\hline & & & يصطحبنى فى الزيارات العائلية & YI \\
\hline & & & يصطحبنى فى مواعيد الاطباء & YY \\
\hline & & & يشجعنى فَى مواقف الاحباط & $r \mu$ \\
\hline & & & يحافظ على علاقة طيبة معى & $Y \varepsilon$ \\
\hline & & & يبادر بالاعتذار عندما يخطئ فى حقى & Yo \\
\hline & & & يحترم وجهة نظرى حتى و ان اختلفت وجهات النظر & Y \\
\hline & & & يساندنى فى الاوقات الصعبة & YV \\
\hline & & & يظهر مشاعر الحب و التقدير & $r \wedge$ \\
\hline & & & يتفهم مشاعرى و احتياجاتى العاطفية & rq \\
\hline & & & يحرص زوجى على اجراء حوار معى لنناقش مشاكلنا & $r$. \\
\hline & & & يثق زوجى في قدراتى و يحترمنى & $M$ \\
\hline
\end{tabular}




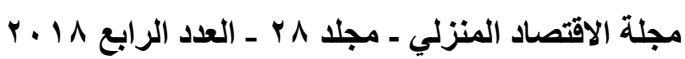

ملحق (r) استبيان الضغوط الوجدانية

عزيزتي ربة الأسرة ارجو توضيح اجابتك اذا كنت تتعرضين لهذه الموطن التف التالية :

\begin{tabular}{|c|c|c|c|c|}
\hline نادرا & احيانا & دائما & العبارات & م \\
\hline & & & يتوعلى زوجى بحياة صعبة اذا لم استجب الى اوامره & 1 \\
\hline & & & يلمى الى الطلاق باسلوب فيه مزاح & $r$ \\
\hline & & & يـهادنى بانه سيصاب بالامر اض اذا لم انفذ طلباته & $r$ \\
\hline & & & يريد المزيد دائما بغض النظر عما اقدمه لاسرتى & $\varepsilon$ \\
\hline & & & يتوقع استسلامى لاوامره & 0 \\
\hline & & & يستخف بمشاعرى & 7 \\
\hline & & & يتجاهل رغباتى & $\mathrm{V}$ \\
\hline & & & يعدنى برحلة ممتعة اذا استجبت لاوامره و لا يفى بوعده & $\Lambda$ \\
\hline & & & يصفنى بالانانية اذا لم انفذ رغباته & 9 \\
\hline & & & يلمح الى اننى عديمة المشاعر عندما اتجاهل اوامره & 1. \\
\hline & & & اسمع عبارات الاستحسان من زوجى عندما انفذ طلباته & 11 \\
\hline & & & يقام زوجى الهايا عندما استجيب لرغباته & Ir \\
\hline & & & يريدر زوجى ما يجب ان افعله فى الوقت الذى يريده و بالطريقة التى & 14 \\
\hline & & & اخشى من وقوع الطلاق & $1 \varepsilon$ \\
\hline & & & اشعر بعدم الامان فى علاقتى بزوجى & 10 \\
\hline & & & يستخدم زوجى اخطائى كسلاح ضدى & 17 \\
\hline & & & ضغوط زوجى اصبحت امرا يوميا اعتياديا & IV \\
\hline & & & اشعر بالفتور فى علاقتى بزوجى & 11 \\
\hline & & & يتهمنى باننى سبب فى مشاكل عمله & 19 \\
\hline & & & يمارس اسلوب الاهمال عندما نختلف على طلباته & 20 \\
\hline & & & يخيرنى بينه و بين اهلى فى بعض المواقف & 21 \\
\hline & & & لا يفصح عن ما يضايقه و يطلب منى ان اكتثفه & 22 \\
\hline & & & يقارن بينى و بين اخريات فى بعض الامور بطريقة تؤذى مشاعرى & 23 \\
\hline & & & عندما اختلف مع زوجى يتهمنى بالمرض النفسى & 24 \\
\hline & & & يتحدث امام ( الاقارب ـ الاصدقاء ـ الاسرة ) بسلبياتى كنوع من الضفط & 25 \\
\hline & & & لا استطيع تحمل مخاصمة زوجى & 26 \\
\hline & & & اتخلى عن الاتشطة التى اهتم بها لارضاء زوجى & TV \\
\hline
\end{tabular}




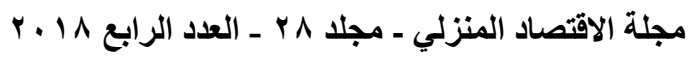

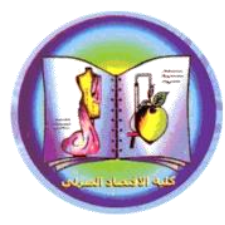

The $6^{\text {th }}$ international- $20^{\text {th }}$ Arabic conference for Home Economics

Home Economics and Educational quality

assurance December 23rd -24th, 2018

Journal of Home

Economics

http://homeEcon.menofia.edu.eg

ISSN 1110-2578

The husband carries the family responsibilities from the point of view of the wife and his relationship to emotional pressure by the husband

\author{
Alaa Saad Abd Elhamid Abouraya ${ }^{1}$, Shimaa Abd Elsalam Abd \\ Elwahed Abd EIrhiam ${ }^{2}$ \\ Lecture of home managementHome Economic departmentThe faculty of specific \\ educationEl Mansoura university ${ }^{1}$, Lecturer of Home Management and \\ InstitutionsHome Economic departmentFaculty of Specific Education Aswan \\ University $^{2}$
}

The main aim of the research is to reveal the nature of the relationship between the husband's responsibility for the family responsibilities from the point of view of the wife and the emotional pressure of the husband in a sample of female heads of household. (Husband's age, number of years of marriage, number of children, level of husband's education, type of work of husband, number of working hours of husband, husband's income, participation of husband and wife). Viscosity in household expenses), The number of years of marriage, the number of children, the level of husband's education, the type of work of the husband, the number of hours worked by the husband, the husband's income, the wife's participation in household expenses), And the number of basic research sample (191) housewives (working) have been selected in a concave manner of different social and economic levels belonging to integrated families (father and mother) and some of the forms were excluded because the responses to the questionnaire or not Meet family requirements. The research tools included the general data form, the scale of carrying family responsibilities, and the measure of emotional pressure 


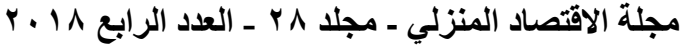

The most important results are: There is an inverse correlation between the husband's responsibility for the family responsibilities as a whole and the emotional pressure as a whole. There is a difference in the husband's tolerance of family responsibilities as a whole depending on the age groups of the husband in favor of the age group 50 and above. Category 15 and above. There is a variation in the husband's tolerance of family responsibilities as a whole depending on the number of children in favor of the category of $1<3$ sons, and there is a difference in emotional pressure as a whole depending on the age groups of the husband in favor of the age group of $20<35$, and there is a difference in emotional pressure as a whole depending on the number of years of marriage in favor of category of $1<5$ years, There is also a difference in the emotional pressure as a whole depending on the number of children in favor of the group of 5 and above, there is variation in the husband's bearing family responsibilities as a whole depending on the number of working hours in favor of the class less than 8 hours. 4000, There is a discrepancy in the husband's responsibility for family responsibilities as a whole according to the wife's participation in household expenses for the category less than $25 \%$, and the husband's responsibility towards the wife is one of the most influential factors on the emotional pressure by the husband at a rate of 0.759 , followed by the husband's liability to the child by 0.683 .

Recommendations:

- Design and production of radio and television programs aimed at housewives to raise awareness and confront emotional pressure.

- Producing programs that support constructive family relationships.

- Design guidance programs aimed at housewives to raise awareness of family responsibilities and define roles, duties and rights 


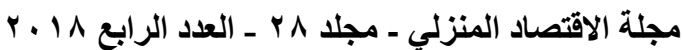

